\title{
A Study of Educational Achievement in Sub-Saharan Africa
}

\author{
By
}

Moyosola Oluwakemi Medu

A thesis submitted to the Faculty of Graduate and Postdoctoral Affairs in partial fulfillment of the requirements for the degree of

Doctor of Philosophy

in

International Affairs

Carleton University

Ottawa, Ontario

(C) 2019

Moyosola 'Kemi Medu 


\section{Abstract}

This thesis investigates the role of education achievement in explaining the growth experiences of countries in sub-Saharan Africa (SSA). Chapter one presents a new regional measure of educational achievement for SSA developed from three large-scale assessments: Le Programme d'Analyse des Systèmes Educatifs de la CONFEMEN, the Southern and Eastern Africa Consortium for Monitoring Educational Quality and the Monitoring Learning Project.

Chapter one also presents a cross-country macro-level analysis of the determinants of educational achievement. The results suggest that family factors (proxied using the adult literacy rate and GDP per capita) and school factors (proxied using the percentage of trained teachers) play a role in explaining educational achievement at the primary level in SSA but the magnitude of each effect is dependent on assessment subject.

Chapter two presents a micro-level case study of the determinants of educational achievement. Cameroon is selected for this case study as it is identified as one of the outliers in Chapter one. The results of the analysis suggest that initial performance and included student-, school-, and class- factors are important determinants of educational outcomes but each effect is nuanced and varies by education sector (Anglophone or Francophone), school location (rural area or urban area) and/or assessment subject (numeracy or literacy). The results also provide evidence of the complexities associated with estimating determinants of educational achievement and show that local context as well as family and school characteristics matter. Also important are assessment subject, quality of the adopted proxies and interactions between the various explanatory factors. 
Chapter three investigates the effect of the educational quality measure developed in Chapter one on economic growth in SSA. The findings from the regional analyses are generally weak. However, the results of the global analysis provide evidence that lend credence to existing literature on the importance of education in promoting growth. The global results also provide corroborating evidence of the essential role of educational quality in promoting economic growth. Finally, the global results suggest that educational quality and educational quantity are distinct yet complementary components of human capital development and explain different aspects of the educational process. 


\section{Acknowledgements}

It feels surreal to be writing this piece as it signals that I am officially at the end of this remarkable PhD journey. I could not have made it this far without the support of so many along the way and would like to express my heartfelt gratitude to everyone.

I am especially indebted to my thesis advisory committee. To my supervisor, Professor Dane Rowlands, thank you for your unwavering support, patience, motivation, and for sharing your immense knowledge with me. You encouraged my research and supported my professional career and I could not have asked for a better mentor to guide me on this journey. To Professor Yiagadeesen (Teddy) Samy, thank you for your guidance and your constructive suggestions which were instrumental in improving the quality of this thesis. To Professor Richard Maclure, thank you for your encouragement, insightful contributions and for helping me think outside the "quantitative analysis" box.

My sincere appreciation also goes to my colleagues and faculty members at the Norman Paterson School of International Affairs (NPSIA). Special thanks to Professors Jean Daudelin and Yanling Wang, for all the encouragement along the way. To the Administrative staff at NPSIA especially the amazing Patricia Lacroix, thank you very much.

I want to thank my dad (the original curator of this dream) and my mom (the prayer warrior) who raised us to reach beyond the stars and taught us that through God, hard work and perseverance all things are possible. Special thanks to all my other parents, 
uncles, aunts, and friends for their unwavering support and prayers. To my sisters and brothers, I love you and thank you all. Special thanks to the one and only Onascious for sticking it out with me in the trenches and my very own Brolicious for being the inspiring embodiment of the "no quit" spirit.

Most importantly, I would like to thank my husband and our girls. Olanrewaju mi, my pride and joy. Thank you for believing in the possibility of this dream and for all you've done to make it a reality. Going through this $\mathrm{PhD}$ journey with you has been such a special experience and watching you earnestly pursue your $\mathrm{PhD}$ helped motivate me. To Dami, Ire, and Wumi thank you for all your love, patience, and support every step of the way. This dream could never have become a reality for me and your dad without you all. Special thanks to Dami for keeping us accountable and helping us stay motivated. Finally, "to Him who is able to do immeasurable more than all we ask or imagine" be honor and glory for ever and ever. Amen 


\section{Table of Contents}

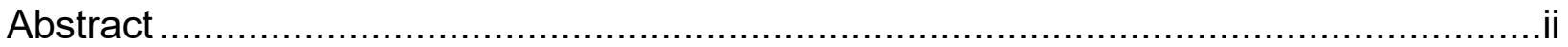

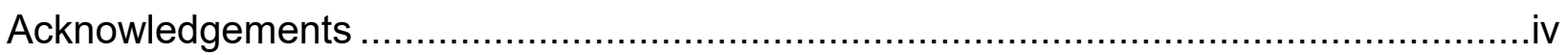

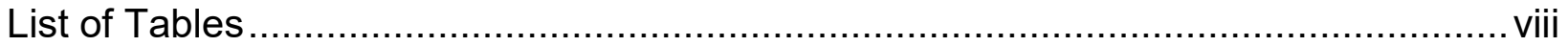

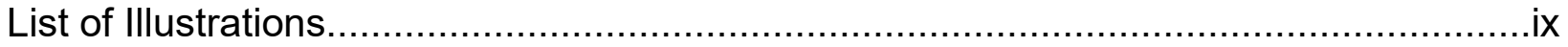

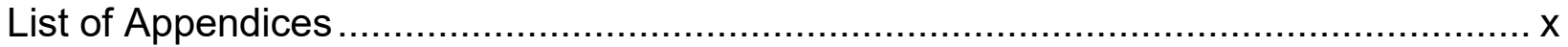

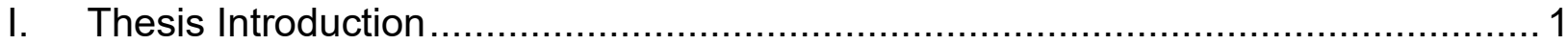

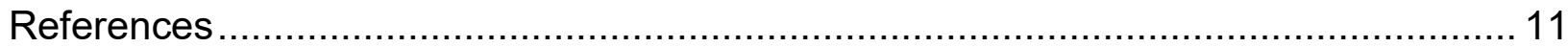

1. Chapter One: Macro-level Determinants of Educational Achievement in SSA...... 13

1.1 SSA Participation in International and Regional Assessments ..................... 14

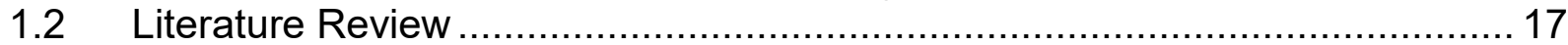

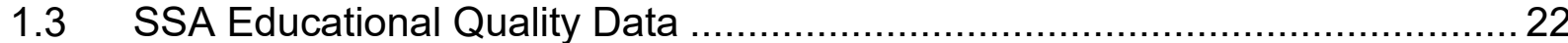

1.3.1 Developing an Educational Quality Measure .................................... 22

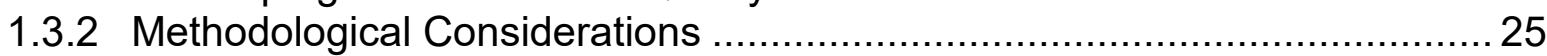

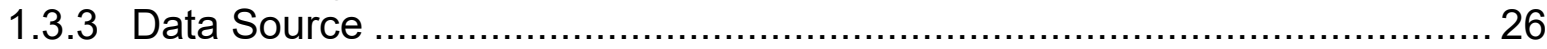

1.4 Overview of Derived Assessment Scores ................................................. 27

1.4.1 Comparison with other Educational Achievement Data............................. 31

1.4.2 Comparison with Measures of Educational Attainment ........................... 32

1.4.3 Gender and Colonial Identity Comparisons ............................................. 34

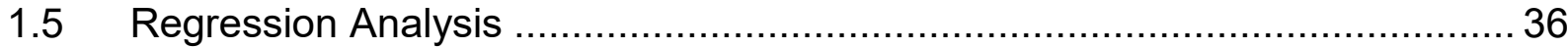

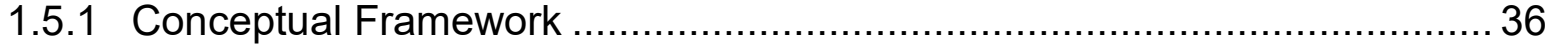

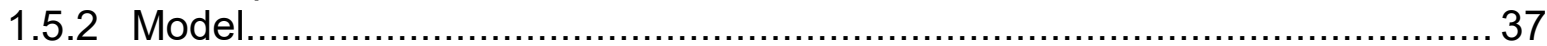

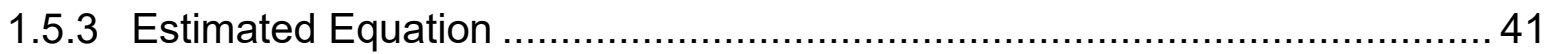

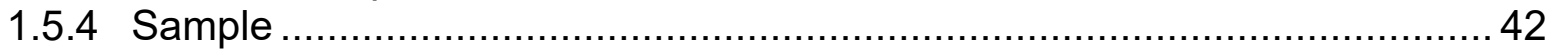

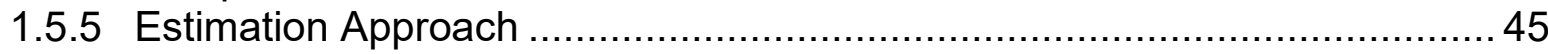

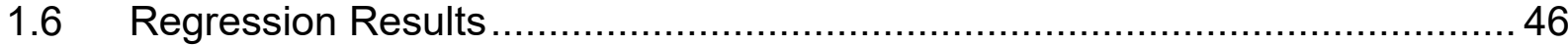

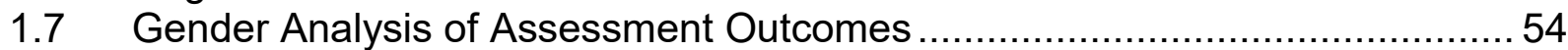

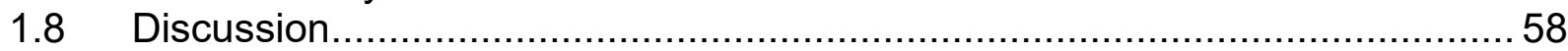

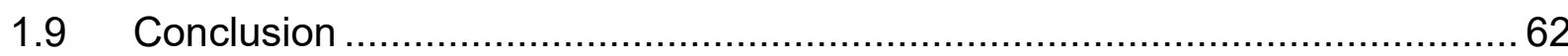

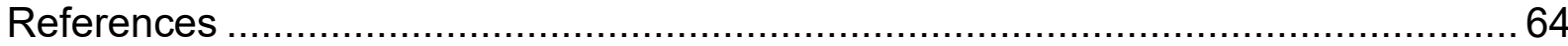

2 Chapter Two: Micro-level Determinants of Educational Achievement in Cameroon 71

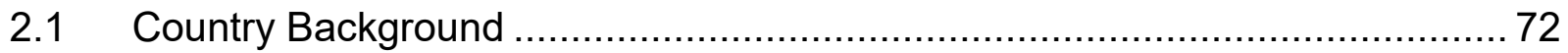

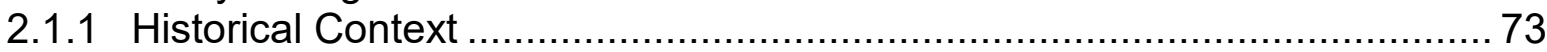

2.1.2 Economic, Social and Political Overview......................................... 75

2.1.3 Overview of the Education Sector and Education Reform ........................ 76

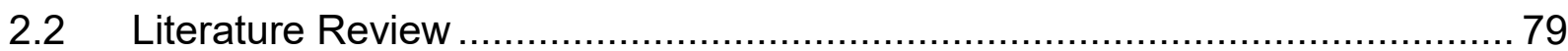

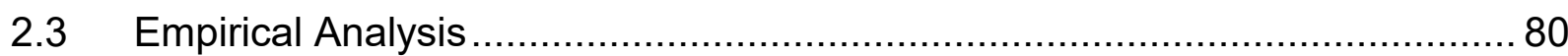

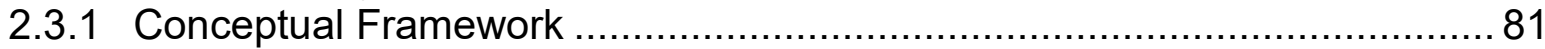

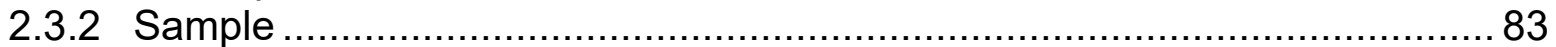




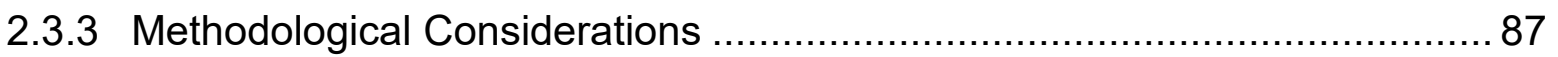

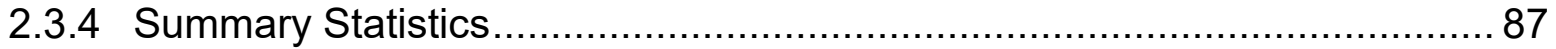

2.3.5 Estimation Approach and Results .................................................. 92

2.4 Additional Analysis: Role of Student's Prior Knowledge and Learning.......... 106

2.5 Additional Analysis: Role of Teacher Remuneration ................................. 112

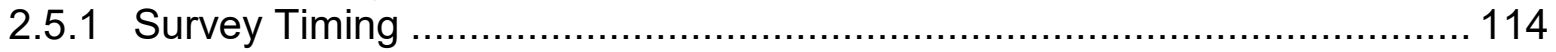

2.5.2 Differences in Salary Grid and Teacher Type..................................... 116

2.5.3 Issues with the Teacher Registration System.................................... 116

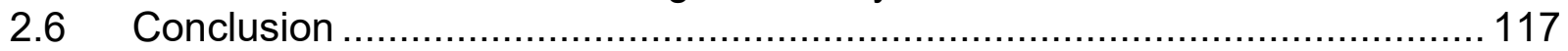

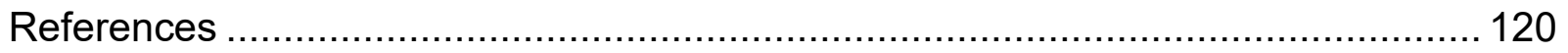

3 Chapter Three: A Study of the Effect of Educational Achievement on Economic

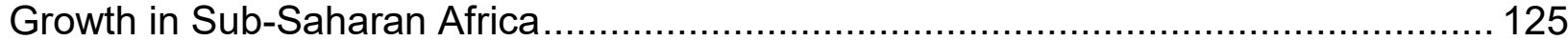

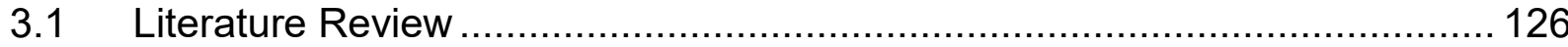

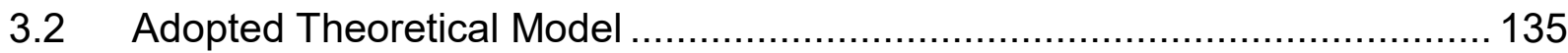

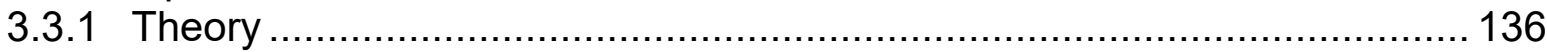

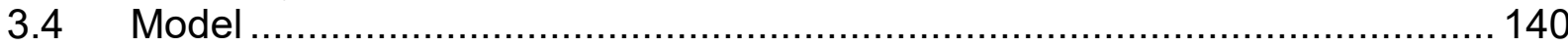

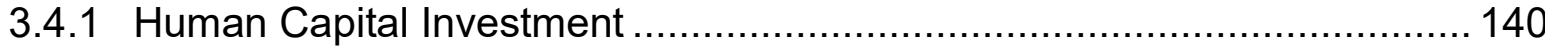

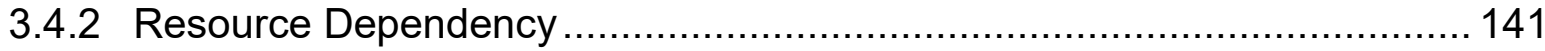

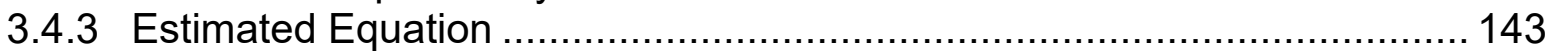

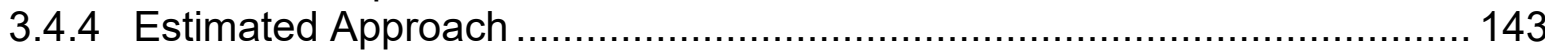

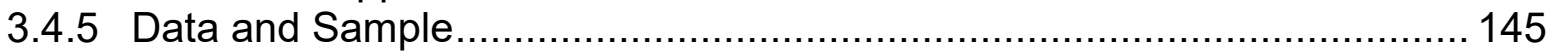

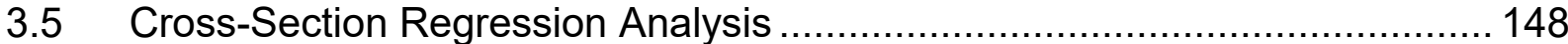

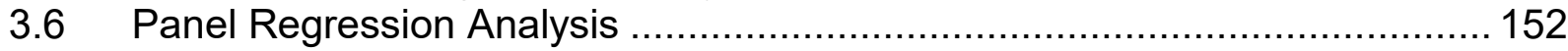

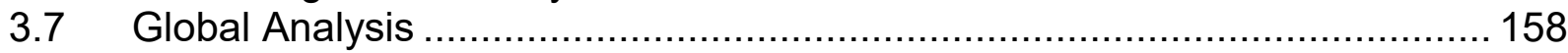

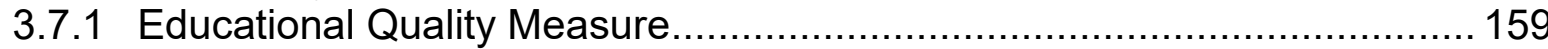

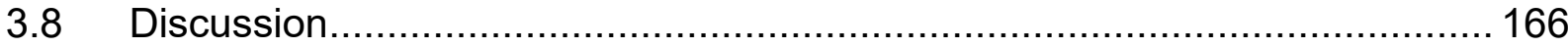

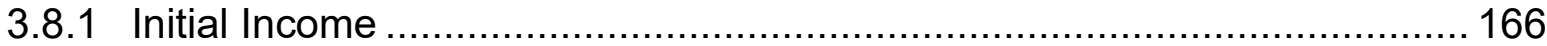

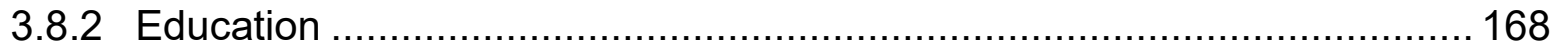

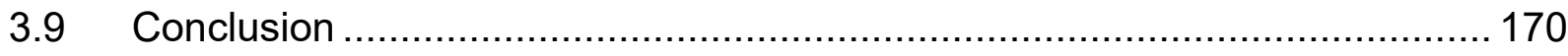

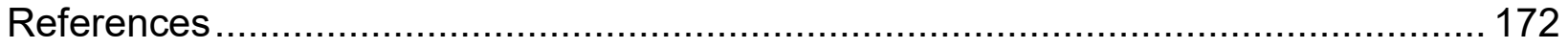

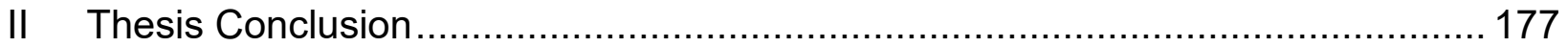

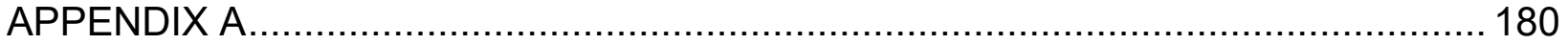

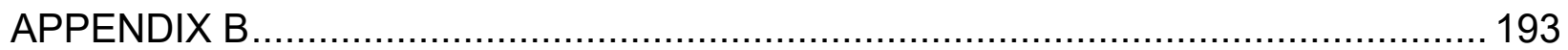

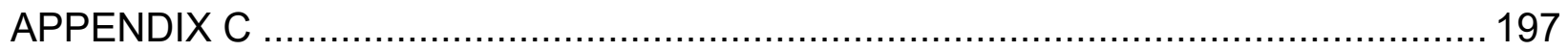




\section{List of Tables}

Table 1 : Summary Statistics of Educational Attainment Indicators ............................2 27

Table 2: Correlation between Educational Achievement Indicators and Select

Educational Attainment Measures.................................................................... 34

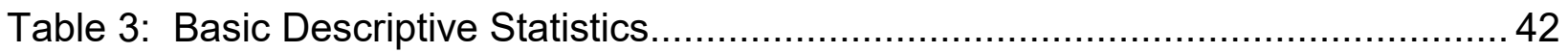

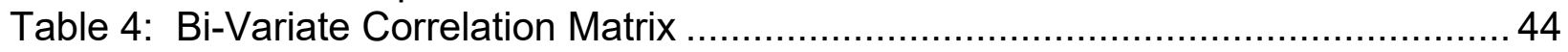

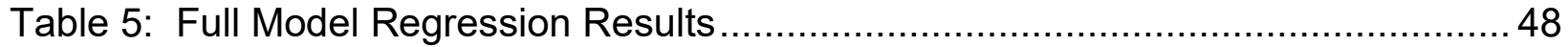

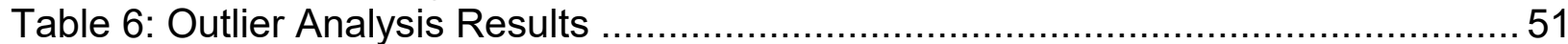

Table 7: Full and Reduced Models without Mauritania Results ................................5 53

Table 8: Full Models (without Mauritania Results) by Gender ..................................5 56

Table 9: Reduced Models without Mauritania Results by Gender .............................5 57

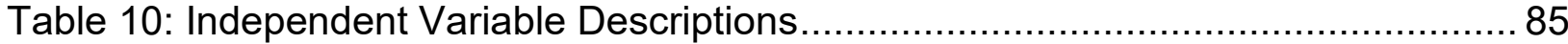

Table 11: Descriptive Statistics: Dependent Variables ......................................... 88

Table 12: Descriptive Statistics: Independent Variables, Continuous Variables............ 89

Table 13: Descriptive Statistics: Independent Variables, Dummy Variables ................. 91

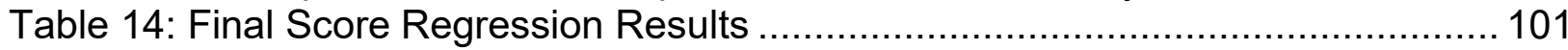

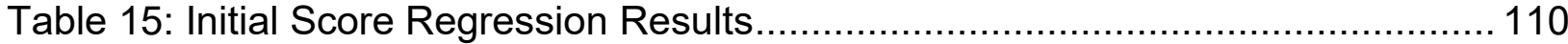

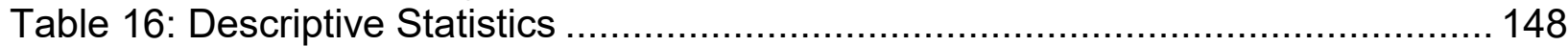

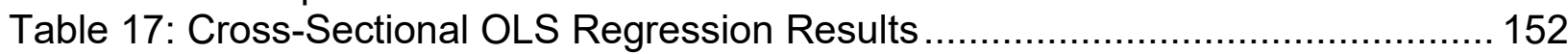

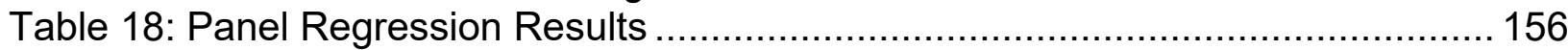

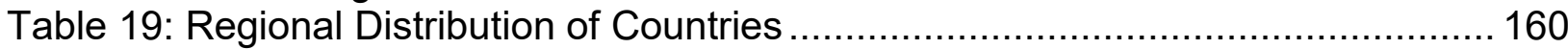

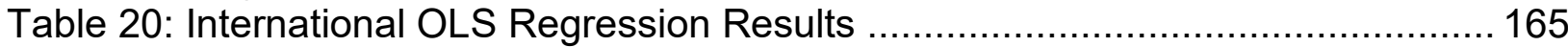

Table 21: Descriptive Statistics based on Initial Income (in 1960)* ......................... 167 


\section{List of Illustrations}

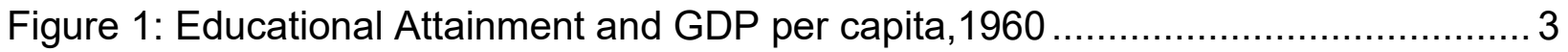

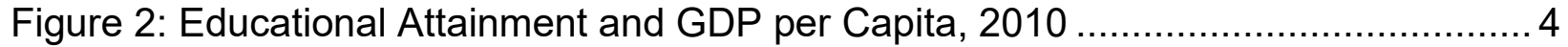

Figure 3: Educational Attainment and GDP per Capita Percentage Change between

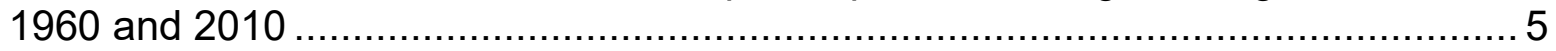

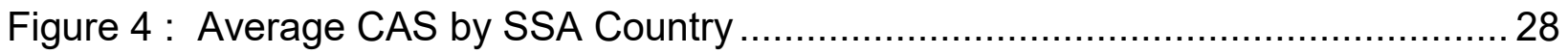

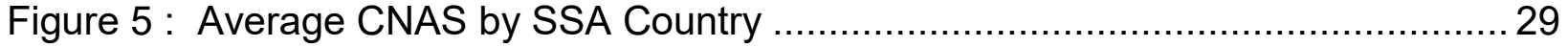

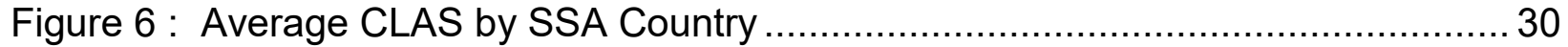

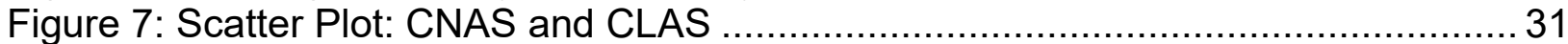

Figure 8: CAS Full Regression Model Residual Plot ............................................50

Figure 9: Leverage-versus-Residual Squared Plot, CAS Full Regression.....................5 52

Figure 10: Map of Cameroon and Neighbouring Countries ..................................... 73

Figure 11: Map of Cameroon showing the Anglophone Region ............................... 74

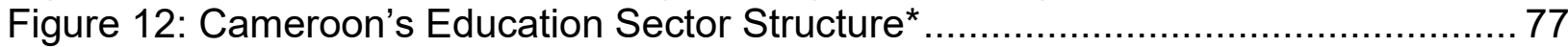

Figure 13: Distribution of Surveyed Teachers by Years of Teaching Experience........ 113

Figure 14: Number of Teachers in Primary Education, Cameroon ............................. 115

Figure 15: Full Regression Model Residual Plot ................................................ 158 


\section{List of Appendices}

APPENDIX A APPENDIX A1

APPENDIX A2

APPENDIX A3

APPENDIX A4

APPENDIX B

APPENDIX B1

APPENDIX C APPENDIX C1 APPENDIX C2
CHAPTER ONE

Participation of SSA Countries by Assessment: 1995 to 2010

Regional and International Assessment Scores, SSA Countries

Derived Assessment Scores, SSA Countries

Variable Description \& Data Source

CHAPTER TWO

Full Final Assessment Regression Results

CHAPTER THREE

Variable Description \& Data Source

Regression Country List 


\section{Thesis Introduction}

It has been widely observed that increases in national output have been large compared with the increases of land, man-hours, and physical reproducible capital. Investment in human capital is probably the major explanation for this difference. (Schultz, 1961, pp.1)

During the 1960s, pioneering economists including Theodore Schultz (Schultz, 1959), Gary Becker (Becker, 1964) and Jacob Mincer (Mincer, 1958) developed human capital theory to explain the growing realization that growth in physical capital could only explain a fraction of the growth in income. Becker (1964) describes human capital as productive worker talents, competencies acquired either formally (through education or training) or informally (through experience).

Education and training are the most important investments in human capital. Human capital theory argues that education or training raises the productivity of workers by imparting useful knowledge and skills, thereby raising their future income and lifetime earnings (Becker, 1993). The link between human capital investment and economic growth lies in its ability to expand scientific and technical knowledge and subsequently, raise the productivity of labour and other factors of production.

More generally, education promotes economic growth by: increasing labor productivity and output growth; increasing the innovative capacity of the economy; and assisting with the diffusion and transmission of knowledge needed to understand, process and implement new information and technologies (Hanushek and Woessmann, 2007). 
Seminal empirical evidence from the 1990s reinforced the centrality of human capital investment in development policy by showing that increases in investment in education raises the rate of economic growth (Mankiw, Romer and Weil, 1992; Barro, 1991). However, by the early 2000s, doubts were raised; the emerging literature was no longer able to provide conclusive evidence of the positive causal relationship between education and growth (e.g. Bils and Klenow, 2000; and Pritchett, 2001).

Consequently, human capital theory was seen as no longer able to provide a convincing explanation of the growth experience of a number of developing regions. In particular, SSA experienced significant progress between 1960 and 2010 towards achieving the second Millennium Development Goal of Universal Primary Education. However, the increase in educational attainment did not result in the anticipated level of economic growth in the region.

Figure 1 presents the average years of total schooling, a common measure of human capital attainment, and GDP per capita for all regions in $1960 .{ }^{1}$ The results are generally consistent with human capital theory in that regions with relatively higher levels of educational attainment are those with relatively higher GDP per capita, and vice versa. North America is located at the top of the distribution while SSA and South Asia (SAS) are located at the tail end of the distribution.

\footnotetext{
${ }^{1}$ Regional categories include only countries with data in both World Bank Development Indicator and Barro Lee databases in both 1960 and 2010.
} 
Figure 1: Educational Attainment and GDP per capita,1960

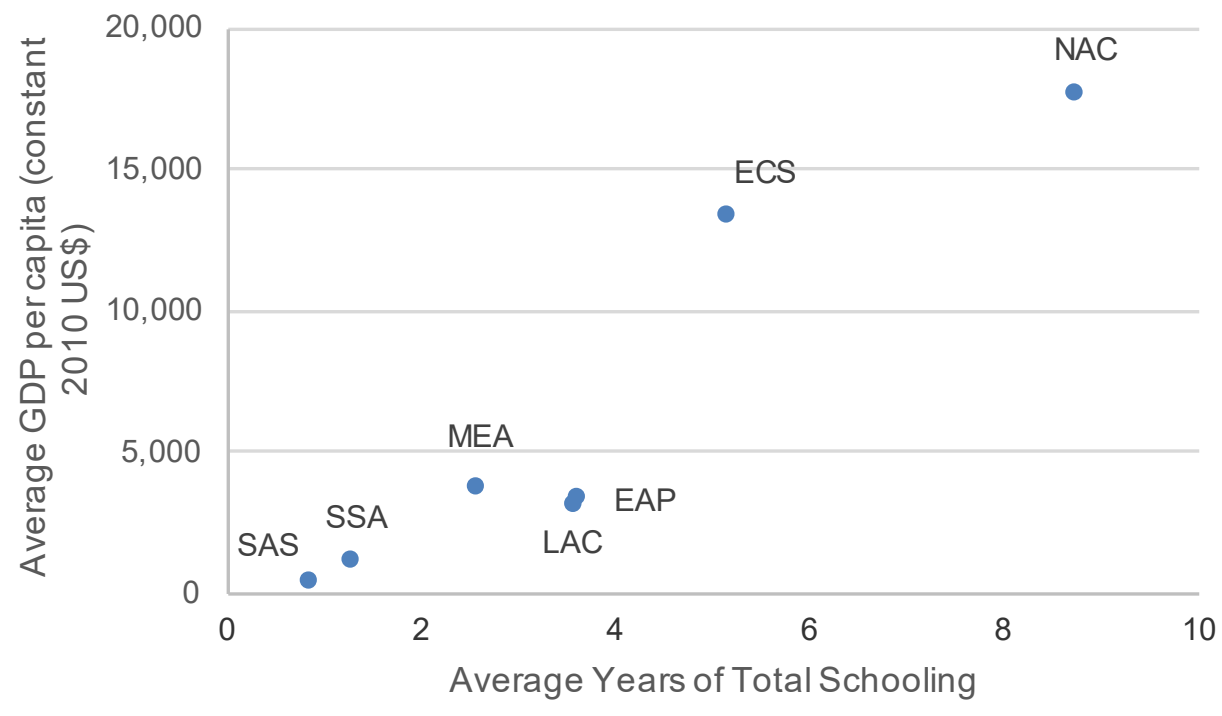

Legend: $\mathrm{SAS}=$ South Asia, $\mathrm{SSA}=$ sub-Saharan Africa, MEA= Middle East and North Africa, EAP= East Asia and the Pacific, LAC = Latin America and the Caribbean, EAP = East Asia and Pacific, ECS= Europe and Central Asia and NAC= North America.

Source: Author's calculation from World Development Indicators and Barro and Lee databases

Figure 2 replicates the same figure for 2010, fifty years later. At first glance, the results appear to also be consistent with human capital theory. Regions with higher levels of educational attainment in the 1960s experienced higher average GDP per capita by 2010. On the other hand, regions with lower levels of educational attainment in 1960 experienced lower average GDP per capita by 2010 . 
Figure 2: Educational Attainment and GDP per Capita, 2010

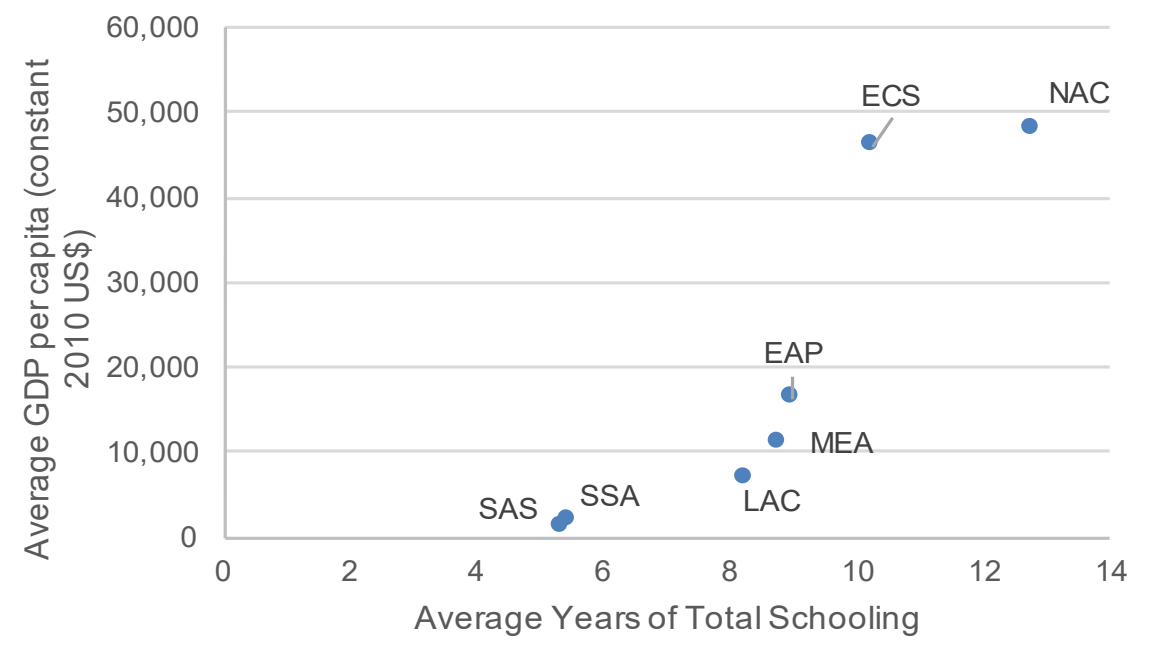

Legend: $\mathrm{SAS}=$ South Asia, $\mathrm{SSA}=$ sub-Saharan Africa, MEA $=$ Middle East and North Africa, $\mathrm{EAP}=$ East Asia and the Pacific, LAC = Latin America and the Caribbean, EAP = East Asia and Pacific, ECS= Europe and Central Asia and NAC= North America.

Source: Author's calculation from World Development Indicators and Barro and Lee databases

However, a closer look at the regions at the bottom of the distribution reveals a puzzling trend. The trend is more apparent in Figure 3, which presents the simple percentage change in average educational attainment and GDP per capita between 1960 and 2010. The percentage increase in educational attainment in SSA (and SAS) are relatively higher than the rest of the regions. As such, it is expected that SSA and SAS will be "rewarded" with a commensurate increase in GDP per capita. However, that is not the case, particularly for SSA. For SSA, the percentage difference in the average years of schooling is almost five times higher than the percentage difference in GDP per capita!

As Pritchett (2001) notes, there are several alternative explanations for the poor growth performance of Least Developed Countries (including those in SSA) that have nothing to 
do with education. Nonetheless, it could certainly still be argued that the trend in education attainment has not resulted in the anticipated economic growth pay-off.

Figure 3: Educational Attainment and GDP per Capita Percentage Change between 1960 and 2010

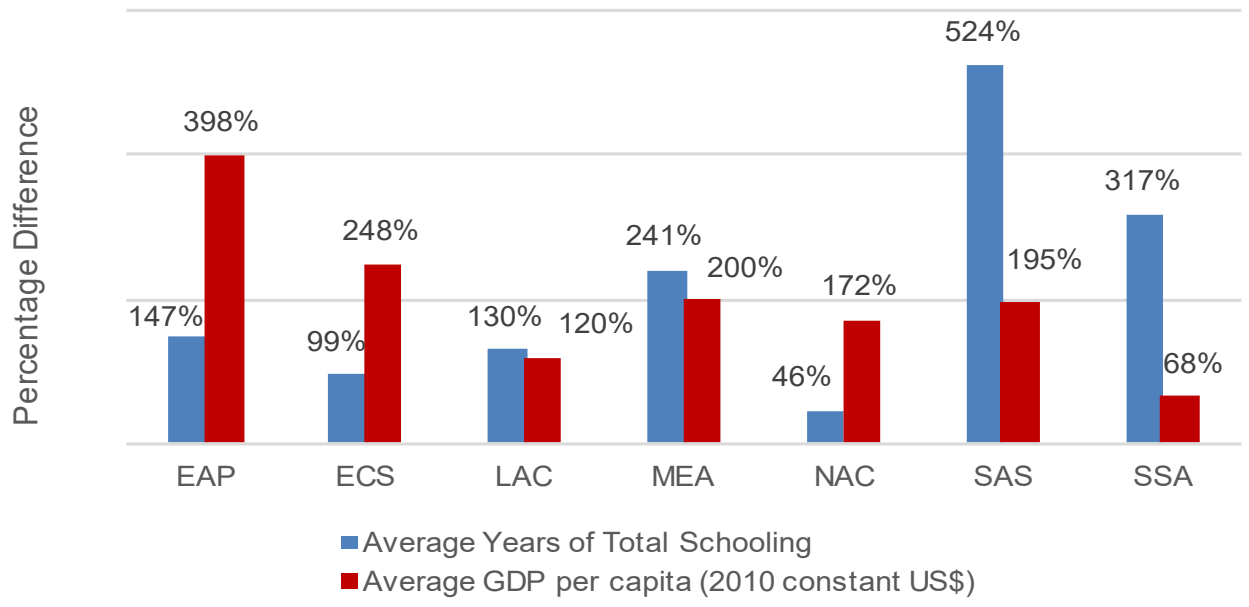

Legend: SAS= South Asia, SSA= sub-Saharan Africa, MEA= Middle East and North Africa, EAP= East Asia and the Pacific, LAC = Latin America and the Caribbean, EAP = East Asia and Pacific, ECS= Europe and Central Asia, NAC $=$ North America.

Source: Authors' calculation from World Development Indicators and Barro and Lee databases

So, why do we observe such an unexpectedly low correlation between education and GDP per capita in SSA? The literature on human capital theory typically assumes that an increase in educational investment occurs through an increase in the number of years of schooling attained within a population (i.e., increase in the quantity of schooling). International treaties were primarily developed based on this premise. For example, the United Nations Millennium Declaration's commitment to achieve Universal Primary Education by 2015 was set to improve the quantity of education. 
However, such a measure assumes a year of schooling produces a similar amount of student achievement over time and in every country (Hanushek, 2008). Evidence now points to the central role of cognitive skills or educational achievement of students, the quality of schooling. The effect of cognitive skills on educational quality has been shown to be more important than the effect of years of schooling on economic growth (for example, Hanushek and Kimko, 2000 and Hanushek and Woessmann, 2008).

As such, ignoring differences in the quality of education across countries distorts the picture of how educational and economic outcomes are related (Hanushek and Woessmann, 2008). This refined perspective is epitomized in the fourth goal of the Sustainable Development Goals (SDGs) laid out in the 2030 Agenda for Sustainable Development adopted by world leaders in 2015. According to United Nations (2015), the fourth SDG states: "ensure inclusive and equitable quality education and promote lifelong learning opportunities for all" (p.14).

Many definitions of quality in education currently exist. According to UNICEF (2000), there is consensus that there are five dimensions:

- learners who are healthy, well-nourished and ready to participate and learn, and supported in learning by their families and communities;

- environments that are healthy, safe, protective and gender-sensitive, and provide adequate resources and facilities;

- content that is reflected in relevant curricula and materials for the acquisition of basic skills, especially in the areas of literacy, numeracy and skills for life, and knowledge in such areas as gender, health, nutrition, HIVIAIDS prevention and peace;

- processes through which trained teachers use child-centred teaching approaches in well-managed classrooms and schools and skilful assessment to facilitate learning and reduce disparities; and

- outcomes that encompass knowledge, skills and attitudes, and are linked to national goals for education and positive participation in society. (p.4) 
Educational quality is measured in the literature either: indirectly through measures of schooling resources and inputs (such as educational expenditure); or directly through student cognitive skills and performance on standardized tests, i.e. outcomes or achievements (Hanushek and Kimko, 2000). The measure of educational quality adopted in this thesis is primarily based on a direct measure of educational outcomes or achievement. The terms educational quality, educational achievement and educational outcomes are used interchangeably in this thesis. Educational outcomes are often proxied in the literature using performance on international assessments.

OECD (2015), note the following advantages of using achievement results as a measure of human capital:

...First, it captures variations in the knowledge and ability that schools strive to produce and thus relates the putative outputs of schooling to subsequent economic success. Second, by emphasising total outcomes of education, it incorporates skills from any source- families, innate ability as well as schools. Third, by allowing for differences in performance among students whose schooling differs in quality (but possibly not in quantity), it acknowledges - and invites investigation of - the effect of different policies on school quality...(p.90)

However, only a few SSA countries have ever participated in international assessments. For example, the International Association for the Evaluation of Educational Achievement's Trends in International Mathematics and Science Study (TIMSS) has assessed student achievement in mathematics and science in the fourth and eighth grades every four years since 1995. Of the 49 countries that participated in the 2015 TIMSS fourth grade assessments (or 38 participants in the eighth-grade assessments), 
only two were from SSA: Botswana and South Africa. ${ }^{2}$ The performance of both countries ranked at the bottom of the distribution in both mathematics and science assessments even though both of these tests assessed their students in a higher grade to better match curricula. ${ }^{3}$ Also, South African grade four students only participated in the TIMSS Numeracy Assessment, a less difficult version of the fourth-grade mathematics assessment.

Given that these countries are considered strong performers relative to other SSA countries, their performance is highly suggestive of the low level of educational quality that currently exists within the region. Thus, there exists many unanswered research questions regarding education quality in SSA and the role that education can play in closing the development gap between SSA and the rest of the world.

Ignoring the effect of quality of education in promoting economic growth has serious resource and policy implications as SSA governments already devote a significant amount of their often very limited financial resources to the education sector. According to the World Bank, in 2015, the average public spending on education (as a percentage of government expenditure) in SSA was $18 \%{ }^{4}$ This percentage is higher than the Organisation of Economic Co-operation and Development (OECD) and World averages

\footnotetext{
2 The only other SSA country that has ever participated in TIMSS is Ghana (from 2003 to 2011).

${ }^{3}$ Botswana only participated in TIMSS 2015 grade eight assessment. Both Botswana and South Africa administered TIMSS' grade eight assessment to grade nine students. South Africa administered the grade four TIMSS Numeracy assessment to grade five students.

${ }^{4} 2015$ is the most recent year available in World Development Indicator database for SSA, OECD and the World.
} 
(13\% and $14 \%$ respectively).${ }^{5}$ An overemphasis on quantity encourages SSA countries to devote even more of their limited resources to expanding the sector at the expense of improving its quality.

The prevalence of this viewpoint is understood, as robust evidence on the effect of the quality of education based on regional assessment data is presently sparse in SSA. Addressing this knowledge gap is important, from a public policy perspective, to ensure that SSA governments, bilateral agencies and multilateral agencies develop and implement educational policies and funding priorities that promote educational quality, efficient use of resources and result in sustainable economic growth in the region. Addressing the gap will also help support the African Union's Agenda 2063. One of the goals or aspirations of the Agenda posits a "people-driven" development as a vehicle for achieving the Pan African vision of "an integrated, prosperous and peaceful Africa, driven by its own citizens and representing a dynamic force in the international arena" (African Union Commission, 2015, p.1).

To that end, this thesis critically examines the role of educational quality in promoting economic growth in SSA. The thesis is comprised of three chapters, each of which is intended to be a stand-alone paper. The first chapter develops a new measure of educational quality for SSA using regional assessment data and estimates the macrolevel determinants of educational quality in SSA. The second chapter extends the analysis in Chapter one by exploring the micro-level determinants of educational quality

\footnotetext{
${ }^{5}$ Public expenditure on education consists of current and capital government spending on educational institutions (both public and private), education administration as well as subsidies for private entities (students/households and other private entities).
} 
using student-level assessment data to conduct a case study of Cameroon, an outlier country in Chapter one. The final chapter examines the relationship between educational quality and economic growth in a cross-country analysis.

In other words, the first chapter primarily focuses on developing a measure of educational quality and understanding its determinants. The second chapter examines the determinants of educational quality from a more granular perspective to refine the understanding of the key determinants of educational quality. The final chapter documents the application of the developed regional measure of educational quality in an empirical analysis of aggregate country growth in SSA. 


\section{References}

African Union Commission. (2015). Agenda 2063: The Africa we Want. Available online at: https://www.un.org/en/africa/osaa/pdf/au/agenda2063.pdf

Barro, R. (1991). Economic growth in a cross-section of countries. Quarterly Journal of Economics, 106(2),407-443.

Becker, G. (1964). Human capital: a theoretical and empirical analysis, with special reference to education. New York: Columbia University Press.

Becker, G.S. (1993). Human capital, 3rd ed University of Chicago Press: Part 1.

Bils, M. \& Klenow, P. (2000). Does schooling cause growth? American Economic Review, $90,1160-83$

Hanushek, E. \& D. Kimko. (2000). Schooling, labor force quality, and the growth of nations." American Economic Review. 90,1184-1208.

Hanushek, E. and Woessmann, L. (2007).The role of education quality for economic growth. Policy Research Working Paper Series 4122, The World Bank.

(2008). The role of cognitive skills in economic development. Journal of Economic Literature, 46 (3), 607-668.

Mankiw, N. G., Romer, D. \& Weil D.N. (1992). A contribution to the empirics of economic Growth. Quarterly Journal of Economics, 107 (2), 407-437.

Mincer, J. (1958). Investments in human capital and personal income distribution. Journal of Political Economy,66 (4), 281-302.

.(1974). Schooling, experience and earnings. New York: National Bureau of Economic Research.

OECD. (2015). Universal basic skills: what countries stand to gain. OECD Publishing. http://dx.doi.org/10.17879789264234833.en

Schultz, T.W. (1959). Investment in man: an economist's view. Social Service Review, 33,109-117.

. (1961). Investment in human capital. The American Economic Review, $51(1), 1-17$.

Pritchett, L. (2001). Where has all the education gone? The World Bank Economic Review, 15(3), 367-391. 
UNESCO (2005). Chapter 1: understanding educational quality. EFA Global Monitoring Report.

UNICEF (2000). Defining quality in education. A paper presented by UNICEF at the meeting of The International Working Group on Education Florence, Italy. Document no. UNICEF/PD/ED/00/02.

United Nations (2015). Transforming our world: the 2030 Agenda for Sustainable Development. Available online: https://www.un.org/ga/search/view_doc.asp?symbol=A/RES/70/1\&Lang=E

World Bank (2019). World Development Indicators. Washington, D.C.: The World Bank. 


\section{Chapter One: Macro-level Determinants of Educational Achievement in SSA}

Education is widely considered to be an important instrument for promoting economic growth and development. Human capital theory provides a basis for understanding the private and public (social) benefits of education to individuals and their societies. Understanding the role of education in promoting economic growth and development is especially important for countries in sub-Saharan Africa (SSA).

According to the 2015 United Nations Millennium Development Report, SSA had the best record of improvement in primary education of any region since the Millennium Development Goals were established. Despite this progress, SSA continues to lag on major economic development indicators.

A growing body of literature points to the imperfect measurement of education as the primary reason for this disconnect. Increases in educational investment from human capital theory have been historically assumed to occur by increasing the quantity of schooling. This viewpoint is changing as recent empirical evidence shows that theory is equally consistent with increasing the quality of schooling.

Educational quality is often proxied in the literature by using performance on international assessments. However, only a few SSA countries have ever participated in international assessments. Regional assessments are more prevalent in SSA. As such, the focus of this chapter is on developing a regional measure of educational quality for SSA and 
understanding its determinants. More precisely, this chapter addresses two main research questions:

- how does educational quality differ across SSA countries?

- what are the determinants of educational quality in SSA?

\subsection{SSA Participation in International and Regional Assessments}

According to Hanushek and Woessman (2010a), the origin of international testing was a series of meetings in the late 1950 s and early 1960s where several academics designed an international testing program. This work led to the first major international test in 1964 where 12 countries participated in the First International Mathematics Study (FIMS). The FIMS and a series of subsequent assessments were conducted in nations voluntarily participating in assessments developed primarily by the International Association for the Evaluation of Educational Achievement (IEA). Currently, two assessments mainly used in the education literature are: the Trends in International Mathematics and Science Study (TIMSS) developed by IEA; and the Programme for International Student Assessment (PISA) developed by OECD.

TIMSS has monitored trends in mathematics and science achievement at the fourth and eighth grades every four years since 1995. PISA is a triennial international survey that has tested the skills and knowledge of 15 -year-old students in science, mathematics and reading since 2000 .

The number of participating countries in TIMSS and PISA has expanded dramatically 
since their inception. In 1995, around 29 countries participated in the TIMSS fourth grade math assessment compared to 49 countries in the 2015 assessment. Similarly, 43 countries took part in PISA 2000 compared to 72 countries and economies that took part in PISA 2015. However, the level of participation of SSA countries in both assessments is very low. Only one SSA country (Mauritius) has ever participated in PISA and only three SSA countries have ever participated in TIMSS: Botswana, Ghana, and South Africa.

Regional assessments are more frequently utilized in SSA. However, regional assessments are relatively novel and only date back to the 1990s. Two large-scale regional assessments in SSA are: Le Programme d'Analyse des Systèmes Educatifs de la CONFEMEN (PASEC) and the Southern and Eastern Africa Consortium for Monitoring Educational Quality (SACMEQ). A third large-scale assessment with sizeable SSA participation is the Monitoring Learning Achievement Project (MLA).

PASEC has been conducted since 1993 in 22 Francophone SSA countries. PASEC is managed by CONFEMEN (Conférence des Ministres de l'Education des Etats et Gouvernements de la Francophonie). PASEC assesses performance of students in mathematics and written comprehension (referred to hence forth as "language") and is typically administered to students in grades two and five or six at the beginning and end of the same school year, to measure their "growth" over the course of the year. ${ }^{6}$ The

${ }^{6}$ PASEC was administered to fifth graders from 2004 to 2010 and to sixth graders beginning in 2014. Also, several changes have been made to the PASEC framework since 2012 to align it closer to international assessments. Stronger partnership with SACMEQ has also been forged to enable score comparison across SSA countries. 
assessments are conducted typically every five years and in the official language of instruction. Questionnaires are also administered to students, teachers and principals to gather information on the general conditions of schooling and the background of students and teachers. Assessments are based on a two-stage stratified cluster sample where schools are sampled with probability proportional to size. Students are then randomly sampled within the same classroom (and randomly selected from the available classroom).

SACMEQ is a collaborative effort between 15 ministries of education in Southern and Eastern Africa working closely with the International Institute for Educational Planning (Ross et al, 2000; UNESCO, 2003g). SACMEQ assesses the abilities of students in grade six in reading English and mathematics. According to GEM (2015), the choice of grade could be partly explained by the timing of the transition between the use of local and official languages in classrooms. To date, SACMEQ has completed four cross-national educational research projects at five- to six-year intervals (SACMEQ I,1995-1999; SACMEQ II, 1998-2004; SACMEQ III, 2005-2010 and SACMEQ IV, 2012-2014). Questionnaires are also administered to teachers and principals to provide information on the general conditions of schooling and the background of the students and teachers. SACMEQ assessment is also based on a stratified cluster sample.

The MLA began in 1992 as a joint United Nations Educational, Scientific and Cultural Organization (UNESCO)/United Nations International Children's Emergency Fund (UNICEF) initiative (Chinapah, 1997). Between 1991 and 2004, MLA I and MLA II were 
completed in 72 countries. In MLA I, the achievements of grade four students were assessed in literacy (reading/writing), numeracy, and life skills (relating to awareness and knowledge of health, nutrition, sanitation, hygiene). In MLA II, grade eight students' achievements were assessed in mathematics and science. In both MLA I and II, data are collected on students' backgrounds, school characteristics, and family backgrounds. To date, 40 African countries have participated in MLA I and 11 in MLA II.

The three assessments provide data for 33 out of the 48 SSA countries, around $69 \%$ of the countries within SSA. Assessment data are available for several countries for multiple years and assessments. The full list of country participants is provided in Table A1 in Appendix A.

\subsection{Literature Review}

The effect of educational quality has gained prominence particularly in the growth literature. More recent studies generally demonstrate that better measures of human capital (i.e. educational achievement as opposed to educational attainment) alter the effect of education on economic growth (for example, Hanushek and Kim, 1995; Hanushek and Kimko, 2000; and Hanushek and Woessman, 2012).

More relevant to this paper is the strand of literature that focuses on developing a measure of educational quality and understanding its determinants. According to the evidence, two streams of factors affect educational outcome: family factors and school factors. A landmark study from the United States by Coleman et al. (1966) demonstrates 
that family differences are very important in explaining variations in achievement across students. Hanushek (1995) also presents evidence of a strong effect of family background and socioeconomic factors and weak effect of school resource effects on student outcomes. $^{7}$

Similarly, Lee and Barro (1997) investigate the determinants of educational quality in a panel data set that includes output and input measures for several countries. The results show that family inputs and school resources are closely related to school outcomes, as measured by IEA test scores, repetition rates and drop-out rates. Family characteristics such as income and education of parents also have strong effects on student performance.

In addition, Hanushek and Kim (1995) examine the importance on labour force quality, measured by cognitive skills in mathematics and science on cross-national growth. They develop quality measures for countries by combining all available IEA and IAEP assessment results between 1963 and 1991 for about 39 countries which are then projected on countries not participating in testing programs resulting in estimates for around 78 countries (including about 15 SSA countries). They also develop a model to examine the determinants of school quality and generally conclude that school resources do not have strong effects on test performance. In addition, the effect of education of parents tends to be positive and significant at conventional levels.

\footnotetext{
${ }^{7}$ Kremer (1995) and others have criticized the methodology adopted by Hanushek (1995) and its conclusion.
} 
On the other hand, Heyneman and Loxley (1983) argue that such generalizations are mainly driven from developed regions and school resource effects, particularly quality of schools and teachers, have a large effect on academic achievement particularly in lowincome countries. In other words, the effect of school and teacher quality on student performance is relatively higher than family socioeconomic status in developing countries compared to their developed counterparts. This conclusion is referred to as the "Heyneman-Loxely" effect in Badr et al (2012). Several studies, mostly using data from PISA and TIMSS, also suggest that system features can have large and positive effects on cognitive skills. Key elements include increased school autonomy (Fuchs and Woessmann, 2007) and educational institutions (Woessmann, 2003).

Most of these studies have limited applicability to SSA countries given the relatively small number of SSA countries that participate in international assessment. Other studies have attempted to increase the number of SSA studies in their analyses by including regional assessment results. For example, Angrist, Patrinos and Schlotter (2013) assemble a panel data set to measure cognitive achievement for 128 countries (including 29 African countries) from 1965 to 2010 in five-year intervals. Their results suggest that key drivers of global achievement are civil rights and economic freedom across all countries, and democracy and economic freedom in a subset of African and Latin American countries. While novel, these group of studies typically splice regional assessment with international assessment data thereby obscuring important regional contexts and effects. 
A final group of studies have studied the determinants of educational quality specific to SSA countries by basing their analysis strictly on regional assessment data. For example, Fehrler et al. (2009) conduct an analysis of both PASEC and SACMEQ to estimate the impact of educational inputs (particularly school equipment, teacher quality and class organization) on student achievement in 21 SSA countries. The analysis is conducted separately for PASEC and SACMEQ results and their results show a positive correlation between achievement test scores and the possession of textbooks and a negative correlation with teaching in shifts. In addition, their results also provide evidence of the importance of academic and professional qualification of teachers, but only for SACMEQ countries. The lack of evidence for PASEC countries can be explained in part by the quality and precision of the indicator of teacher's qualification and training. In PASEC, "indicators of both professional training and educational attainment only capture duration while no information is available on quality" (p.15).

Atherton (2009) uses data from SACMEQ to investigate the effect of school resources, teacher quality and quantity on pupils' mathematical ability, after controlling for outside school influences. Meta-regression analysis is used to identify consistent effects across the sample. Findings suggest that both the quantity and quality of teachers is strongly correlated with achievement. In addition, the results suggest a strong relationship between achievement and external factors, such as household wealth and parental education. 
Lee, Zuze and Ross (2005) examine how school characteristics are linked with educational effectiveness in 14 SSA countries. Effectiveness is defined in terms of students' literacy achievement at the end of grade six, after controlling for differences in social and academic backgrounds. SACMEQ data and a multilevel method is used. Results suggest that student achievement is strongly correlated with students' social and academic background in all SACMEQ countries. However, school effects vary across countries.

These studies mainly use one (or two) sources of regional assessment data and consequently do not utilize all available assessment data within the SSA region. As far as I am aware, only one study has attempted to combine all three regional assessment data in a study of educational quality in SSA. Majaard and Mingat (2012) examine learning outcomes in primary education in SSA and discuss the types of policies that can be effective in improving student learning. They create the Africa Student Learning Index (ASLI) which is a composite of mathematics and literacy scores from MLA, PASEC and SACMEQ. The results show that in most SSA countries, average student learning is low. However, their regression analysis of the determinants of education quality is based solely on PASEC data. The results highlight the importance of school resource effects, in particular, the ability of schools and teachers to transform inputs into learning.

From this review, it is apparent that a crucial gap remains in the SSA literature in understanding the nature and determinants of educational quality that is based on a comprehensive regional assessment dataset. 
This study will address this gap and build on existing literature by:

- introducing a combined assessment dataset based on all three assessment tests;

- developing subject- and gender-specific regional achievement measures; and

- refining the evidence on the characteristics and determinants of educational quality in SSA.

This study differs from Fehrler et al. (2009), Atherton (2009) and Lee, Zuze and Ross (2005) based on the use of multiple regional sources of achievement data. This study also differs from Majaard and Mingat (2012) based on the additional subject- and genderspecific assessment measures developed and applied in this analysis.

\subsection{SSA Educational Quality Data}

This section provides a summary of the process used to construct the dataset, methodological considerations, and data sources.

\subsubsection{Developing an Educational Quality Measure}

The overall objective of this chapter is to develop a single measure of educational quality for each applicable SSA country using assessment results from 1995 to 2010 . The following indicators are new and developed in this analysis:

- Combined Numeracy Assessment Score (CNAS): combined average numeracy scores from MLA, PASEC and SACMEQ data.

- Combined Literacy Assessment Score (CLAS): combined average literacy scores from MLA, PASEC and SACMEQ data. 
- Combined Assessment Score (CAS): combined average numeracy and literacy scores from MLA, PASEC and SACMEQ data. ${ }^{8}$

Gender-specific CAS, CNAS and CLAS measures (i.e. six additional measures) are also developed.

The approach used to transform the data is the same as the method adopted by Majaard and Mingat (2012). The first step involves improving the comparability of the assessment scores. This is necessary because test scores are reported in multiple forms: SACMEQ centrepoint is 500 while MLA and PASEC are on a 0 to 100 scale.

A two-staged multiplicative transformation approach is used to convert the distribution of the PASEC and SACMEQ scores to the same distribution as MLA scores. MLA scores are not transformed as they already have a mean of 50 and standard deviation of 10 . First, the z-score for each PASEC and SACMEQ score is calculated using the respective mean and standard deviation for each sample with the formula:

$$
z-\text { score }=\frac{\text { raw score }- \text { mean }}{\text { standard deviation }}
$$

Second, given that z-scores can be negative and have decimals, z-scores are converted to t-scores using the formula:

$$
t-\text { score }=10(z-\text { score })+50
$$

\footnotetext{
${ }^{8}$ Numeracy scores are a combination of mathematics (PASEC and SACMEQ) and numeracy (MLA) assessment scores. Literacy scores are a combination of reading English/French (SACMEQ and PASEC) and English reading and writing (MLA).
} 
For each assessment, the range of scores is now between 1 and 100 and has a mean of 50 and a standard deviation of 10 . However, ensuring that the scores have a similar distribution is only the first step. For them to be truly comparable, they also need to be on a similar scale.

To get the assessments on a similar scale, PASEC t-scores are multiplied by a constant that is calibrated so that the mean PASEC score is identical to the mean MLA score for the three countries (Madagascar, Mauritius and Senegal) that have both PASEC and MLA scores. Similarly, SACMEQ t-scores are multiplied by a constant calibrated so that the mean SACMEQ score is identical to the mean MLA score for the six countries (Botswana, Malawi, Mauritius, South Africa, Uganda and Zambia) that have both SACMEQ and MLA scores.

The final measures (CNAS, CLAS and CAS) for each country are constructed by taking the arithmetic mean of all available transformed assessment scores. Gender specific version of each measure are also constructed. For a given country, the scores may be based on one, two or three scores depending on the number of surveys the country participated in. Mauritius is the only country that participated in all three assessments.

Tables A2 and A3 in the Appendix provides the regional and derived assessment scores. From both tables, it can be seen that the distribution of the PASEC, SACMEQ and MLA scores are approximately symmetric prior to transformation. Skewness and kurtosis statistics of the transformed scores are even closer to a normal distribution. 


\subsubsection{Methodological Considerations}

The adopted measurement approach is not without limitations. First, the multiplicative transformation relies on a strong assumption that the intertemporal mean in performance is constant and countries taking the tests are a random draw from the SSA distribution (Hanushek and Kimko, 2000).

Second, mismeasurement may occur when educational quality changes significantly over time. However, averaging assessment data over long periods of time is often justified based on the assumption that "quality of schooling evolves slowly over time in part due to the stationarity of technology and the slow turnover of teachers and other personnel" (Hanushek and Kimko, 2000, p.1186).

Third, the focus on numeracy and literacy ignores other important dimensions of cognitive competence, many of which do not easily lend themselves to standardized tests (Woessman, 2003). However, studies, such as Hanushek and Kim (1999), suggest that comparative scores, particularly in mathematics and science, have a strong effect on economic growth. It could also be argued that cognitive skills in mathematics and science serve as a proxy (albeit weak) for other skills (Woessmann, 2003). The inclusion of literacy scores improves the ability of the derived measures to capture and reflect other key dimensions of cognitive competence. 
Fourth, assessment data used to derive the assessment scores are based on grades four to six. As such, the focus is on learning outcomes in primary education. However, it has been argued that the foundational years of primary school have an effect not only on knowledge and skills acquisition in later grades but also on long-term development and economic growth.

Finally, there are gaps in data coverage. For all countries, assessment data is only available for a few years and in some cases, only one. Further, it is difficult to ensure the same level of quality control in sampling, development/administration of the test instrument, field execution and data collection across countries. While it is important to be aware of the limitations, it is also important to keep in mind the benefits of the derived assessment scores and the potential contribution to the scant SSA literature.

\subsubsection{Data Source}

The primary source for SACMEQ and PASEC data is the World Bank's Education Statistics (EdStats) portal. The portal provides data for all countries that participate in SACMEQ and 13 countries that participate in PASEC. Additional PASEC data are from country reports provided by CONFEMEN upon request.

The primary source of MLA data is Chinapah et al (2000), the UNESCO report on MLA I for 11 countries: Botswana, Madagascar, Malawi, Mali, Morocco, Mauritius, Niger, Senegal, Tunisia, Uganda, Zambia. Data for Nigeria and Liberia are from UNESCO World Data on Education country reports. 


\subsection{Overview of Derived Assessment Scores}

Table 1 provides the summary statistics for the constructed quality measures. Each number indicates the percentage literacy and/or numeracy grade-level subject matter an average student has absorbed and understood at the time of testing. In other words, the extent to which students are learning what is expected of them (Majaard and Mingat, 2012).

On average, $46 \%$ of the numeracy and literacy grade-level content is comprehended by participants of the three assessment tests. In other words, assessment participants on average learned less than half of what was expected of them.

Table 1 : Summary Statistics of Educational Attainment Indicators

\begin{tabular}{|c|c|c|c|c|c|}
\hline $\begin{array}{c}\text { Quality } \\
\text { Measure }\end{array}$ & Mean* (\%) & $\begin{array}{c}\text { Standard } \\
\text { Deviation }\end{array}$ & Minimum (\%) & Maximum (\%) & $\begin{array}{c}\text { Number of } \\
\text { Countries }\end{array}$ \\
\hline CAS & 46 & 9 & 25 & 63 & 33 \\
\hline CNAS & 43 & 8 & 23 & 57 & 33 \\
\hline CLAS & 50 & 11 & 25 & 74 & 33 \\
\hline
\end{tabular}

*unweighted averages

Source: Author's calculation based on MLA, PASEC, and SACMEQ scores.

There is noticeable variation in average CAS across countries. Figure 4 shows the range of performance for SSA countries. The highest average CAS, $63 \%$, belongs to Seychelles. Gabon, Kenya, and Mauritius also each have an average score of at least $60 \%$. At the other end of the spectrum, Mauritania and Nigeria have the lowest average CAS scores with average scores less than $30 \%$. 
Figure 4 : Average CAS by SSA Country

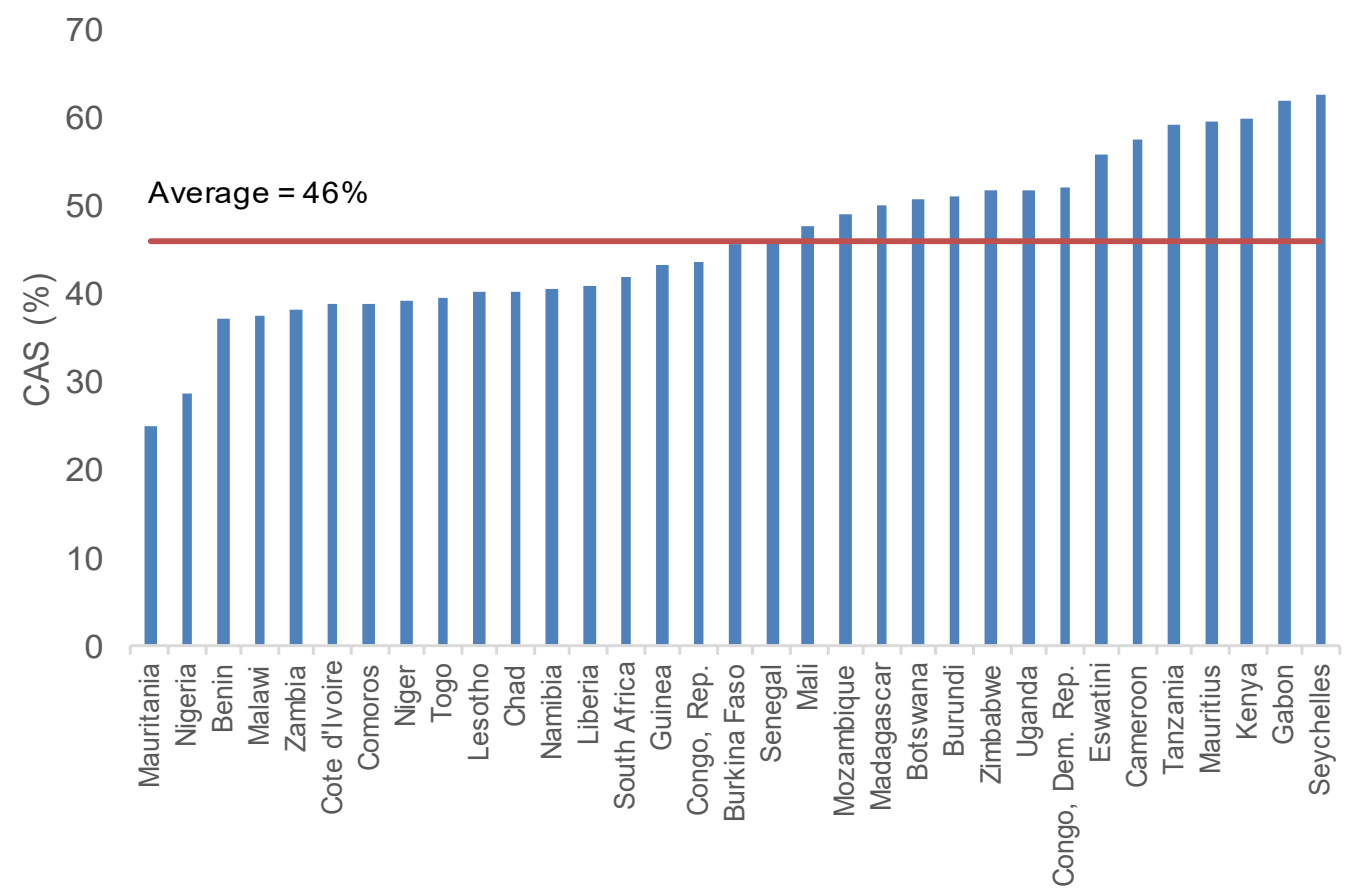

Source: Author's calculation based on MLA, PASEC, and SACMEQ scores.

Note: Swaziland was renamed Eswatini in 2018.

Figure 5 presents the average CNAS scores across the sample. The average CNAS score is close to the CAS average score and there are similar countries at both ends of the distribution. 
Figure 5 : Average CNAS by SSA Country

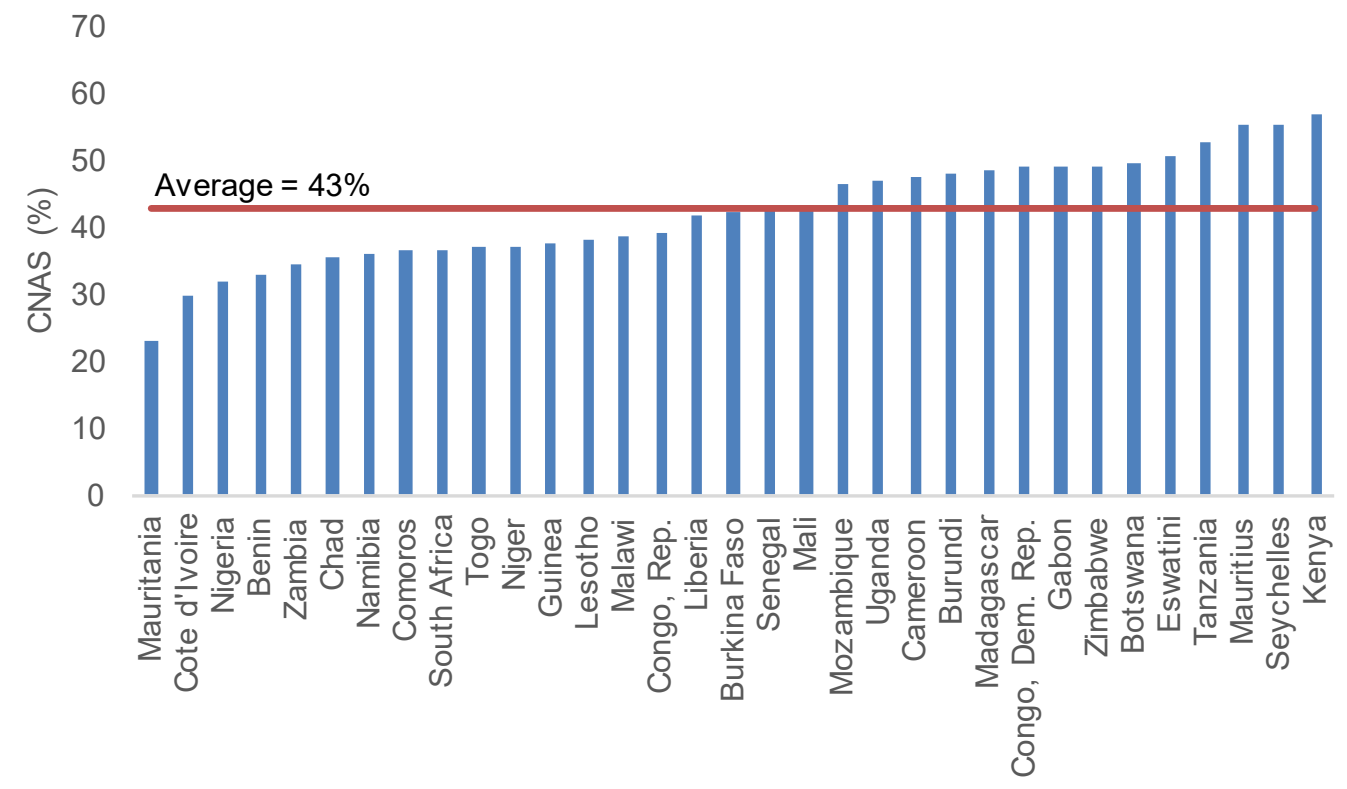

Source: Author's calculation based on MLA, PASEC, and SACMEQ scores.

Note: Swaziland was renamed Eswatini in 2018.

The higher CLAS average provides a slightly better picture of overall performance. Figure 6 provides the average CLAS score by country and the highest CLAS, $73 \%$, belongs to Gabon. Seychelles, Cameroon and Tanzania also have average scores greater than $65 \%$. Countries at the lowest end of the distribution continue to be Mauritania and Nigeria with average scores less than $35 \% .^{9}$

\footnotetext{
${ }^{9}$ The literacy outcomes of Anglophone and Francophone countries are generally similar. The four countries with the highest CLAS average include both PASEC and SACMEQ participants (Gabon and Cameroon participated in PASEC only while Seychelles and Tanzania participated in SACMEQ only). F-test and t-test are conducted to examine the difference in the means and variances of the literacy outcomes of PASEC and SACMEQ participants. The results show that the differences in the means and variances are not statistically significant at the 0.05 level.
} 
Figure 6 : Average CLAS by SSA Country

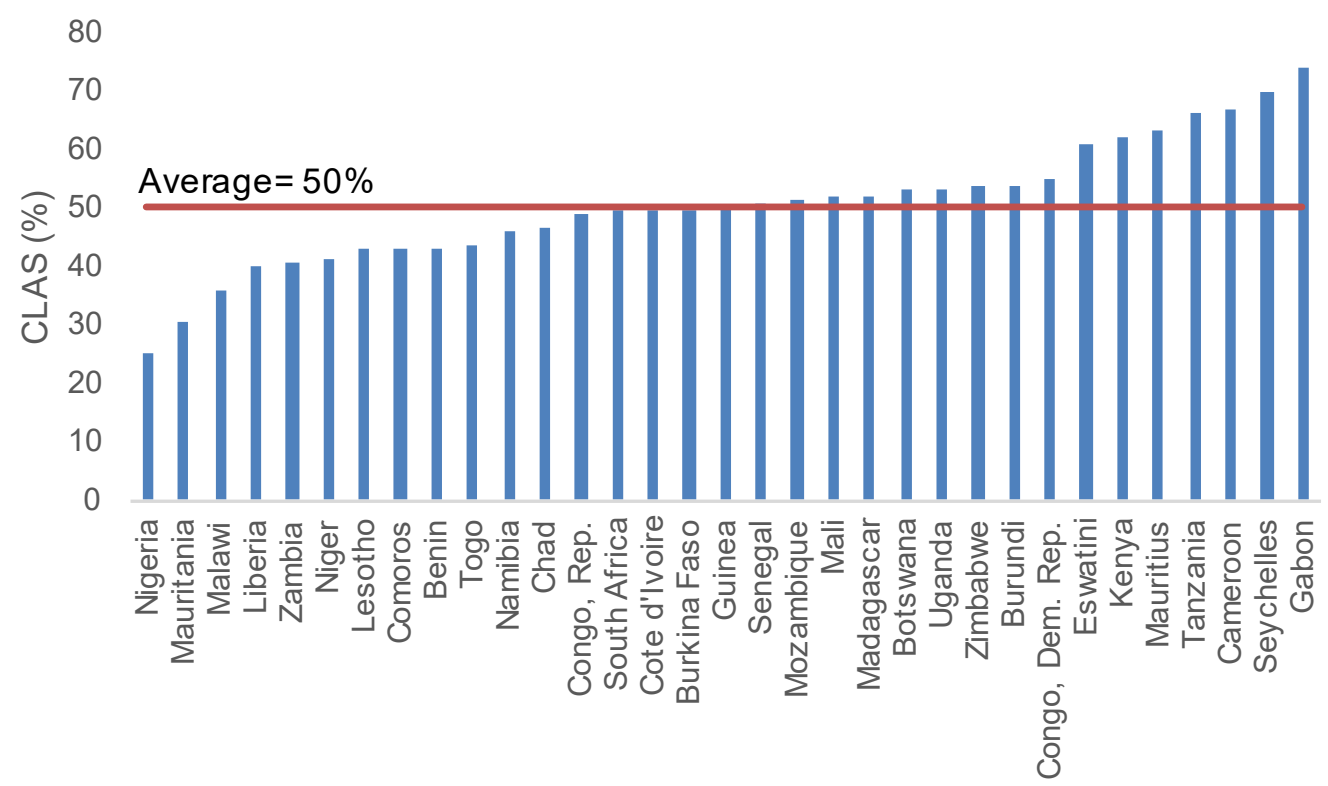

Source: Author's calculation based on MLA, PASEC, and SACMEQ scores.

Note: Swaziland was renamed Eswatini in 2018.

Figure 7 provides a scatter plot of CNAS and CLAS and shows a positive relationship between both variables. The Pearson correlation between both variables is also very high at 0.82 . However, the CNAS average score, $42 \%$, is lower than the CLAS average score, $50 \%$ and the result of the t-test shows that this difference is statistically significant at the 0.01 level. ${ }^{10}$ As such, both variables in addition to CAS, are used in the analysis.

${ }^{10} \mathrm{~A}$ t-test is also conducted to compare the means of the CLAS and CAS samples. According to the result, while there is a difference between both means, it is only statistically significant at the 0.1 level. 


\section{Figure 7: Scatter Plot: CNAS and CLAS}

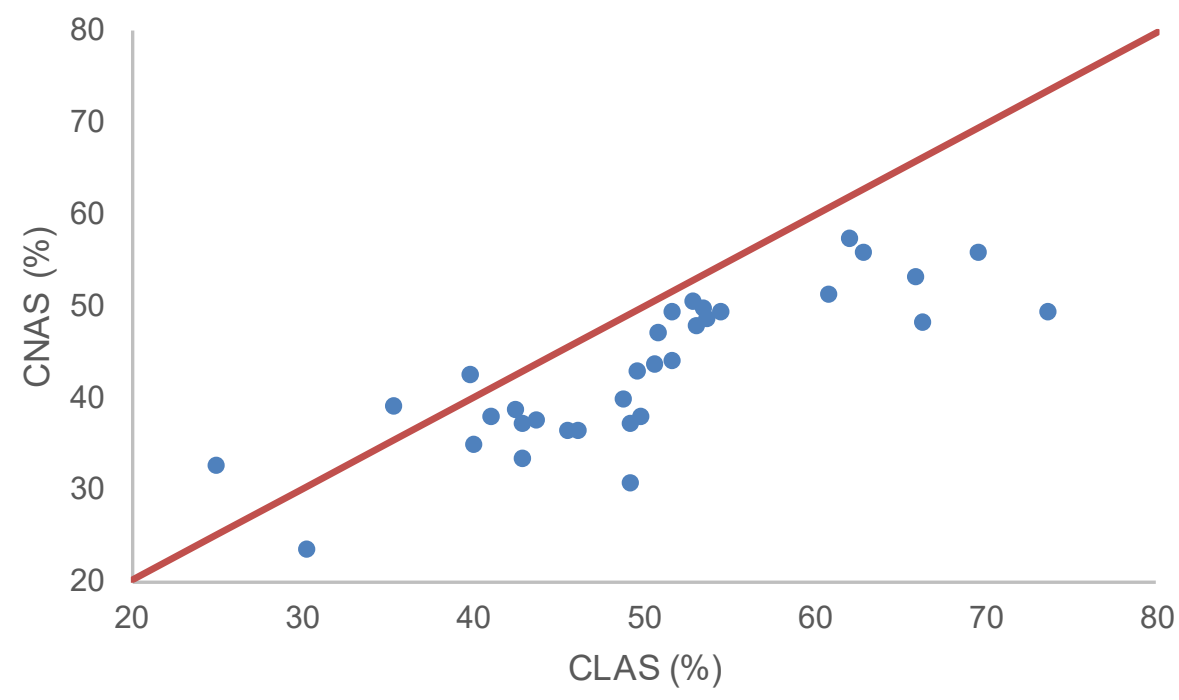

Note: 45-degree line reference line is added to chart.

Source: Author's calculation based on MLA, PASEC, and SACMEQ scores.

\subsubsection{Comparison with other Educational Achievement Data}

The derived scores are highly and significantly correlated with other measures of educational attainment in the literature. The derived scores are compared to the Majaard and Mingat (2012) and Angrist, Patrinos and Schlotter (2013) data sets. As previously noted, Majaard and Mingat (2012) developed ASLI, a combined index of numeracy and literacy scores based on the PASEC, SACMEQ and MLA data. The Angrist, Patrinos and Schlotter (2013) data set measures cognitive achievement for 128 countries (including 29 African countries) from 1965 to 2010.

When the CAS scores are compared with the ASLI scores from Maajard and Mingat (2012), the Pearson Correlation is 0.89 (based on 30 observations). The CNAS is also compared with the mathematics indicator in the Angrist, Patrinos and Schlotter (2013) 
database because of the higher common sample of mathematics scores. The Pearson Correlation between CNAS and the Angrist, Patrinos and Schlotter is also 0.89 (based on 20 observations). Both correlations are statistically significant at the 0.01 significance level. These comparisons suggest that the CAS and CNAS measures calculated here are comparable to those calculated by other researchers, providing a degree of corroboration of the approach taken here, and evidence of the legitimacy of the scores.

The developed measures have a number of strengths over alternative measures. The measures are available for a slightly larger number of SSA countries compared to Maajard and Mingat (2012) (33 versus 30 countries). ${ }^{11}$ More importantly, the additional measures developed in this study allow for a deeper exploration of subject- and genderspecific differences in the determinants of educational quality. Finally, the developed measures are solely based on regional assessment data unlike Angrist, Patrinos and Schlotter (2013) whose methodology combines regional and international assessment data.

\subsubsection{Comparison with Measures of Educational Attainment}

Prior to examining the correlation between educational achievement measures and other measures of educational attainment widely adopted in the literature, comparable data is first derived for each measure (i.e. average score from 1995 to 2010). Educational attainment data developed by Barro and Lee $(2000,2010$ and 2013) is one of the most utilized measure of educational quantity in the literature. The correlation between

\footnotetext{
11 The three additional countries are Comoros, Democratic Republic of the Congo and Liberia.
} 
developed educational achievement measures and Barro and Lee's average total years of primary schooling and average years of total schooling is low (range is between 0.17 and 0.24 for average total years of primary schooling and 0.19 to 0.30 for average total years of schooling). The absence of strong correlation between such a widely-adopted quantity indicator and the derived quality indicators corroborates existing literature on the differences between these two measures and the importance of considering the quality dimension of education in the measurement of human capital (for example, Hanushek and Kimko, 2000 and Hanushek and Woessmann, 2008).

Other measures of educational attainment typically utilized in the literature relating to primary education include primary enrollment rates, primary school attendance rates, primary school drop-out rates and primary completion rate. Some of these variables (for example, drop-out rates and repetition rates) have also been used in the literature as proxies for educational quality. Table 2 presents the correlation between these measures and the derived assessment scores.

From the table, it can be seen that only the urban primary school net attendance rate has a relatively high and statistically significant correlation with all three variables. The dropout-rate, primary completion rate, net attendance rate (total and rural), government expenditure on primary education are also modestly correlated with the variables but these correlations are generally not statistically significant. ${ }^{12}$ At the other end of the spectrum, primary repetition rate has the lowest correlation with all three assessment

\footnotetext{
12 Possible explanation for the negative correlation between the educational achievement variables and government expenditure on primary education is discussed in footnote 19.
} 
variables and the correlations are not statistically significant. In general, these results suggest that alternative measures of educational attainment particularly drop-out rates, attendance rate, and repetition rates are also weak proxies for educational achievement for countries in SSA.

Table 2: Correlation between Educational Achievement Indicators and Select Educational Attainment Measures

\begin{tabular}{|l|c|c|c|}
\hline Variables & CNAS & CLAS & CAS \\
\hline Primary net attendance rate_urban area & $0.44^{*}$ & $0.37^{*}$ & $0.44^{*}$ \\
\hline Primary completion rate & $0.37^{*}$ & 0.27 & 0.33 \\
\hline Primary net attendance rate & 0.33 & 0.33 & 0.37 \\
\hline Cumulative drop-out rate to the last grade of primary education & -0.33 & -0.33 & -0.33 \\
\hline Primary net attendance rate_rural area & 0.33 & 0.33 & 0.36 \\
\hline Primary net enrolment rate & 0.26 & 0.31 & 0.31 \\
\hline Expenditure on primary as \% of government expenditure on education $(\%)$ & -0.27 & $-0.42^{*}$ & -0.34 \\
\hline Expenditure per primary student (\$) & 0.29 & $0.38^{*}$ & 0.32 \\
\hline Primary adjusted net enrolment rate & 0.25 & 0.30 & 0.30 \\
\hline Primary school repetition rate (all grades) & -0.16 & 0.07 & -0.04 \\
\hline
\end{tabular}

Note: ${ }^{*}$ correlation is significant at the 0.05 level (2-tailed).

\subsubsection{Gender and Colonial Identity Comparisons}

Research alludes to the likelihood of a difference in assessment performance based on gender. This difference is mainly because mathematics and science are often stereotyped as male domains even though the evidence on gender-based performance differences is mixed (for example, Fennema and Sherman, 1978 and Eccles, 1982). In the SSA literature, the gender differences observed in a regional assessment of performance has been relatively small or not statistically significant (Chinapah et al, 2000 and Mioko, 1998). 
The relationship between colonial identity and educational outcomes has also been examined by researchers. According to Garnier and Schafer (2006), Britain and France followed two very distinct approaches to education in their African colonies. Education under the British system was more de-centralized while the state under the French system maintained significant control over the provision of education. It has been argued that the British system was more conducive to increasing enrolment and literacy and evidence appears to support this assertion. When African countries gained independence, former British colonies had higher school enrolment rates on average than former French colonies (Cogneau and Moradi, 2014; Benavot and Riddle, 1988 and Brown, 2000).

It is therefore expected that there would not be a significant gender difference in mean assessment scores but there would be a significant difference in mean assessment scores based on colonial identity and history. ${ }^{13}$ T-tests are carried out to test each hypothesis. While the average male scores are slightly higher than their female counterparts, there is no significant gender difference in mean CAS, CLAS or CNAS at the 0.05 significance level. In addition, even though the average CNAS is slightly higher for British colonies (opposite is the case for CLAS), there is also no significant difference in the mean of CAS, CLAS or CAS with respect to colonial history at the 0.05 significance level. Colonial distinction is excluded from the rest of the analysis and gender distinction is examined in more detail in Section 1.7.

\footnotetext{
${ }^{13}$ Test only includes countries that were either colonized by the British (nine countries) or French (14 countries). Countries with multiple colonial powers (such as Mauritius and South Africa) or those colonized by Belgium, Germany and Portugal are excluded.
} 


\subsection{Regression Analysis}

This section presents the conceptual and analytical framework used to examine the determinants of educational quality in SSA.

\subsubsection{Conceptual Framework}

The approach often adopted in the literature to examine the determinants of educational quality is based on a micro-level estimation of student performance using a human capital production function. More closely related to this study however are the studies that have adapted this approach for use in an international study of educational quality (for example, Hanushek and Kim,1995 and Lee and Barro,1997).

The underlying assumption that allows for the application of the production function at the macro-level is the idea that average innate ability of students does not vary across countries (or at the very least is exogenous to other determinants in the model). ${ }^{14}$ Consequently, cross-country differences in performance can be associated (and possibly caused) by country-specific variables that measure family and school system attributes. Accordingly, the macro-level education production function can be described as follows:

$$
E Q_{i}=\beta_{1}+\beta_{2} \text { Family }_{i}+\beta_{3} \text { School }_{i}+\beta_{4} \text { Other }_{i}+\epsilon_{i}
$$

Where: $\mathrm{EQ}=$ educational quality of country $\mathrm{i}_{\mathrm{i}}$; Family= family factors for country $\mathrm{i}$; School= school factors for country $\mathrm{i}$; Other $=$ other factors for country $\mathrm{i}$; and $\epsilon=$ error term (capturing unmeasured factors influencing educational quality).

\footnotetext{
14 While this assumption allows for the use of aggregate population characteristics (Hanushek and Kim, 1995), it is important to remain sensitive to the fact that aggregation of the data obscures variation that exists in the data at the school or student level.
} 
This model implies that educational achievement of a country, is related to inputs that are directly controlled within the education system (for example, characteristics of schools, teachers, curricula, and school resources) and those that are exogenous (to some extent) to the system (for example, family characteristics). It is also important to note though that educational achievement is measured at specific time periods; however, the educational process is cumulative and past inputs do influence current levels of student achievement (Hanushek, 2007).

\subsubsection{Model}

Educational quality, the dependent variable, is measured using the educational achievement variables (CNAS, CLAS and CAS) derived in the previous sub-section. The independent variables are described below.

\subsubsection{Family Factors}

Family background (typically socioeconomic characteristics) affects not only the probability that children enroll in, attend and complete school but also the learning of children in schools (Lockheed and Verspoor, 1991). In other words, socioeconomic factors are proxies for the quality of the home learning environment (Hanushek,1979). Key variables that have been identified in the literature include: parent's education level and family income. 
At the aggregate level, parental education level is proxied using the adult literacy rate of a country. ${ }^{15}$ The adult literacy rate is used instead of the more popular Barro and Lee (2013) measure of educational attainment because, in theory, a parent's actual cognitive ability should have a strong causal link to the quality of educational achievements of their children. The use of this alternative variable, however, is not expected to significantly affect the explanatory power of the model as both the adult literacy rate and the average years of total schooling variable are highly correlated (the Pearson Correlation between both variables is 0.79 ).

The final variable measuring family attributes is income. Lee and Barro (1997) note that countries with higher income, on average, are likely to devote a higher level of resources to public education (i.e. causality is likely to run in both directions). Family income is proxied using the average income per capita of the country. ${ }^{16}$ Family income is retained, despite the concern of reverse causality as the approach is consistent with the underlying theory and available evidence. Lagged values of family income are not utilized as it is difficult to determine the appropriate length of lag to adopt. Approach is also not expected to significantly alter the results. Lee and Barro (1997) estimate an alternate specification where they allowed a five-year lag of input variables in the regressions and find that "the

\footnotetext{
15 An alternate measure of parental education, the average primary completion rate between 1980 and 1990 , is also considered. This time frame was chosen to coincide with the earliest probable period when the parents of the students in the sample likely completed their primary education. The results are not presented as the predictive power of the model is generally lower (and at best comparable) with the model with adult literacy rate.

${ }^{16}$ In accordance with literature (for example, Barro and Lee, 1997), an alternative specification, the natural logarithm, is also used in the analysis. Again, the results are not presented as the pair-wise correlation with the dependent variables, significance of the coefficient and explanatory power of the model are comparatively lower than the level specification.
} 
empirical results did not change in qualitative terms" (p.22). Unit of measurement of variable is re-scaled (to thousands of dollars) in the regression analysis.

\subsubsection{School Factors}

Cross-country analyses generally suggest that quantitative measures of school inputs such as expenditure and class size do not account for the cross-country variation in educational achievement. What appears to matter for student achievement are the quality of instructional material and the quality of the teaching force (Woessmann, 2016). As such, measures of both school inputs and quality of the teaching force are included in the analysis.

Quality of the school resources is measured using the percentage of trained primary school teachers. It is typically assumed that a high percentage of teachers certified to teach in schools implies that a large portion of the teaching force is trained and have the requisite skills, knowledge to teach and use instructional resources.

Two additional school input measures are included in the analysis, the pupil-teacher ratio and government expenditure per primary student. It is generally assumed that a low pupilteacher ratio signifies smaller classes, thereby enabling the teacher to pay more attention to individual students, which in turn should contribute to improved student performance. The share of income per primary school student could be considered a signal of the level 
of importance placed on primary education by the government and, the level of resources available to the public education system. ${ }^{17}$

\subsubsection{Other Factors}

Two variables are added to the model to account for differences in the level of growth within SSA: population growth and indicator of democracy. ${ }^{18}$ Social scientists (including economists and demographers) have examined the relationship between demographic change and economic outcomes. In recent years, general agreement is that improving economic conditions for individuals typically leads to lower birth rates and consequently, lower population growth. As such, population growth is introduced to capture the level of development of each country. A negative relationship also supports the hypothesis from the literature of the deleterious effect of larger family sizes on the academic achievement of children (Hanushek, 1992). As expected, population growth is strongly correlated with GDP per capita (Pearson correlation is -0.50 ).

Schultz (1975) advances a landmark hypothesis that human capital is most valuable in the presence of unexpected price, productivity or technology shocks that require managerial decisions to reallocate time and resources. In other words, if a country imposes economic or political institutions that inhibit individual economic choice, then there would be lower returns to skill in the country. Evidence from SSA appears to support

\footnotetext{
17 Government expenditure on primary education as a fraction of education expenditure is excluded from the analysis because of its negative correlation with the derived achievement variables. It is likely that the negative correlation is the result of low percentages (from $2 \%$ to $15 \%$ ) and minimal variation within the sample.

18 The intention was to also include a child mortality rate variable to capture the inter-relationship between the health and academic performance of students. However, this variable is excluded because of measurement issues. There is a large and unexplainable range of outcomes for SSA countries (between $14 \%$ and $216 \%)$.
} 
this hypothesis. For example, Angrist, Patrinos and Schlotter (2013) suggest that key drivers of educational achievement are democracy and economic freedom in a subset of African and Latin American countries. As such, polity variable (composite indicator of democracy and autocracy) from the Polity IV Project is included in the analysis.

\subsubsection{Estimated Equation}

The choice of estimation equation and technique is rooted in economic theory. However, economic theory is balanced with statistical methods and testing in recognition of the nuances associated with real world application of theory. As Kennedy (1998) notes:

It remains a fact, though, that in practice good results depend as much on the input of sound and imaginative economic theory as on the application of correct statistical methods. The skill of the econometrician lies in judiciously mixing these two essential ingredients. (p.2)

Accordingly, the proposed full model is:

$$
\begin{gathered}
E Q=\beta_{1}+\beta_{2} \text { literacyrate }+\beta_{3} \text { trainedteachers }+\beta_{4} \text { pupil }- \text { teacher }+\beta_{5} \text { GDPpercapita } \\
+\beta_{6} \text { govtexpenditure }+\beta_{7} \text { popgrowth }+\beta_{8} \text { polity }+\epsilon
\end{gathered}
$$

Where: literacyrate $=$ adult literacy rate, trainedteachers $=$ percentage of trained teachers in primary education, pupil-teacher $=$ pupil-teacher ratio in primary education, GDPpercap $=$ GDP per capita, govtexpenditure $=$ government expenditure per primary student, popgrowth $=$ population growth, polity = composite democracy and autocracy indicator .

In accordance with the empirical literature, it is expected that the coefficients of: literacyrate, GDPpercap, trainedteachers, govtexpenditure and polity will be positive; pupil-teacher and popgrowth will be negative. Accordingly, testable hypotheses include:

- If educational resources increase, then the quality of education will increase; 
- If the primary school system efficiently allocates financial, human and material resources, then the quality of the system will be high; and

- If the population growth rate is high, then the quality of education will be relatively low.

\subsubsection{Sample}

Data for most independent variables is obtained from the World Bank's Edstats. Polity variable is from the Center from Systemic Peace Polity IV Project. Additional information on the source, definition and description of each variable is provided in Table A3 in the Appendix. The dataset is a cross-sectional data set of 33 SSA countries averaged over 1995 to 2010 to match constructed quality variables.

Summary statistics of the independent variables are presented in Table 3 and generally show that on average, SSA countries outcomes on development, education and governance indicators are generally low. However, the table also shows a marked variation in range of performance on the various indicators across SSA countries.

Table 3: Basic Descriptive Statistics

\begin{tabular}{|l|c|c|c|c|l|}
\hline & Mean* $^{*}$ & Std Dev & Min & Max & N \\
\hline Adult literacy rate (\%) & 58 & 21 & 22 & 93 & 45 \\
\hline Trained teachers (\%) & 75 & 18 & 37 & 100 & 41 \\
\hline Pupil- teacher ratio & 44 & 14 & 14 & 92 & 46 \\
\hline GDP per capita (\$) & 1,877 & 2,679 & 218 & 10,834 & 46 \\
\hline Government expenditure per primary student (\$) & 231 & 322 & 12 & 1,420 & 36 \\
\hline Population growth (\%) & 3 & 1 & 1 & 4 & 48 \\
\hline Polity & 1 & 5 & -9 & 10 & 44 \\
\hline
\end{tabular}

*unweighted averages 
Given the small sample size, it is imperative that the adopted model is parsimonious. As such, pairwise correlation between all the variables is examined to ensure that the chosen explanatory variables not only have a strong theoretical underpinning but are also strongly correlated with the dependent variables.

The correlation coefficient matrix is presented in Table 4. Adult literacy rate has the highest correlation with the dependent variables and these correlations are statistically significant at the 0.05 level. At the other end of the spectrum, the polity variable has the lowest correlation with the dependent variables and is excluded from the rest of the analysis. ${ }^{19}$

\footnotetext{
19 The polity variable is included in an alternate specification and the result validates its exclusion. The coefficient on the polity variable is not significant in any of the specifications and the inclusion of the variable significantly reduces the explanatory power of the model.
} 
Table 4: $\mathrm{Bi}-$ Variate Correlation Matrix

\begin{tabular}{|c|c|c|c|c|c|c|c|c|c|c|}
\hline & CNAS & CLAS & CAS & $\begin{array}{l}\text { Adult } \\
\text { literacy } \\
\text { rate }\end{array}$ & $\begin{array}{l}\text { GDP per } \\
\text { capita }\end{array}$ & $\begin{array}{c}\text { Govt } \\
\text { Expenditure } \\
\text { per Primary } \\
\text { student) }\end{array}$ & $\begin{array}{l}\text { Trained } \\
\text { teachers }\end{array}$ & $\begin{array}{l}\text { Pupil- } \\
\text { teacher } \\
\text { ratio }\end{array}$ & $\begin{array}{l}\text { Population } \\
\text { growth }\end{array}$ & Polity \\
\hline CNAS & 1 & & & & & & & & & \\
\hline CLAS & $0.82^{*}$ & 1 & & & & & & & & \\
\hline CAS & $0.95^{*}$ & $0.96^{*}$ & 1 & & & & & & & \\
\hline Adult literacy rate & $0.48^{*}$ & $0.43^{*}$ & $0.48^{*}$ & 1 & & & & & & \\
\hline GDP per capita & 0.30 & $0.50^{*}$ & $0.42^{*}$ & $0.61^{*}$ & 1 & & & & & \\
\hline Govt Expenditure & 0.29 & $0.39^{*}$ & 0.32 & $0.60^{* *}$ & $0.98^{*}$ & 1 & & & & \\
\hline Trained teachers & 0.27 & $0.37^{*}$ & 0.34 & 0.25 & 0.13 & 0.25 & 1 & & & \\
\hline Pupil-teacher ratio & -0.28 & -0.24 & -0.25 & $-0.45^{\star}$ & $-0.42^{*}$ & $-0.66^{*}$ & -0.12 & 1 & & \\
\hline Population growth & -0.29 & -0.34 & -0.32 & $-0.56^{*}$ & $-0.36^{*}$ & $-0.69^{*}$ & -0.22 & $0.34^{*}$ & 1 & \\
\hline Polity & 0.04 & -0.17 & -0.08 & 0.11 & 0.01 & 0.44 & -0.10 & -0.12 & -0.28 & 1 \\
\hline
\end{tabular}

* Significant at 0.05 level 


\subsubsection{Estimation Approach}

The widely-adopted approach for estimation of linear regressions, Ordinary Least Squares (OLS), is the chosen estimation approach. OLS remains a suitable approach for estimating the model even when the dependent variable is deemed to include random measurement errors which may well be the case given that most SSA governments have limited resources for collecting statistics. The estimated coefficients will still be unbiased and the impact will be limited to increasing the unexplained portion of the regression (Fearon, 2001).

A more serious issue arises when the explanatory variables include random measurement errors and it is quite conceivable that some of the SSA data are measured with noise. When an independent variable is measured with error, standard OLS regression tends to bias the estimated slope coefficient towards zero. In multiple regression, measurement error in one independent variable can also bias estimates of the effects of other independent variables.

Therefore, as a check, the model is also estimated using the Errors-in-Variables regression model. Errors-in-Variables regression model is useful when one or more of the independent variables are measured with additive noise. Measure of reliability is determined by producing a range of values to describe the sensitivity of the estimates to possible error levels. 


\subsection{Regression Results}

Prior to running the regressions, a series of tests are conducted. ${ }^{20}$ First, the normality condition of the residuals is examined. Test is important as one of the classical linear model assumptions is that the error terms are normally distributed. The Shapiro-Wilk test (considered more appropriate for small samples) is conducted to examine normality of the residuals and the results show that the residuals are normally distributed (at the 0.01 significance level).

Second, a test for multicollinearity is also conducted. Multicollinearity is a concern because when high multicollinearity is present, standard errors are higher and independent variable coefficients will need to be larger to be statistically significant. The presence of multicollinearity is detected by examining the: Spearman correlation coefficients, Tolerance and Variance Inflation Factors (VIF).

Multicollinearity is deemed to not be of concern for most variables as their VIFs were less than 5 , tolerances were greater than 0.20 , and correlation coefficient less than 0.75 (see Table 4) except for government expenditure per student. ${ }^{21}$ Government expenditure per student is highly correlated with GDP per capita and is excluded from the rest of the analysis. ${ }^{22}$

\footnotetext{
${ }^{20} \mathrm{~A}$ test for serial correlation (autocorrelation) is not conducted because the data is cross-sectional.

21 I used a smaller threshold for VIF and Tolerance than the more widely used cut-off (10 and 0.10 respectively) because of the small sample size.

${ }^{22}$ Government expenditure per primary student as a percentage of GDP per capita is considered as a potential proxy for government expenditure per primary student but was excluded because of the low bivariate correlation between both variables $(0.22)$ and the weaker regression results.
} 
Finally, the presence of heteroscedasticity is detected using the Breusch-Pagan test. Testing for heteroscedasticity is important as statistical inference assumes that the errors are homoscedastic. The results show that the errors are homoscedastic at the 0.01 significance level for all three model specifications.

Based on the results of the tests, the Gauss- Markov assumptions (linear in parameters, random sampling, zero conditional mean, sample variation in independent variable and homoscedasticity) are expected to hold. In other words, OLS is expected to be BLUE (Best Linear Unbiased Estimator).

The results of the regressions are presented in Table 5. The first three columns contain the full-model regression results. The F-test statistics show that both the CAS and CNAS have no predictive capability (i.e. all the regression coefficients are equal to zero). The opposite is the case for the CLAS results and so CLAS result will be the only full-model results discussed. The explanatory power of the CLAS model is relatively modest and most of the estimated coefficient have the expected signs (except for population growth and pupil-teacher ratio). Also, only the coefficient on GDP per capita is statistically significant at the 0.1 level. 
Table 5: Full Model Regression Results

\begin{tabular}{|l|c|c|c|c|c|c|}
\hline \multirow{2}{*}{$\begin{array}{l}\text { Dependent } \\
\text { Variable }\end{array}$} & \multicolumn{3}{|c|}{ Full Model } & \multicolumn{3}{c|}{ Reduced Model } \\
\cline { 2 - 7 } & CAS & CLAS & CNAS & CAS & CLAS & CNAS \\
\hline Adult literacy rate & 0.15 & 0.09 & 0.16 & $0.15^{*}$ & & $0.18^{* * *}$ \\
& $(1.33)$ & $(0.75)$ & $(1.67)$ & $(1.69)$ & & $(2.91)$ \\
\hline GDP per capita & 0.97 & $1.68^{*}$ & 0.27 & 0.81 & $1.75^{* *}$ & \\
& $(1.16)$ & $(1.77)$ & $(0.37)$ & $(1.14)$ & $(2.65)$ & \\
\hline Trained teachers & 0.09 & 0.13 & 0.05 & & 0.15 & \\
& $(0.94)$ & $(1.14)$ & $(0.55)$ & & $(1.47)$ & \\
\hline Pupil-teach ratio & 0.04 & 0.08 & -0.03 & & & \\
& $(0.25)$ & $(0.43)$ & $(-0.22)$ & & & \\
\hline Pop growth & 1.31 & 0.70 & 1.35 & & & \\
& $(0.42)$ & $(0.19)$ & $(0.48)$ & & & \\
\hline Constant & 22.85 & 25.95 & $26.01^{*}$ & $35.64^{* * *}$ & $35.19^{* * *}$ & $31.66^{* * *}$ \\
& $(1.45)$ & $(1.45)$ & $(1.86)$ & $(7.39)$ & $(4.54)$ & $(8.09)$ \\
\hline $\mathbf{R}^{2}$ & $\mathbf{0 . 3 0}$ & $\mathbf{0 . 3 3}$ & $\mathbf{0 . 2 4}$ & $\mathbf{0 . 2 6}$ & $\mathbf{0 . 3 0}$ & $\mathbf{0 . 2 3}$ \\
\hline Adjusted $\mathbf{R}^{2}$ & $\mathbf{0 . 1 5}$ & $\mathbf{0 . 1 9}$ & $\mathbf{0 . 0 9}$ & $\mathbf{0 . 2 1}$ & $\mathbf{0 . 2 6}$ & $\mathbf{0 . 2 0}$ \\
\hline F statistic & $\mathbf{2 . 0 3}$ & $\mathbf{2 . 3 4}$ & 1.55 & $\mathbf{4 . 9 5}$ & $\mathbf{6 . 3 3}$ & $\mathbf{8 . 4 8}$ \\
& $\mathbf{0 . 1 1 )}$ & $\mathbf{( 0 . 0 7 )}$ & $\mathbf{( 0 . 2 1 )}$ & $\mathbf{( 0 . 0 1 )}$ & $\mathbf{( 0 . 0 1 )}$ & $\mathbf{( 0 . 0 1 )}$ \\
\hline N & $\mathbf{3 0}$ & $\mathbf{3 0}$ & $\mathbf{3 0}$ & $\mathbf{3 1}$ & $\mathbf{3 2}$ & $\mathbf{3 1}$ \\
\hline
\end{tabular}

Note: $t$-statistic reported in parentheses except for the $\mathrm{F}$ statistic where the $\mathrm{p}$-value is reported. Two-tailed p-values: * significant at 0.1 level; ${ }^{* *}$ significant at the 0.05 level; ${ }^{* * *}$ significant at 0.01 level.

There is a concern that the model is "overfitted". Overfitting occurs when a regression model contains too many explanatory models relative to the number of observations and limits the accuracy of the regression parameters. As such, the full model is reduced to its most parsimonious version. ${ }^{23}$ The results of the reduced model are presented in last three columns in Table 5 and are relatively stronger. The null hypothesis of the F-test is

\footnotetext{
${ }^{23}$ The reduced model is a result of a step-by-step elimination of independent variables with the lowest explanatory power. Removal of explanatory variables ceases once the adjusted $R^{2}$ is maximized. F-test and Root Mean Square Error (Root MSE) are also compared at each step to ensure that the model with the best fit is selected as the reduced model.
} 
now rejected for all three models. Also, the adjusted $\mathrm{R}^{2}$, a more important measure when comparing between models, is now relatively higher.

The reduced models generally suggest that the most important explanatory variable are family factors. The coefficients on adult literacy rate in both CAS and CNAS regressions are positive and statistically significant at either the 0.01 or 0.1 levels. A per cent increase in the adult literacy rate is estimated to increase CAS and CNAS by about 0.20 percentage points. GDP per capita is an important explanatory factor in the CLAS regression with the estimated coefficient statistically significant at the 0.05 level; a $\$ 1$ increase in GDP per capita is estimated to increase CLAS by 1.75 percentage points.

The percentage of trained primary school teachers appears to play a positive and important role in explaining CLAS but the estimated coefficient is not statistically significant at conventional testing levels.

Figure 8 presents the residual plot for the CAS full model regression and shows that there are a few potential outliers in the sample. A series of tests are conducted to determine the extent of their effect and subsequently, their influence on the regression results. 
Figure 8: CAS Full Regression Model Residual Plot

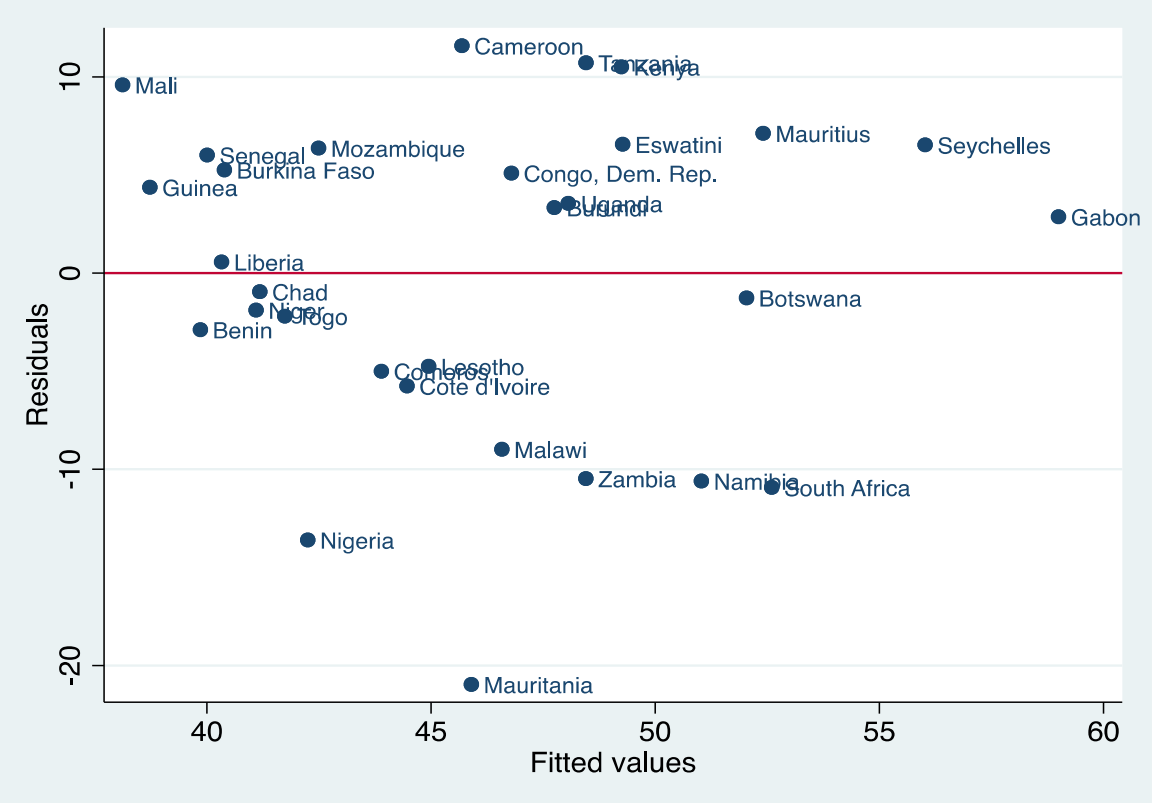

The outlier tests conducted measure the: discrepancy (difference between the predicted $\mathrm{Y}$ and observed $\mathrm{Y}$ ); leverage (data point with extreme value(s) of an explanatory variable(s)); and influence (function of both discrepancy and leverage and identifies data point that unduly influences any part of a regression analysis). ${ }^{24}$

\footnotetext{
${ }^{24}$ Studentized Residuals, a measure of discrepancy, is a t-statistic for testing the significance of a dummy variable that takes on the value 1 in the observation in question and 0 elsewhere (Belsley, Kuh and Welsh, 1980). The purpose of the dummy variable is to "absorb the observation and so remove its influence in determining the other coefficients in the model" (Williams, 2016). Concerns arise when the statistic has a value of 3 or greater (or -3 or less). Leverage measure calculates the Hosmer and Lemeshow leverage. High leverage exists in small samples when leverage $>3 \mathrm{k} / \mathrm{n}$ (where $\mathrm{k}$ is the number of explanatory variables and $n$ is the sample size). DFBETA measures influence and Belsely, Kuh and Welsh (1980) suggest observations with DFBETAs $>2 / \operatorname{sqrt}(n)$ should be examined but it is also common practice to use 1 as the cutoff. The final statistic, Cook's Distance, is also a measure of influence. Values greater than $4 / n$ (where $\mathrm{n}$ is the sample size) are considered an issue.
} 
Table 6 presents the results of the outlier tests and identifies 10 potential outliers. ${ }^{25}$ Discrepancy does not appear to be of concern as the studentized residual for most is lower than 3 (except perhaps Mauritania). Also, there does not appear to be an issue of high leverage as all the observations are below the cutoff ( 0.5 in this case); the closest observation to the cut off is Malawi. Mauritania and Malawi appear to be influential (more so Mauritania) as their DFBETA scores are lower than the 0.37 cut-off but their Cook's distance scores are above the 0.13 cut off.

Table 6: Outlier Analysis Results

\begin{tabular}{|l|c|c|c|c|}
\hline Country & $\begin{array}{c}\text { Studentized } \\
\text { Residual }\end{array}$ & Leverage & DFBETA & $\begin{array}{c}\text { Cook's } \\
\text { Distance }\end{array}$ \\
\hline Mauritania & -2.87 & 0.13 & 0.34 & 0.16 \\
\hline Nigeria & -1.67 & 0.11 & 0.04 & 0.05 \\
\hline South Africa & -1.38 & 0.19 & -0.22 & 0.07 \\
\hline Malawi & -1.26 & 0.35 & -0.25 & 0.14 \\
\hline Namibia & -1.25 & 0.08 & -0.08 & 0.02 \\
\hline Mauritius & 0.93 & 0.27 & -0.18 & 0.05 \\
\hline Mali & 1.22 & 0.21 & -0.29 & 0.07 \\
\hline Kenya & 1.30 & 0.16 & 0.28 & 0.05 \\
\hline Tanzania & 1.31 & 0.14 & 0.22 & 0.04 \\
\hline Cameroon & 1.40 & 0.11 & 0.32 & 0.04 \\
\hline
\end{tabular}

The Ivr2plot (leverage-versus-residual-squared plot), presented in Figure 9 confirms that Mauritania is the most problematic outlier and as such, is the only country eliminated from the sample and a revised analysis is conducted. ${ }^{26}$

\footnotetext{
${ }^{25}$ Outlier table is generated using the "Extremes" function. By default, the function returns the five highest and five lowest values based on the first variable included in the test.

${ }^{26}$ Coding error is a possible reason why Mauritania is an outlier as the country data was manually calculated directly from the file provided by PASEC.
} 
Figure 9: Leverage-versus-Residual Squared Plot, CAS Full Regression

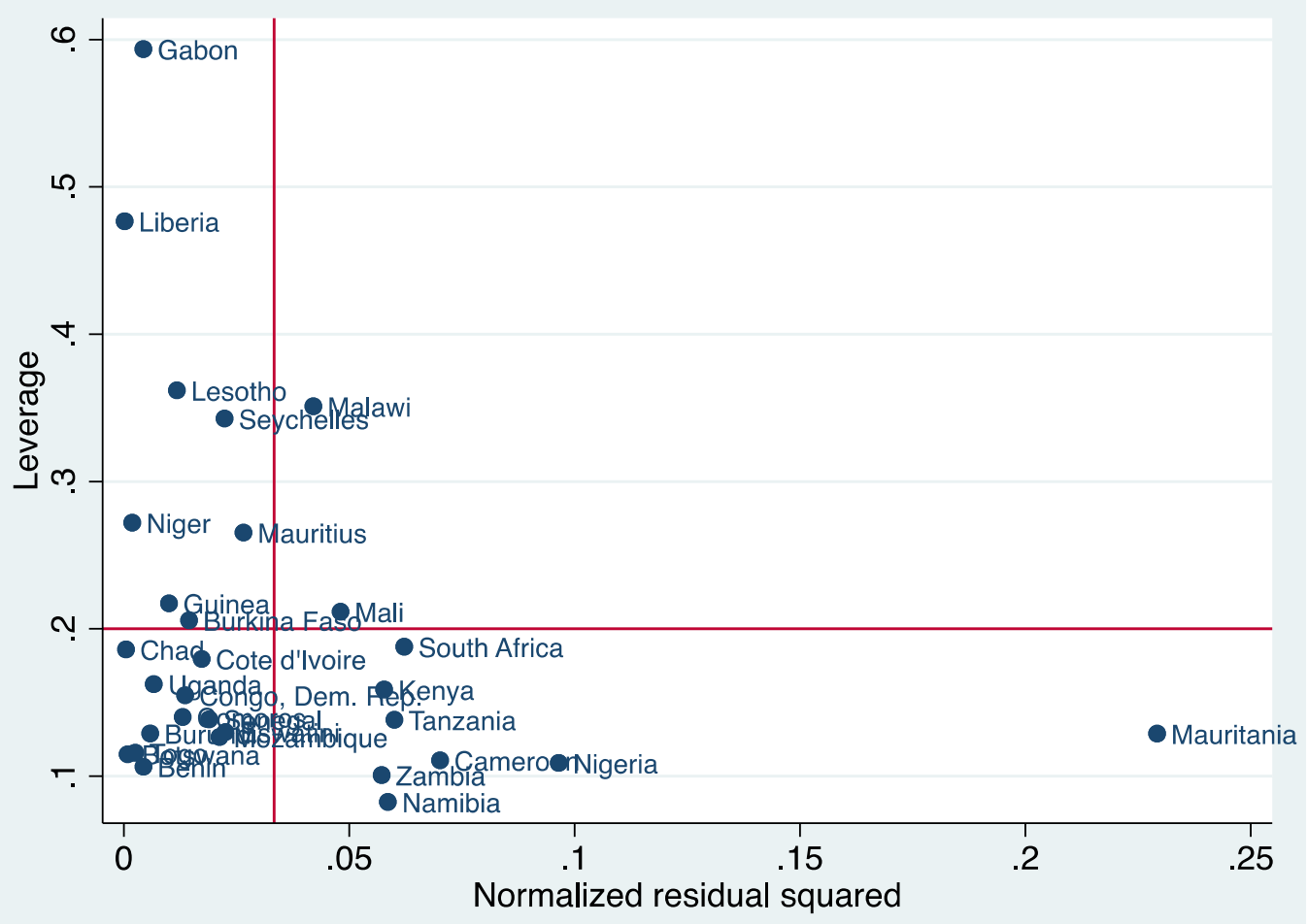

Table 7 presents the updated results of the full and reduced models without Mauritania. The exclusion of Mauritania increased the predictive capability of the model specifications (as the null hypothesis of the F-test is now consistently rejected); the explanatory power of the models is also higher. In terms of the full-models, the signs of the coefficients are generally consistent with the hypothesized signs (except the coefficients on popgrowth and pupil-teacher ratio in CAS and CLAS regressions). The coefficient on GDP per capita remains significant at the 0.1 level in the CLAS regression. In addition, the coefficient on trained teachers is now statistically significant (at the 0.1 level) in both the CLAS and CAS regressions. 
Table 7: Full and Reduced Models without Mauritania Results

\begin{tabular}{|l|c|c|c|c|c|c|}
\hline \multirow{3}{*}{$\begin{array}{c}\text { Dependent } \\
\text { Variable }\end{array}$} & \multicolumn{3}{|c|}{ Full Model } & \multicolumn{3}{c|}{ Reduced Model } \\
\cline { 2 - 7 } & CAS & CLAS & CNAS & CAS & CLAS & CNAS \\
\hline Adult literacy rate & 0.11 & 0.06 & 0.14 & 0.08 & & $0.13^{*}$ \\
& $(1.17)$ & $(0.53)$ & $(1.55)$ & $(1.02)$ & & $(2.06)$ \\
\hline GDP per capita & 0.87 & $1.58^{*}$ & 0.18 & 0.71 & $1.52^{* *}$ & 0.11 \\
& $(1.18)$ & $(1.80)$ & $(0.28)$ & $(1.10)$ & $(2.50)$ & $(1.49)$ \\
\hline Trained teachers & $0.17^{*}$ & $0.20^{*}$ & 0.12 & $0.17^{*}$ & $0.21^{* *}$ & \\
& $(1.86)$ & $(1.85)$ & $(1.43)$ & $(1.90)$ & $(2.25)$ & \\
\hline Pupil-teach ratio & 0.01 & 0.05 & -0.06 & & & \\
& $(0.04)$ & $(0.28)$ & $(-0.49)$ & & & \\
\hline Pop growth & 1.76 & 1.13 & 1.75 & & & \\
& $(0.63)$ & $(0.34)$ & $(0.71)$ & & & \\
\hline Constant & 20.29 & 23.49 & $23.74^{*}$ & $27.28^{* * *}$ & $31.29^{* * *}$ & $26.44^{* * *}$ \\
& $(1.47)$ & $(1.42)$ & $(1.93)$ & $(3.98)$ & $(4.33)$ & $(4.64)$ \\
\hline$R^{2}$ & 0.38 & 0.39 & 0.31 & 0.37 & 0.37 & 0.29 \\
\hline Adjusted $R^{2}$ & 0.24 & 0.25 & 0.16 & 0.29 & 0.33 & 0.24 \\
\hline F statistic & 2.79 & 2.90 & 2.09 & 4.81 & 8.36 & 5.35 \\
& $(0.04)$ & $(0.04)$ & $(0.10)$ & $(0.01)$ & $(0.00)$ & $(0.01)$ \\
\hline $\mathrm{N}$ & 29 & 29 & 29 & 29 & 31 & 29 \\
\hline
\end{tabular}

Note: t-statistic reported in parentheses except for F-statistic where p-value is reported. * significant at 0.1 level; ${ }^{* *}$ significant at the 0.05 level; ${ }^{* * *}$ significant at 0.01 level.

Most important are the results of the reduced models. Family effects (measured by adult literacy rate) is still statistically significant at the 0.1 level in the CNAS results. The results indicate that a per cent increase in adult literacy rate is estimated to increase CNAS scores by 0.13 percentage points. It is interesting to note that adult literacy rate does not appear to play a significant role in determining CLAS outcomes. Also, school effects, measured by the percentage of trained primary school teachers appears to play an important role in determining CLAS and CAS results with the coefficients statistically significant at either the 0.05 or 0.01 levels. A per cent increase in trained teachers is estimated to increase both assessment outcomes by about 0.20 percentage points. 
Finally, the second family factor, income, plays a statistically significant role in determining CLAS outcomes; the coefficient is statistically significant at the 0.05 level. The variable has the highest predictive effect and a $\$ 1$ increase in GDP per capita is estimated to increase CLAS assessment scores by 1.52 percentage points.

In summary, the reduced model results suggest that:

- Family factors have a statistically significant role in determining both numeracy and literacy assessment outcomes.

- School factors play significant role in determining literacy assessment outcomes and overall assessment outcomes.

In other words, the results generally suggest that both group of factors: family factors and school factors matter in determining educational assessment outcomes. However, the magnitude of each effect depends largely on assessment subject. ${ }^{27}$ In addition, the strength of the association between variables and assessment results is statistically relatively weak, suggesting that associated effects are relatively heterogeneous, and that a lot of variation in performance is either random or not captured well in the model.

\subsection{Gender Analysis of Assessment Outcomes}

While the results in the preceding section allude to a lack of significant gender difference in assessment outcomes, a legitimate question remains as to whether explanatory factors

\footnotetext{
${ }^{27}$ Error-in-variable regressions results generally mirror the OLS full model without Mauritania regression results. The reliability estimate used to test the sensitivity of the results is 0.80 ; smaller values returned an error.
} 
have the same causal effect on both male and female assessment outcomes. To address this question, the full and reduced models are replicated with gender delineated assessment outcomes.

The results of the full model are presented in Table 8 . The null hypothesis of the F-test that all the independent coefficients are equal to zero is not rejected for the male regressions. As such, only the female assessment results are discussed. In general, the model appears to be relatively stronger at explaining female assessment outcomes. ${ }^{28}$ Also, while the signs on the coefficients remain unchanged, there are some differences in the predicted effects and statistical significance of the coefficients. More specifically, only the coefficient on GDP per capita in the CLAS female regression is statistically significant at the 0.05 level.

\footnotetext{
${ }^{28}$ It is possible that the higher $\mathrm{R}$ squared for the female results might be due to gender driven differences in the sample variance. The premise is that variation may be lower in the female scores than their male counterparts resulting in a higher level of significance of the constant in the female regressions. The difference in the variance between both groups is tested using sdtest and I fail to reject the null hypothesis that the standard deviations for both groups are the same for all three assessment scores.
} 
Table 8: Full Models (without Mauritania Results) by Gender

\begin{tabular}{|l|l|l|l|l|l|l|}
\hline Dependent Variable & \multicolumn{2}{|c|}{ CAS } & \multicolumn{2}{c|}{ CLAS } & \multicolumn{2}{c|}{ CNAS } \\
\hline & Males & Females & Males & Females & Males & Females \\
\hline Adult literacy rate & 0.11 & 0.10 & 0.04 & 0.06 & 0.15 & 0.12 \\
& $(1.10)$ & $(1.13)$ & $(0.33)$ & $(0.64)$ & $(1.65)$ & $(1.37)$ \\
\hline GDP per capita & 0.72 & 0.95 & $1.60^{*}$ & $1.57^{\star *}$ & -0.08 & 0.30 \\
& $(0.95)$ & $(1.47)$ & $(1.72)$ & $(2.31)$ & $(-0.12)$ & $(0.47)$ \\
\hline Trained teachers & 0.10 & 0.09 & 0.08 & 0.08 & 0.09 & 0.09 \\
& $(0.93)$ & $(1.03)$ & $(0.63)$ & $(0.78)$ & $(0.92)$ & $(0.93)$ \\
\hline Pupil-teach ratio & -0.02 & -0.09 & -0.02 & -0.11 & -0.06 & -0.10 \\
& $(-0.10)$ & $(-0.62)$ & $(-0.08)$ & $(-0.76)$ & $(-0.37)$ & $(-0.72)$ \\
\hline Pop growth & 3.30 & 0.91 & 4.12 & 0.98 & 2.23 & 0.73 \\
& $(0.95)$ & $(0.31)$ & $(0.97)$ & $(0.32)$ & $(0.72)$ & $(0.25)$ \\
\hline Constant & 24.77 & $32.39^{\star *}$ & $31.36^{*}$ & $40.48^{\star * *}$ & $25.13^{*}$ & $30.08^{* *}$ \\
& $(1.67)$ & $(2.59)$ & $(1.74)$ & $(3.07)$ & $(1.90)$ & $(2.41)$ \\
\hline $\mathbf{R}^{2}$ & $\mathbf{0 . 2 3}$ & $\mathbf{0 . 4 5}$ & $\mathbf{0 . 2 1}$ & $\mathbf{0 . 5 0}$ & $\mathbf{0 . 2 4}$ & $\mathbf{0 . 3 6}$ \\
\hline Adjusted $\mathbf{R}^{\mathbf{2}}$ & $\mathbf{0 . 0 5}$ & $\mathbf{0 . 3 2}$ & $\mathbf{0 . 0 3}$ & $\mathbf{0 . 3 8}$ & $\mathbf{0 . 0 7}$ & $\mathbf{0 . 2 1}$ \\
\hline F- statistic & $\mathbf{1 . 2 6}$ & $\mathbf{3 . 4 8}$ & $\mathbf{1 . 1 4}$ & $\mathbf{4 . 2 5}$ & $\mathbf{1 . 3 6}$ & $\mathbf{2 . 4 1}$ \\
& $\mathbf{( 0 . 3 2 )}$ & $\mathbf{( 0 . 0 2 )}$ & $\mathbf{( 0 . 3 7 )}$ & $\mathbf{( 0 . 0 1 )}$ & $\mathbf{( 0 . 2 8 )}$ & $\mathbf{( 0 . 0 7 )}$ \\
\hline $\mathbf{N}$ & $\mathbf{2 7}$ & $\mathbf{2 7}$ & $\mathbf{2 7}$ & $\mathbf{2 7}$ & $\mathbf{2 7}$ & $\mathbf{2 7}$ \\
\hline
\end{tabular}

Note: $\mathrm{t}$-statistic reported in parentheses except F-test where $\mathrm{p}$-value is reported. Two-tailed $\mathrm{p}$ vales: * significant at 0.1 level; ${ }^{* *}$ significant at the 0.05 level; ${ }^{* * *}$ significant at 0.01 level.

The reduced model for the sample disaggregated by gender is presented in Table 9 and the results again suggest that the model is better explaining the determinants of female student assessment outcomes. Also, compared to the reduced model without gender distinctions, there are three differences worth noting. Parental education is now a significant determinant of CAS for both male and female students at the 0.01 level. Also, percentage of trained teachers is no longer a significant determinant of CAS or CLAS for both male and female students. Finally, family income is now a significant determinant of CAS for female students at the 0.01 level. 
Table 9: Reduced Models without Mauritania Results by Gender

\begin{tabular}{|c|c|c|c|c|c|c|}
\hline \multirow[t]{2}{*}{ Dependent Variable } & \multicolumn{2}{|c|}{ CAS } & \multicolumn{2}{|c|}{ CLAS } & \multicolumn{2}{|c|}{ CNAS } \\
\hline & Males & Females & Males & Females & Males & Females \\
\hline Adult literacy rate & $\begin{array}{l}0.13^{*} \\
(1.94)\end{array}$ & $\begin{array}{l}0.13^{*} \\
(1.83)\end{array}$ & & & $\begin{array}{l}0.11^{*} \\
(1.77)\end{array}$ & $\begin{array}{l}0.15^{\star *} \\
(2.52)\end{array}$ \\
\hline GDP per capita & & $\begin{array}{c}1.05^{\star} \\
(1.91)\end{array}$ & $\begin{array}{l}1.34^{\star *} \\
(2.22)\end{array}$ & $\begin{array}{l}1.60^{\star \star *} \\
(2.93)\end{array}$ & & \\
\hline Trained teachers & & & & $\begin{array}{c}0.09 \\
(1.08)\end{array}$ & $\begin{array}{c}0.10 \\
(1.12)\end{array}$ & $\begin{array}{c}0.10 \\
(1.24)\end{array}$ \\
\hline Pupil-teach ratio & & & & $\begin{array}{c}-0.13 \\
(-1.12)\end{array}$ & & \\
\hline Pop growth & & & & & & \\
\hline Constant & $\begin{array}{c}40.71^{* \star *} \\
(9.45) \\
\end{array}$ & $\begin{array}{c}36.41^{* \star *} \\
(9.37) \\
\end{array}$ & $\begin{array}{c}50.32^{\star \star \star} \\
(24.58)\end{array}$ & $\begin{array}{c}45.80^{\star \star *} \\
(4.72)\end{array}$ & $\begin{array}{c}29.53^{\star \star *} \\
(4.39)\end{array}$ & $\begin{array}{c}24.46^{* * *} \\
(3.81)\end{array}$ \\
\hline $\mathrm{R}^{2}$ & 0.13 & 0.40 & 0.15 & 0.49 & 0.22 & 0.33 \\
\hline Adjusted $\mathrm{R}^{2}$ & 0.10 & 0.35 & 0.12 & 0.43 & 0.16 & 0.28 \\
\hline F- statistic & $\begin{array}{c}3.77 \\
(0.06) \\
\end{array}$ & $\begin{array}{c}8.34 \\
(0.00) \\
\end{array}$ & $\begin{array}{c}4.94 \\
(0.03) \\
\end{array}$ & $\begin{array}{c}8.06 \\
(0.00) \\
\end{array}$ & $\begin{array}{c}3.45 \\
(0.05) \\
\end{array}$ & $\begin{array}{c}5.98 \\
(0.01) \\
\end{array}$ \\
\hline$N$ & 28 & 28 & 27 & 29 & 27 & 27 \\
\hline
\end{tabular}

Note: $\mathrm{t}$-statistic reported in parentheses except F-test where $p$-value is reported. Two-tailed $p$ value:* significant at 0.1 level; ${ }^{* *}$ significant at the 0.05 level; ${ }^{* * *}$ significant at 0.01 level.

An additional analysis is conducted to determine the extent to which gender distinctions in the explanatory variables could help explain the result and the focus is primarily on the literacy rate of the adult population. The literacy rate of the adult male population is considered a proxy for average level of education of the fathers while the literacy rate of the adult female population, a proxy for the average level of education of mothers.

The importance of parental education in the determination of children's cognitive development and educational attainment is documented in the empirical literature (for example, Wolfe and Haveman, 2002). Traditional literature suggests that the effect of 
mothers' schooling on children's education are positive and tend to be much greater than the effects of father's schooling. The literature also suggest that there are relatively larger effects on daughters' education compared to sons' education (Behrman, 1997).

To examine the effect of parental education, the full models (without Mauritania) are modified by including the adult literacy rates for both males and females in place of the overall adult literacy rate. The results are unreported as they are generally consistent with the results of the models disaggregated by gender (i.e. the null hypothesis of the Ftest that all the independent coefficients are equal to zero cannot be rejected for the male student regressions). Also, the estimated coefficients on education on both adult males and females are not statistically significant at the conventional testing levels in the female student regressions. In other words, the results surprisingly suggest that the delineation of parental education by gender adds very little to the strength of the model and discourse.

\subsection{Discussion}

In general, the results support existing evidence of the importance of family factors (adult literacy rate and family income) in determining educational outcome. In addition, results suggest that school factors (particularly, the prevalence of trained teachers) also play a key role.

A strong family effect is generally in line with studies that utilize regional assessment results and those that adopt a similar conceptual framework and methodology. For example, Hanushek and Kim (1995) note, 
... The education of parents, proxied by quantity of schooling of the population, tends to be positive and significant at conventional levels. (p. 26)

The importance of family income, measured by GDP per capita, in the determination of literacy assessment outcomes is also consistent with literature. Lee and Barro (1997) results where GDP per capita is found to be " insignificantly related to mathematics and science test scores but strongly related to reading scores" (p.30).

A significant relationship between school resource and educational achievement is somewhat in line with historical evidence from developing countries that point to the importance of school resource effects relative to socio-economic and family factors (Heyneman and Loxley, 1986). However, the results of this analysis do not necessarily suggest a dominance of school effects over family effects, rather, the results highlight the importance of assessment subject in determining the magnitude of each effect.

In addition, the assessment subject could also explain the inconsistency documented in the literature with respect to school effects. Hanushek and Kim (1995) note,

...variations in school resources do not have strong effects on test performance. The estimated effects of resources are either statistically insignificant, or, more frequently, statistically significant but with the wrong sign. This finding holds regardless of the specific measure of school resources, whether pupil-teacher ratios, recurrent expenditure, total expenditure or a variety of other measures. (p.26)

Similarly, Fehrler, Michaelowa and Wechtler (2009) conclude,

...that despite rather discouraging evidence on the international level, for developing countries in general, and for most of the very poor SSA countries in 
particular, school resources still play an important role in improving education quality. However, even for these countries, the estimated relationship between school resources and student achievement is far from consistent across studies, so that there is no easy recipe for successful policy interventions. (p.1547)

It is also not clear why the sign on the coefficient for population growth is different from the hypothesized signs in most of the model specifications (though not statistically significant). This finding contradicts the literature which suggests a negative and statistically significant relationship between population growth and educational achievement (for example, Hanushek and Kim, 1995). This result is also contrary to the negative bi-variate correlation that exists between the population growth and each of the three measures of educational quality, suggesting that the variable may be capturing unexplained variation from possibly excluded explanatory variable(s).

Results of the gender analysis generally suggest that the model is better suited for explaining assessment outcomes of female students. The results also suggest an increased importance particularly of the effect of adult literacy rate in the disaggregated samples. The results from the gender analysis are especially interesting given the lack of statistical gender difference in assessment outcomes. It is however important to keep in mind that these results were derived from country-level proxy data instead of actual household level data.

There is a possibility that omitted variable bias, a common flaw in education production function estimates (Hanushek, Rivkin and Taylor, 1996), could explain some (or most) of the contradictory evidence. It is also important to note that the presence of omitted variable bias causes OLS coefficient estimates to be biased. The following note from Hanushek and Kim (1995) also applies to this analysis "...organization and incentive 
structures of schools....., vary widely across nations, would be expected to influence performance strongly, and are unmeasured in this work" (p.26).

Two additional issues may have inadvertently compounded the likely omitted variable bias in the analysis. Barro and Lee (2000) note that education increases with the level of per capita income across countries and through time for a given country. This makes education an endogenous variable (i.e. causality is likely to run in both directions).

In addition, the "principle of parsimony", adopted to mitigate the effect of a small sample size, increases the likelihood of omitted variables. One of the main approaches for addressing omitted variable bias and the issue of endogeneity is to increase the sample size as it is likely that the results will change (or become stronger) with a larger number of observations. A larger sample will also improve the explanatory power of the model and opens the possibility for exploring alternative estimation approaches. However, increasing the sample size is difficult given the current scarcity of regional assessment data in SSA.

In summary, the results appear to suggest that like other regions, family and school factors both play a role in the determination of educational quality in SSA countries. The results also note potential differences in the effect of family and school factors based on assessment subject and gender. In other words, the strength of the Heyneman-Loxley effect is dependent on several related factors, particularly assessment subject. The results speak to the importance of developing a nuanced approach in understanding the determinants of educational quality in SSA. 


\subsection{Conclusion}

This impetus of this research is the current conventional thinking that outcomes of the educational process are best captured by measures that reflect the quality (and not just the quantity) of education. Given the limited evidence from SSA countries, a new measure of educational achievement is developed from three large-scale assessment data available for SSA. The resulting educational achievement measures are produced for 33 SSA countries from 1995 to 2010.

The relationship between educational achievement and measures of educational attainment support available evidence that educational quantity measures are a weak proxy for educational quality. The analysis of the determinants of educational achievement that is presented here is unique in its examination of numeracy and literacy assessment outcomes based solely on data from all three regional SSA assessments.

The findings suggest that family factors, measured by the adult literacy rate and GDP per capita, and school resource factors, measured by the percentage of trained teachers, play a role in explaining educational achievement at the primary level. The results also highlight the importance of accounting for gender and assessment subject in the determination of educational achievement.

Further research ought to be directed towards replicating this study (in other developing regions for example and with larger samples) to validate the findings. The results also suggest that more work is needed to improve the understanding of educational quality in SSA, especially since there remains considerable unexplained variation in assessment 
scores and a high probability that current models are missing important explanatory factors. In addition, an in-depth single country analysis or qualitative study (for example of outlier countries) could help contextualize the results. Finally, further research is required to examine how the derived measures affect the nature of the relationship between the education and economic growth in SSA. 


\section{References}

Altinok, N. \& Murseli, H. (2006). International database on human capital quality. HAL archives.

Altinok, N., Diebolt, C. \& Demeulemeester, J-L (2014). A new international database on educational quality:1965-2010. Applied Economics, 46 (11),1212-1247.

Angrist, N., Patrinos, H \& Schlotter. (2013). An expansion of a global data set on educational quality: a focus on achievement in developing countries. World Bank Policy Research Working Paper No. 6536.

Atherton, P. (2009). School effectiveness and educational quality across Southern and Eastern Africa. Mimeo.

Badr,M.Morrisey, O. \& Appleton, S. (2012). Determinants of Educational Attainment in MENA. CREDIT Research Paper, No.12/03.

Barro,R. (1991). Economic growth in a cross-section of countries. Quarterly Journal of Economics, 106(2),407-443.

Barro, R.J. \& Lee, J.W. (1994). Sources of economic growth. Carnegie-Rochester Conference Series on Public Policy, 40, 1-46.

(2000). International data on educational attainment: updates and implications. CID Working Paper No. 42.

. (2010). A new data set of educational attainment in the world, 1950-2010. NBER Working Paper 15902.

. (2013). A new data set of educational attainment in the world, 1950-2010. Journal of Development Economics, 104,184-198.

(2015). Education matters: global schooling gains from the $19^{\text {th }}$ to the $21^{\text {st }}$ century. Oxford, UK: Oxford University Press.

Becker, G. (1962.) Investment in human capital: a theoretical analysis. Journal of Political Economy, 70(5), 9-49. 
. (1964). Human capital: a theoretical and empirical analysis. New York: Columbia University Press.

. (1993). Human capital, 3rd ed University of Chicago Press: Part 1.

Behrman, J. (1997). Mother's schooling and child education: a survey. Penn Institute for Economic Research, Working Paper 97-025.

Belsley, D., Kuh, E., \& and Welsch, R. (1980). Regression diagnostics: identifying influential data and sources of collinearity. New York, New York: John Wiley and Sons.

Benavot, A. \& Riddle, P. (1988). The expansion of primary education, 1870-1940: trends and issues. Sociology of Education, 61 (3), 191-210.

Boissiere, M. (2004). Determinants of primary education outcomes in developing countries: background paper for the evaluation of the World Bank's support to primary education. World Bank, Washington, D.C.

Brown (2000). Democracy, colonization and human capital in sub-Saharan Africa. Studies in Comparative International Development, 35(1), 20-40.

Coleman, J.S. (1966). Equality of Educational Opportunity. National Center for Educational Statistics. Report Number OE-380001.

Chinapah, V. (1997). Handbook on monitoring learning achievement: towards capacity building. Paris: UNESCO.

Chinapah, V., H'ddigui, E., Kanji, A. ,Falayajo, W., Fomba, C, Hamissou, O. , Rafalimanana, A. \& Byamugisha, A. (2000). With Africa for Africa: towards quality education for all. Pretoria: Human Sciences Research Council.

Cogneau, D. \& Moradi, A. (2014). British and French educational legacies in Africa. CEPR Polity Portal.

Eccles, J. (1982). Sex differences in math achievement and course enrolment. Paper presented as part of a symposium at the annual meeting of the American Educational Research Association, New York. 
Fearon, J. D. (2001). Regression part V, and final review of course topics: some final points about OLS. Department. of Political Science, Stanford University. Available online at: https://web.stanford.edu/class/polisci100a/regress5.pdf

Fehler, S., Michaelowa, K. \& Wechtler, A. (2009). The effectiveness of inputs in primary education: insights from recent student surveys for Sub-Saharan Africa. Journal of Development Studies, 45 (9),1545-78.

Fennema, E. \& Sherman, J. (1978). Sex-related differences in mathematical achievement and related factors: a further study. Journal for Research in Mathematics Education, 9, 189-203.

Fuchs, T. \& Woessmann, L. (2007). What accounts for international differences in student performance? A re-examination using PISA data. Empirical Economics, 32(2), 433-464.

Garnier,M. \& Schafer, M. (2006). Educational model and expansion of enrolments in subSaharan Africa. Sociology of Education, 79:2.

Glewwe, P. (2002). Schools and skills in developing countries: education policies and socioeconomic outcomes. Journal of Economic Literature, 40, 436-482.

Hanushek, E. (1979). Conceptual and empirical issues in the estimation of educational production functions. The Journal of Human Resources, 14:3, 351-88.

(1986). The economics of schooling: production and efficiency in public schools. Journal of Economic Literature, 24:3, 1141-77.

. (1992). The trade-off between child quantity and quality. The Journal of Political Economy, 100:1, 84-117.

.(1995). Interpreting recent research on schooling in developing countries. World Bank Observer 10:2, 227-46.

. (2007). Education production functions. Mimeo, Palgave Encyclopedia.

(2013). Economic growth in developing countries: the role of human capital. Mimeo, Standard University.

Hanushek, E., Kim, D. (1995). Schooling, labor force quality and economic growth. NBER Working Paper No. 5399. 
(1999). Immigration and home-country school quality. Mimeo, University of Rochester.

Hanushek, E. \& Kimko, D. (2000). Schooling, labor-force quality, and the growth of nations." American Economic Review. 90,1184-1208.

Hanushek, E. \& Luque, J. (2003). Efficiency and equity in schools around the world. Economics of Education Review, 22, 481-502.

Hanushek, E. and Woessmann, L. (2006). Does educational tracking affect performance and inequality? Differences-in-differences evidence across countries. The Economic Journal, 116, C63-C76.

.(2007). The role of education quality for economic growth. Policy Research Working Paper Series 4122, The World Bank.

(2008). The role of cognitive skills in economic development. Journal of Economic Literature, 46 (3), 607-668.

.(2009). Do better schools lead to more growth? Cognitive skills, economic outcomes and causation. NBER Working Paper No. 14633.

(2010a). The economics of international differences in educational achievement. NBER Working Paper No. 4925.

- (2010b). Education and Economic Growth. In: Penelope Peterson, Eva Baker, Barry McGaw, (Editors), International Encyclopedia of Education. volume 2, pp. 245-252. Oxford: Elsevier.

(2012). Schooling, educational achievement and the Latin America growth puzzle. Journal of Development Economics,99, 497-512.

Hanushek, E. Rivkin,S. \& Taylor, L. (1996). Aggregation and the estimated effects of school resources. National Bureau of Economic Research Working Papers no. 5548

Heyneman,S. and Jamison, D. (1980). Student learning in Uganda: textbook availability and other factors. Comparative Education Review,24,206-20. 
Heyneman, S., and Loxley, W. (1983). The effect of primary- school quality on academic achievement across twenty-nine high- and low-income countries. American Journal of Sociology, 88(6),1162-1194.

Kellaghan, T. (2004). Public examinations, nationals and international assessments, and educational policy. Educational Research Centre.

Kennedy, P. (1998). A guide to econometrics: fourth edition. Cambridge, MA: MIT Press.

Kremer, M. (1995). Research on schooling: what we know and what we don't: a comment on Hanushek. World Bank Research Observer 10:2,247-54.

Lee, J.W. \& Barro, R.J. (1997). Schooling quality in a cross section of countries. NBER Working Paper Series No. 6198.

Lee,V. Zuze, T, \& Ross, K. (2005). School effectiveness in 14 sub-Saharan African countries: links with $6^{\text {th }}$ graders' reading achievement. Studies in Educational Evaluation,31,207-246.

Lockheed, M. \& Verspoor, A. (1991). Improving primary education in developing countries. New York, NY: Oxford University Press.

Majaard,K. \& Mingat, A. (2012). Education in Sub-Saharan Africa: a comparative analysis. Washington, D.C.: World Bank.

Mankiw, N. G., Romer, D. \& Weil D.N. (1992). A contribution to the empirics of economic Growth. Quarterly Journal of Economics, 107 (2), 407-437.

Michaelowa, K. (2001). Primary education quality in francophone sub-Saharan Africa: determinants of learning achievement and efficiency considerations. World Development, 29(10), 1699-1716.

Mioko, S. (1998). Gender versus socioeconomic status and school location differences in grade 6 reading literacy in five African countries. Harare: Ministry of Education and Culture.

OECD and the World Bank (2015). Annex A: general information about the international surveys reviewed. Available online at: https://www.oecdilibrary.org/docserver/9789264248373-10- 
aen.pdf?expires $=1567999142 \&$ id=id\&accname=guest\&checksum $=8657$ C620E 1 BF7EB154621B1719F58466 (accessed September 05,2019)

Pritchett, L. (2001). Where has all the education gone? The World Bank Economic Review, 15(3), 367-391.

Ross, K, Pfukani, P. , Makuwa, D., Nassor, S., Kanyika,J., Macingiadze,T, Milner, G.\& Leite, S. (2000). Translating educational assessment findings into educational policy and reform measures: lesssons from the SACMEQ initiative in Africa. Paper presented at the World Education Forum in Dakar, Senegal, 26-28 April 2000.

Schultz, T.W. (1975). The value of the ability to deal with disequilibria. Journal of Economic Literature, 13(3),827-46.

Sinding, SW. (2009). Population, poverty and economic development. Philosophical Transactions of the Royal Society B: Biological Sciences, 364(1532), 3023-30.

Smith, A. (1776). An inquiry into the nature and causes of the wealth of nations. London: Methuen \& Co., Ltd.

Spaull, N. (2014). Educational quality in sub-Saharan Africa: an economic approach. Thesis presented for the degree of Doctor of Philosophy (Economics), University of Stellenbosch, South Africa.

The Centre for Global Education Monitoring (GEM). (2015). The Southern and Eastern Africa consortium for monitoring educational quality. Assessment GEM Series no. 8.

UN. (2015). The millennium development goals report. United Nations.

UNESCO. (2003). Southern Africa Consortium for Monitoring Educational Quality. Harare,ZMB: UNESCO

Report.

. (2005). Chapter 1: Understanding education quality. EFA Global Monitoring (2008). School attendance and enrolment global trends and projection. Background Paper Prepared for the Education for All Global Monitoring Report . (2009). Education indicators: technical guidelines. 
. (2010). Country paper: status and major challenges of literacy in Nigeria. Eighth E-9 Ministerial Review Meeting on Education for All, Abuja, Nigeria, 21-24 June 2010.

. (2010/11). World data on education: Nigeria report. World Data on Education, $7^{\text {th }}$ Edition, UNESCO-IBE

. (2010/11). World data on education: Liberia report. World Data on Education, $7^{\text {th }}$ Edition, UNESCO-IBE

West, M. \& Woessman, L. (2010). Every Catholic child in a Catholic school: historical resistance to state schooling, contemporary private competition and student achievement across countries. The Economic Journal, 120 (546), F229-F255.

WHO. (2014). Adolescent pregnancy. World Health Organization Media Centre Fact Sheet. Available online at: http://www.who.int/mediacentre/factsheets/fs364/en/

Williams, R. (2016). Outliers. University of Notre Dame Course Notes. Available online at: https://www3.nd.edu/ rwilliam/stats2//24.pdf

Woessman, L. (2003). Schooling resources, educational institutions and student performance: the international evidence. Oxford Bulletin of Economics and Statistics, 65(2), 117-170.

.(2016). The importance of school systems: evidence from international differences in student achievement. IZA Discussion Paper no.10001.

Wolfe, B., \& Haveman, R. (2002). Social and non-market benefits from education in an advanced economy. Paper presented Conference Series 47, Education in the 21st Century: Meeting the Challenges of a Changing World, Federal Reserve Bank of Boston, June 2002.

World Bank (2019a). World Development Indicators. The World Bank: Washington, D.C. (2019b). EdStats: Education Statistics. The World Bank: Washington, D.C. 


\section{Chapter Two: Micro-level Determinants of Educational Achievement in Cameroon}

The findings of the analysis in Chapter one generally suggest that family factors and school factors are important determinants of educational quality, though the magnitude of each effect largely depends on the assessment subject. While these findings are generally consistent with other international cross-country comparative studies, they only provide suggestive conclusions and identify general areas of consideration (Hanushek, 1995). In other words, the findings do not necessarily provide clear policy recommendations or identify levers that SSA countries can readily adopt to improve cognitive skills and educational outcomes.

As a result, key research questions remain unanswered including:

1. Are the school and family factors (i.e. parent's literacy rate, family income and number of trained teachers) robust (and equal) determinants of educational quality?

2. What other explanatory factors play a role in determining educational quality?

3. What other explanatory or contextual factors (in addition to assessment subject) play a role in moderating the magnitude of the various effects?

More proximate data derived from within individual countries is arguably better suited than aggregate cross-country data for addressing the questions posed above and examining interactions at the most granular level, closest to the learning process of students. To that end, this chapter extends the macro-level analysis in Chapter one by investigating 
educational quality determinants using student-level performance data for a single country.

An outlier case study approach is adopted for this analysis. Cameroon is chosen partly due to data availability. More importantly though, Cameroon is one of the outlier countries identified in Chapter One. Cameroon had the sixth highest average CAS out of the 30 SSA countries included in the cross-sectional regression analysis on the determinants of educational achievement but had the highest residual in the CAS regression analysis. In other words, Cameroon "over-performed" as its actual average combined assessment score was higher than the predicted score.

Cameroon is also a bilingual country with two distinct and parallel educational subsystems (Francophone and Anglophone). Regional assessments data reported for the

country is mainly based on the Francophone sector. Availability of data from the Anglophone sector allows for the introduction of a second "case" into the study.

\subsection{Country Background}

Cameroon is a lower-middle-income country in SSA with a current population close to 25 million (2018). Cameroon is located along the Atlantic Ocean (see Figure 10). The country shares its borders with Chad, Central African Republic, Republic of the Congo, Gabon, Equatorial Guinea, Bight of Biafra and Nigeria. 
Figure 10: Map of Cameroon and Neighbouring Countries

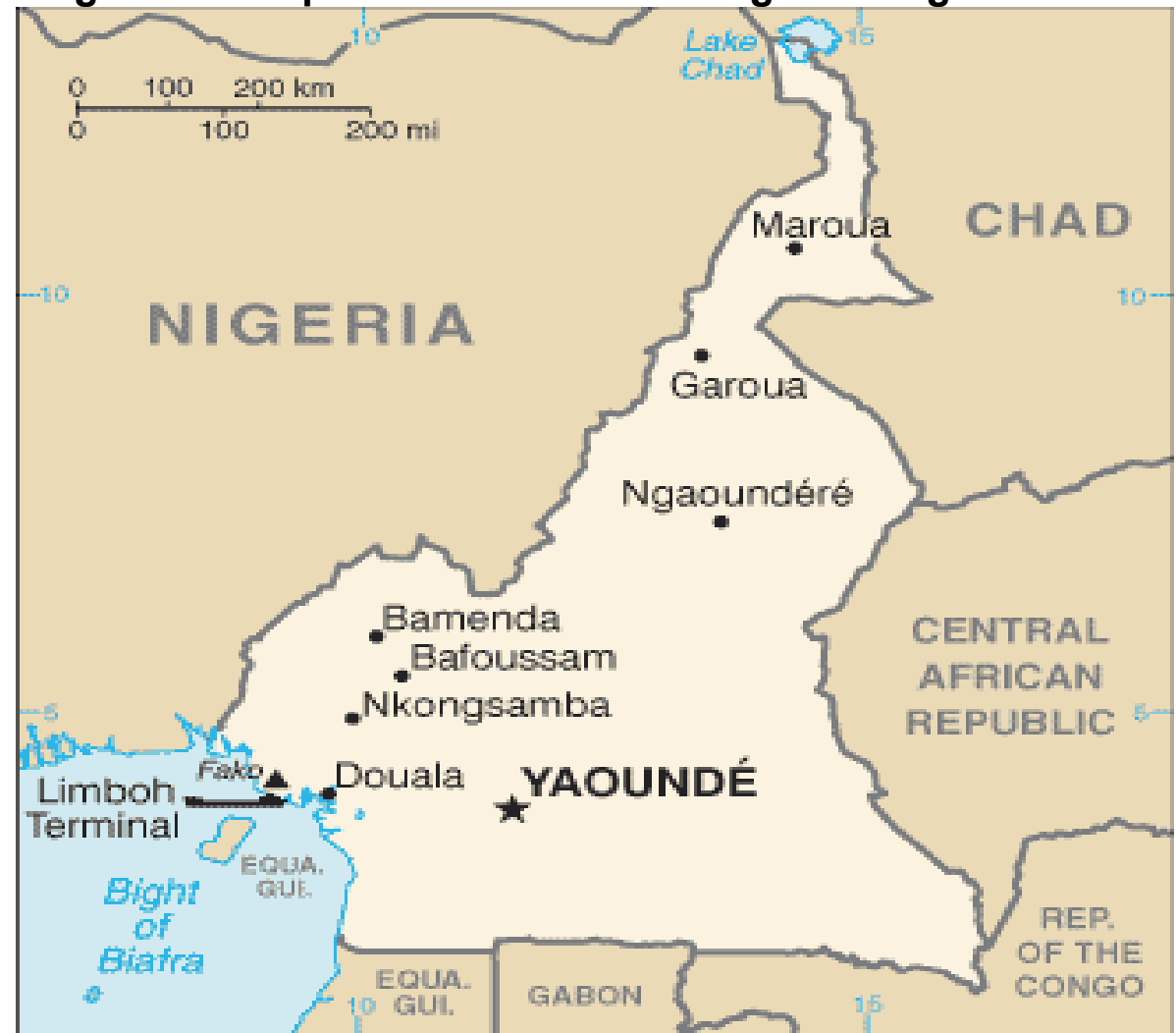

Source:https://www.cia.gov/library/publications/the-worldfactbook/attachments/maps/CM-map.gif

\subsubsection{Historical Context}

The dual colonial legacy of the country dates back to 1916 when France and Britain seized the territory from Germany. In 1960, French-speaking Cameroon won independence and established a new nation: La République du Cameroun. In 1961, English speakers in the British territory decided to join Cameroon, and a bilingual nation was born.

In 1972, a new constitution replaced the federation with a unitary state, the United Republic of Cameroon. The country was renamed the Republic of 
Cameroon in 1984. There are currently ten regions (formerly known as provinces) in Cameroon: eight are Francophone and two are Anglophone. In line with their distinct colonial identity, the Anglophone regions also have a unique cultural identity. Figure 11 shows the location of the two Anglophone regions and, currently, about 80 per cent of the country live in the Francophone regions.

Figure 11: Map of Cameroon showing the Anglophone Region

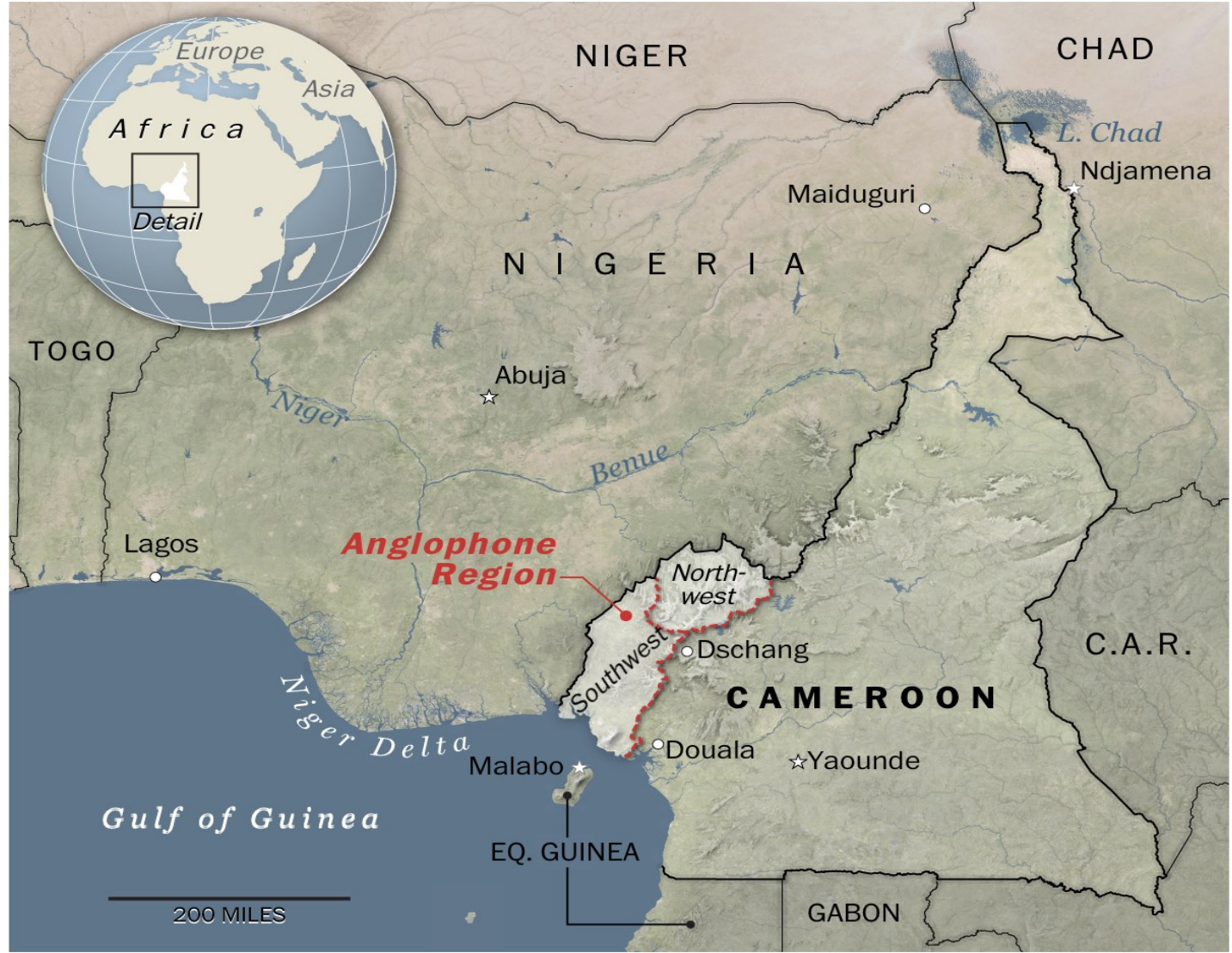

Source: https://www.washingtonpost.com/graphics/2019/world/cameroon-anglophonecrisis/?noredirect=on\&utm_term $=.5 \mathrm{~b} 0358 \mathrm{e} 05 \mathrm{f5}$ 


\subsubsection{Economic, Social and Political Overview}

Cameroon has an ethnically and linguistically diverse population. However, its political landscape is dominated by a single political party, the Cameroon People's Democratic Movement. In 2018, President Paul Biya, who has been in power since 1982, won his seventh term as the country's president. The country has remained relatively stable since independence but is currently dealing with a series of sociopolitical crises including: Boko Haram attacks in the Far North; a secessionist insurgency in the Anglophone region; a large influx of refugees from Central African Republic and Nigeria; and an increased number of internally displaced persons in the Anglophone Northwest and Southwest regions.

Cameroon is the largest economy in the Central African Economic and Monetary Community (CEMAC) and remains the most resilient in Central Africa in terms of diversification (AfDB, 2019). Cameroon's market-based economy includes oil and gas, timber, aluminum, agriculture and mining but oil remains the main export commodity.

According to the Commonwealth, Cameroon developed rapidly from 1978 but growth declined around the mid-1980s, as in many SSA countries. From the late 1980s, the World Bank and International Monetary Fund supported a series of economic reform programmes including cuts in public expenditure and structural adjustment in the country. 
Between 1995 and 2010, the period covered by Chapter One's analysis, Cameroon's economic performance and demographic trend did not particularly stand out. Cameroon's GDP per capita averaged about $\$ 1,000$, lower than the sample average of $\$ 2,000$. Similarly, Cameroon's population growth averaged about three per cent, consistent with the sample average.

Most recently, Cameroon's economic growth rebounded to four percent in 2018 after two years of slowdown. However, weakness in the country's economic growth base (for example, declining security situation in regions of great agricultural importance) and exposure to fluctuations in world prices for raw materials continue to be significant factors of economic vulnerability (AfDB, 2019).

\subsubsection{Overview of the Education Sector and Education Reform}

The country has two separate education sectors, a result of the distinct educational traditions from the colonial era. Cameroon students navigate the education system in each sector according to the pathways presented in Figure 12.

In the Anglophone system, students enter primary school at the age of five and complete seven years of primary education, five years of lower secondary education (ordinary level) and two years of upper secondary education (advanced level) before proceeding to tertiary education. 
In the Francophone system, students enter primary school at the age of six and complete six years of primary education, four years of lower secondary education (ordinary level) and three years of upper secondary education (advanced level) before proceeding to tertiary education. The figure also shows the parallel pathway for technical or vocational education.

Figure 12: Cameroon's Education Sector Structure*

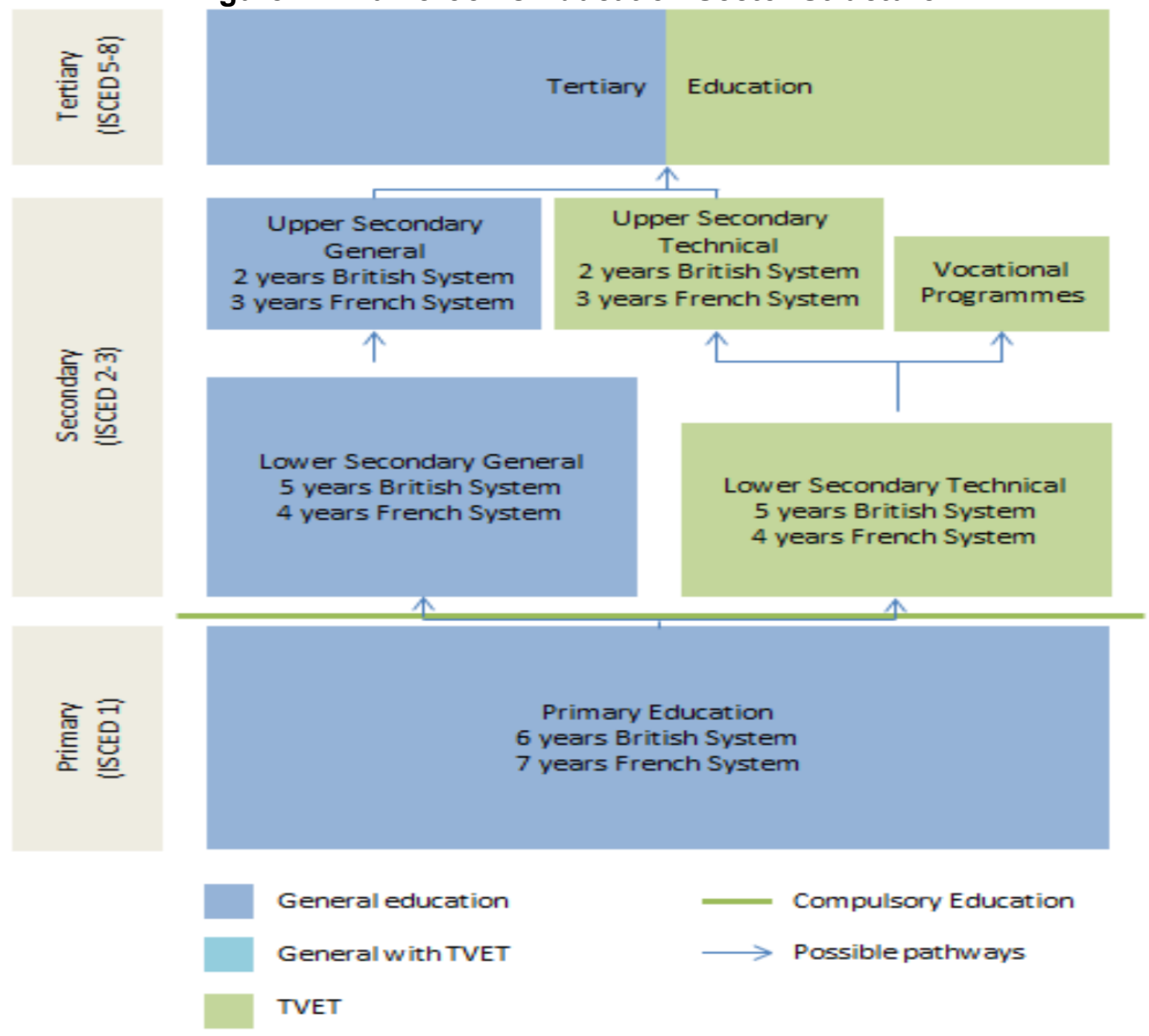

*Note: there is an error in the map in the primary education description. The Anglophone system includes seven years of primary education while the Francophone system includes six years of primary education.

Source: UNESCO (2015) 
There are three different federal ministries responsible for the provision of education in Cameroon: Ministère de l'Education de Base, MINEDUB; Ministère des Enseignements Secondaires, MINESEC; and Ministère de l'Enseignement Supérieur, MINESUP.

The Ministère de Finance (MINFI), in collaboration with MINEDUB and MINESEC, is responsible for allocating finances to the education sector and determining regional allocations. According to World Bank (2012), the federal government provides direct financial assistance to primary schools through: transfers for infrastructure development; distribution of a "minimum package" consisting of instructional aids, office supplies, and sports equipment; and earmarked funds for specific items and activities. Families and local communities can also contribute financially directly to schools and teacher salaries.

Cameroon's education sector has generally experienced periods of growth and decline in financial, physical and human resources similar to the overall economy. The current national plan for the education sector is found in Document de Strategie du Secteur de l'Education et de la Formation 2013-2020 and the main objective of the plan is the achievement of quality universal primary education.

According to World Bank (2018), Cameroon's education sector continues to face a number of pressing structural issues including regional and gender differences in access to basic education; poor quality of basic education (in part due to the shortage, and poor distribution, of teachers around the country); limited provision of early childhood development programs; weak sector management and governance (including inadequate sector coordination and planning); and poor sector financing and internal inefficiency. 


\subsection{Literature Review}

The literature on the determinants of educational quality at the macro and micro levels share the same theoretical underpinnings and generally only differ by the level of analysis and examined explanatory factors. In general, two streams of factors are shown to affect educational outcome: family factors and school factors.

The literature evolved from a landmark study from the United States. Coleman et al. (1966) demonstrate that family differences are very important in explaining variations in achievement across students. This conclusion was disputed for developing countries by Heyneman and Loxley (1983) who argue that school factors are more important for student achievement in developing countries.

The resulting literature on determinants of educational quality is quite rich and has been the subject of numerous reviews (for example, Gleewe, Hanushek, Humpage \& Ravina ,2011; Hanushek, 2003; Hanushek, 1997 and Simons and Leigh, 1975). However, the strand of the literature most relevant to this study, SSA literature on determinants of educational quality based on regional SSA assessment, is relatively sparse.

For example, Michaelowa (2003) reviews the literature from studies based on the PASEC data set. With respect to teachers' competencies, the available evidence suggests that investment in the quality of teacher training is more important than duration of teacher training. Also, instructional materials and physical infrastructure, and textbooks in the 
basic language of instruction, appear to have the most important positive influence on education quality.

The literature from developing countries are mainly based on school-related determinants of educational achievement, arguably due to the Heyneman-Loxley effect and assessment data availability. In general, remarkably little is known about the key determinants of educational quality and the impact of education policies on student outcomes particularly in developing countries. Gleewe et al (2011) provides an apt summary of the literature and notes:

...perhaps the most useful conclusion to draw for policy is that there is little empirical support for a wide variety of school and teacher characteristics that some observers may view as priorities for school spending. While one could argue that the absence of strong results simply reflects insufficient data (low statistical power) to detect systematic effects, it could also be the case that most of the effects are themselves small. Quite plausibly, part of the ambiguity comes from heterogeneous treatment effects, where the impact of various inputs depends importantly on the local circumstances, demands, and capacities. (p.42)

As such, there remains a gap in the SSA literature for in depth country-level analysis of the determinants of educational quality that:

- explores both family-level and school-level determinants; and

- examines moderating factors.

\subsection{Empirical Analysis}

This section provides an overview of the theoretical framework, hypotheses, study sample, methodological consideration and main regression results. 


\subsubsection{Conceptual Framework}

The analysis of the economics of education is mainly based on a human capital production function. The model postulates that the educational achievement of a student is related to inputs. Some of these inputs are directly controlled within the education system (including characteristics of schools, teachers, curricula, and school resources) and school organization (including class sizes, facilities and administrative expenditures). Other inputs are to some extent exogenous to the system (including family characteristics, and other student-related factors).

In the model, educational achievement is measured at specific time periods; however, the educational process is cumulative and past inputs do influence current levels of student achievement (Hanushek, 2007). Accordingly, the production function can be described as follows:

$$
E Q_{i}=\beta_{1}+\beta_{2} \text { initial }_{\text {is }}+\beta_{3} \text { student }_{i}+\beta_{4} \text { class }_{i}+\beta_{5} \text { school }_{i}+\beta_{6} \text { teacher }_{i}+\beta_{7} \text { family }_{i}+\epsilon_{i}
$$

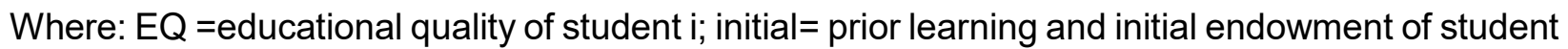
i; student= other student- related factors for student i; class = class-related factors for student i; school= school-related factors for student $\mathrm{i}$; teacher= teacher-related factors for student $\mathrm{i}$; family= family-related factors for student $\mathrm{i}$; and $\epsilon=$ error term (capturing unmeasured factors influencing educational quality).

The choice of estimation equation and technique is rooted in economic theory. Similar to Chapter one, theory is balanced with available evidence and statistical testing. The proxies utilized in this study can be grouped according to the categories above: initial student's endowment (initial performance of student), other student-related factors (age 
and gender), class-related factors (availability of teaching resources, class size), schoolrelated factors (school location, school accessibility, level of school financing), teacherrelated factors (gender, salary level, number of absences) and family-related factors (availability of books, language spoken at home, living condition, family composition and parent's ability to read). Accordingly, the adopted model equation is as follows:

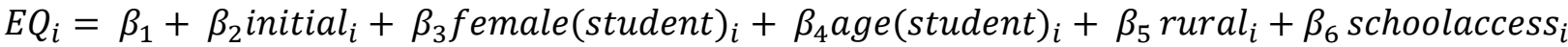

$$
\begin{aligned}
& +\beta_{7} \text { budget }_{i}+\beta_{8} \text { classsize }_{i}++\beta_{9} \text { classcondition }_{i}+\beta_{10} \text { female }_{\text {feacher }}{ }_{i} \\
& +\beta_{11} \text { salary }_{i}+\beta_{12} \text { absent }_{i}+\beta_{13} \text { books }_{i}+\beta_{14} \text { language }_{i}+\beta_{15} \text { livcondition }_{i} \\
& +\beta_{16} \text { read }_{\text {is }}+\beta_{17} \text { livstatus }_{i}+\epsilon
\end{aligned}
$$

Where: $\mathrm{EQ}=$ final test scores for student $\mathrm{i}$; initial = initial test scores for student $\mathrm{i}$; female(student) = gender of student $\mathrm{i}$; age (student) $=$ age of student $\mathrm{i}$; rural = school location of student $\mathrm{i}$; schoolaccess $=$ level of accesibility of school by student $i$; budget $=$ monthly school budget for student; classsize $=$ average class size of student $i$; classcondition $=$ resources available in classroom of student $i$; female (teacher) $=$ gender of teacher of student $i$; salary = monthly teacher salary for student $i$; absent $=$ indication of teacher's absence for student $i$; books = availability of books at home for student $i$; language $=$ official language spoken at home of student $i$; livcondition $=$ living condition of student $\mathrm{i}$; read $=$ parent's reading ability of student $\mathrm{i}$; livstatus $=$ family composition of student $\mathrm{i}$.

It is expected that the coefficients of the variables initial, schoolaccess, budget, classcondition, salary, books, language, livcondition, read, and livstatus will be positive; the coefficients of age(student), rural, classsize, and absent will be negative. The expected sign on the coefficients on gender (both student and teacher) is uncertain.

This analysis also examines the assertion that the relationship between widely adopted family or school factors and educational achievement is moderated by a single (or multiple) variables. The premise is that the lack of conclusive and robust evidence of 
family or school factors on educational achievement can potentially be explained by omitted variable bias. Two moderating factors examined in this analysis are: education sector (i.e. Anglophone or Francophone) and school location (i.e. rural or urban). Both factors are chosen as student performance is expected to vary across both dimensions in part due to differences in human, financial and physical resource allocation, family characteristics, community development and available economic opportunities. Accordingly, the following hypothesis is tested:

1. If included school and family factors are interacted with the education sector and/or school location dummy variables, then the magnitude of their effect on educational achievement will differ based on one or both factors.

\subsubsection{Sample}

The data used for this analysis is based on the pooled PASEC assessment results for Francophone and Anglophone grade five students in Cameroon in 2004-05. ${ }^{29}$ Based on the official starting age in both sectors, students are expected to be between 10 and 11 years old at the beginning of grade five. PASEC data is one of the three data sets used to derive the educational quality measures in Chapter one. ${ }^{30}$

PASEC data are particularly well-suited for this analysis as the assessment is intended for analyzing determinants of student achievement. Accordingly, it provides a rich data

\footnotetext{
29 PASEC student level assessment data for $2004 / 05$ for both sectors in Cameroon was provided by CONFEMEN through a special request.

30 See Section 1.1 in Chapter one for more information on the PASEC data set.
} 
set with information on student's competencies, socio-economic background of students as well as class, school and teaching conditions.

It is important to note though that the PASEC data for Cameroon typically reported in international studies and available through the World Bank, are only based on the Francophone sector. Results for both sectors are intentionally reported separately as CONFEMEN (2007) notes (translated):

The tests administered to the English-language subsystem consist of a translation of the tests administered in French to the students of the Francophone subsystem....... In addition, these tests do not have the same fidelity and we had to delete items, especially for tests in English. We will thus refrain from any comparison between results of French and English students. Similarly, international comparisons and over time will only be made for the Francophone subsystem. (p.32)

In other words, CONFEMEN (2007) cautions against direct comparison between both subsystems due to the heterogeneity in the assessment process and instrument. However, running separate models for each group makes it difficult to identify explanatory factors with statistically significant effects across both groups particularly when there are significant differences in sample sizes (as in this case). The intent for pooling the data for both sectors in this analysis is not to compare student performance across sectors. Rather, it is to allow for formal testing of commonalities and the derivation of more efficient standard errors of estimated coefficients. ${ }^{31}$ Individual sector effects are also examined in

\footnotetext{
31 The Francophone and Anglophone aggregate score regressions are estimated individually and the results produced Root Mean Square Errors (i.e. variance of the residuals) that are quite close (10 versus 14). As such, I chose to run variance-constrained regressions on the pooled data.
} 
the bid to account for differences between sectors that extend beyond assessment processes and results.

Educational achievement, the dependent variable, is measured using PASEC final scores (per cent correct) in the grade five assessments, consistent with the analysis in Chapter one. The independent variables are described in Table 10.

\section{Table 10: Independent Variable Descriptions}

\begin{tabular}{|c|c|c|c|c|}
\hline & $\begin{array}{l}\text { Variable } \\
\text { Name }\end{array}$ & Description & Proxy for: & Base Group \\
\hline & $\begin{array}{l}\text { Initial } \\
\text { Performance }\end{array}$ & $\begin{array}{l}\text { Score (per cent correct) of grade } \\
\text { five initial assessment conducted } \\
\text { at the beginning of the school } \\
\text { year }\end{array}$ & $\begin{array}{l}\text { Student's initial } \\
\text { knowledge, ability, } \\
\text { competency and aptitude }\end{array}$ & $\mathrm{N} / \mathrm{A}$ \\
\hline & Francophone & $\begin{array}{l}\text { Dummy variable, } 1 \text { if student is in } \\
\text { Francophone sector and } 0 \text { if } \\
\text { student is in Anglophone sector }\end{array}$ & $\begin{array}{l}\text { Sector driven differences } \\
\text { in performance }\end{array}$ & Anglophone \\
\hline \multirow[t]{2}{*}{$\begin{array}{l}\text { Student } \\
\text { Factors }\end{array}$} & $\begin{array}{l}\text { Female } \\
\text { Student }\end{array}$ & $\begin{array}{l}\text { Dummy variable, } 1 \text { if student is } \\
\text { female and } 0 \text { if student is male }\end{array}$ & $\begin{array}{l}\text { Gender-driven } \\
\text { differences in } \\
\text { participation and } \\
\text { performance }\end{array}$ & Male \\
\hline & Age & Student's age in years & $\begin{array}{l}\text { Age-driven differences in } \\
\text { participation and } \\
\text { performance }\end{array}$ & $\mathrm{N} / \mathrm{A}$ \\
\hline \multirow[t]{4}{*}{$\begin{array}{l}\text { School } \\
\text { Factors }\end{array}$} & Rural & $\begin{array}{l}\text { Dummy variable, } 1 \text { if school is in } \\
\text { a rural area and } 0 \text { if school is in } \\
\text { an urban area }\end{array}$ & $\begin{array}{l}\text { Urban bias in resource } \\
\text { allocation and student } \\
\text { performance }\end{array}$ & Urban \\
\hline & $\begin{array}{l}\text { School } \\
\text { Access }\end{array}$ & $\begin{array}{l}\text { Dummy variable, } 1 \text { if school is } \\
\text { accessible via paved roads and } 0 \\
\text { otherwise }\end{array}$ & $\begin{array}{l}\text { Level of development of } \\
\text { school's community }\end{array}$ & $\begin{array}{l}\text { Not accessible } \\
\text { via paved } \\
\text { roads }\end{array}$ \\
\hline & Class size & Average class size & Pupil-teacher ratio & $\mathrm{N} / \mathrm{A}$ \\
\hline & Financing & $\begin{array}{l}\text { Monthly budget per student in } \\
\text { CFAF }\end{array}$ & $\begin{array}{l}\text { Level of school's financial } \\
\text { resources and resource } \\
\text { allocation }\end{array}$ & $\mathrm{N} / \mathrm{A}$ \\
\hline $\begin{array}{l}\text { Class } \\
\text { Factors }\end{array}$ & Condition & $\begin{array}{l}\text { Dummy variable, } 0 \text { if chalk and } \\
\text { electricity are not available, } 1 \text { if } \\
\text { chalk only is available, } 2 \text { if } \\
\text { electricity only is available and } 3 \\
\text { if both are available in classroom }\end{array}$ & $\begin{array}{l}\text { School's level of } \\
\text { resourcing and } \\
\text { development }\end{array}$ & $\begin{array}{l}\text { Chalk or } \\
\text { electricity if not } \\
\text { available }\end{array}$ \\
\hline $\begin{array}{l}\text { Teacher } \\
\text { Factors }\end{array}$ & $\begin{array}{l}\text { Female } \\
\text { Teacher }\end{array}$ & $\begin{array}{l}\text { Dummy variable, } 1 \text { if teacher is } \\
\text { female and } 0 \text { if male }\end{array}$ & $\begin{array}{l}\text { Gender-driven } \\
\text { differences in teacher's } \\
\text { ability, qualification, } \\
\text { pedagogy and } \\
\text { expectations }\end{array}$ & Male \\
\hline
\end{tabular}




\begin{tabular}{|c|c|c|c|c|}
\hline & $\begin{array}{l}\text { Variable } \\
\text { Name }\end{array}$ & Description & Proxy for: & Base Group \\
\hline & $\begin{array}{l}\text { Teacher } \\
\text { Salary }\end{array}$ & $\begin{array}{l}\text { Dummy variable } 1 \text { if teacher's } \\
\text { monthly salary is } \\
\text { under } 30,000 \text { CFAF, } 2 \text { if it is } \\
30,000 \text { to } 89,000 \text { CFAF, } \\
3 \text { if it is } 90,000 \text { to } 249,000 \text { CFAF } \\
\text { and } 4 \text { if it is } \$ 250,000 \text { CFAF and } \\
\text { above }\end{array}$ & $\begin{array}{l}\text { Differences in teacher's } \\
\text { ability, qualification, } \\
\text { pedagogy and } \\
\text { expectations }\end{array}$ & $\begin{array}{l}\text { Under } \\
30,000 \text { CFAF }\end{array}$ \\
\hline & $\begin{array}{l}\text { Teacher } \\
\text { Absence }\end{array}$ & $\begin{array}{l}\text { Dummy variable } 1 \text { if } \\
\text { teacher has been absent for one } \\
\text { or more days in the previous } \\
\text { month prior to survey date and } \\
0 \text { otherwise }\end{array}$ & $\begin{array}{l}\text { Teacher's participation } \\
\text { and involvement }\end{array}$ & No absence \\
\hline \multirow[t]{5}{*}{$\begin{array}{l}\text { Family } \\
\text { Factors }\end{array}$} & Books & $\begin{array}{l}\text { Dummy variable, } 1 \text { if } \\
\text { books are available in student's } \\
\text { home and } 0 \text { otherwise }\end{array}$ & $\begin{array}{l}\text { Parental literacy and } \\
\text { socio-economic status }\end{array}$ & $\begin{array}{l}\text { Books } \\
\text { unavailable in } \\
\text { the home }\end{array}$ \\
\hline & Language & $\begin{array}{l}\text { Dummy variable, } 1 \text { if English is } \\
\text { spoken at home in the } \\
\text { Anglophone sector or French in } \\
\text { the Francophone sector and } 0 \\
\text { otherwise }\end{array}$ & $\begin{array}{l}\text { Parental literacy and } \\
\text { socio-economic status }\end{array}$ & $\begin{array}{l}\text { French/English } \\
\text { not spoken in } \\
\text { the home }\end{array}$ \\
\hline & $\begin{array}{l}\text { Living } \\
\text { Condition }\end{array}$ & $\begin{array}{l}\text { Dummy variable, } 0 \text { if none of the } \\
\text { following items are available in } \\
\text { student's home (toilet with } \\
\text { running water, electricity, fridge, } \\
\text { television or computer), } 1 \text { if one } \\
\text { or two of the items are available } \\
\text { and } \\
2 \text { if more than two items are } \\
\text { available }\end{array}$ & Socio-economic status & $\begin{array}{l}\text { None of the } \\
\text { items available } \\
\text { in home }\end{array}$ \\
\hline & $\begin{array}{l}\text { Parent's } \\
\text { reading } \\
\text { Ability }\end{array}$ & $\begin{array}{l}\text { Dummy variable, } \\
0 \text { if neither parent or guardian } \\
\text { can read, } 1 \text { if only mom (or female } \\
\text { guardian) can read, } 2 \text { if only dad } \\
\text { (or male guardian) can read and } \\
3 \text { if both can read }\end{array}$ & $\begin{array}{l}\text { Parental literacy, parental } \\
\text { expectations and } \\
\text { involvement }\end{array}$ & $\begin{array}{l}\text { Neither parent } \\
\text { (guardian) is } \\
\text { able to read }\end{array}$ \\
\hline & Living Status & $\begin{array}{l}\text { Dummy variable, } 1 \text { if student lives } \\
\text { with mom only, } 2 \text { if student lives } \\
\text { with dad only and } 3 \text { if student } \\
\text { lives with both mom and dad }\end{array}$ & $\begin{array}{l}\text { Parent-child relationship, } \\
\text { parental expectations } \\
\text { and involvement }\end{array}$ & $\begin{array}{l}\text { Student does } \\
\text { not live with a } \\
\text { parent }\end{array}$ \\
\hline
\end{tabular}

Additional independent variables were considered for inclusion: number of French/English textbooks per student, parental involvement in schools; class type (e.g. multi-grade); availability of breakfast or lunch programs; presence of toilets and water in schools; teacher's highest level of education; quality of school building; and level of 
encouragement of student by school staff. However, these variables are excluded for a number of reasons including incorrect coding, availability of data and minimal variation in the sample.

\subsubsection{Methodological Considerations}

Similar to the analysis in Chapter one, the adopted measurement approach is not without limitations. First, the analysis is based on a cross-sectional dataset derived from a single time-period, 2004-05, and so does not capture important temporal variations in performance and explanatory factors. Second, the focus on numeracy and literacy ignores other important dimensions of cognitive competence many of which do not easily lend themselves to standardized tests (Woessman, 2003). Third, the assessment data used to derive the assessments scores are from grade five. As such, the focus again is on learning outcomes in primary education. While it is important to be aware of the methodological limitations, it is equally important to keep in mind the contribution this analysis makes to the sparse SSA education literature.

\subsubsection{Summary Statistics}

Summary statistics of the dependent variables (for each education sector and aggregate scores) are presented in Table 11. The difference in the number of responses reflects the differences in the student population between both education sectors. Also, average performance is generally consistent but is slightly higher in the Francophone sector. 
However, there are marked differences in the range of performance within and across subjects and education sectors.

Table 11: Descriptive Statistics: Dependent Variables

\begin{tabular}{|l|l|c|c|c|c|c|}
\hline Sector & Variable & Mean* $^{*}$ & Std. Dev & Min & Max & N \\
\hline Francophone & $\begin{array}{l}\text { Aggregated Final } \\
\text { Score }\end{array}$ & 47 & 16 & 11 & 99 & 1,736 \\
\cline { 2 - 7 } & Final math score & 46 & 17 & 5 & 98 & 1,735 \\
\cline { 2 - 7 } & Final language score & 48 & 19 & 2 & 100 & 1,736 \\
\hline Anglophone & $\begin{array}{l}\text { Aggregated Final } \\
\text { Score }\end{array}$ & 42 & 13 & 17 & 83 & 627 \\
\cline { 2 - 7 } & Final math score & 38 & 13 & 8 & 83 & 627 \\
\cline { 2 - 7 } & Final language score & 46 & 17 & 12 & 95 & 627 \\
\hline \multirow{3}{*}{$\begin{array}{l}\text { Sooled } \\
\text { Sample }\end{array}$} & $\begin{array}{l}\text { Aggregated Final } \\
\text { Score }\end{array}$ & 46 & 15 & 11 & 99 & 2,363 \\
\cline { 2 - 7 } & Final math score & 44 & 16 & 5 & 98 & 2,362 \\
\cline { 2 - 7 } & Final language score & 47 & 18 & 2 & 100 & 2,363 \\
\hline
\end{tabular}

*unweighted averages

Table 12 presents the summary statistics of the continuous independent variables for each sector and the pooled sample. Again, the difference in size between education sectors is reflected in the data. Also, the table highlights the marked differences in the range of assessment outcomes and shows initial scores that are unsurprisingly slightly lower, on average, than final assessment scores. The summary also highlights the significant variation across student's age, average class sizes and budget per student. For example, the maximum student age in the data is 20 which is nine years older than the average age in the pooled data set. 
Table 12: Descriptive Statistics: Independent Variables, Continuous Variables

\begin{tabular}{|c|l|c|c|c|c|c|}
\hline Sector & \multicolumn{1}{|c|}{ Variable } & Mean* $^{*}$ & Std. Dev & Min & Max & N \\
\hline \multirow{5}{*}{ Francophone } & Aggregated Initial Score & 46 & 17 & 1 & 95 & 1,779 \\
\cline { 2 - 7 } & Average class size & 51 & 25 & 8 & 159 & 1,781 \\
\cline { 2 - 7 } & Budget per Student** & 2,600 & 5,400 & 91 & 43,750 & 1,539 \\
\cline { 2 - 7 } & Initial language score & 40 & 18 & 3 & 95 & 1,776 \\
\cline { 2 - 7 } & Initial math score & 52 & 18 & 3 & 100 & 1,774 \\
\cline { 2 - 7 } & Student age & 12 & 2 & 8 & 20 & 1,735 \\
\hline \multirow{5}{*}{ Anglophone } & Aggregated Initial Score & 39 & 15 & 8 & 89 & 657 \\
\cline { 2 - 7 } & Average class size & 47 & 26 & 5 & 100 & 658 \\
\cline { 2 - 7 } & Budget per Student** & 2,800 & 4,000 & 182 & 27,100 & 628 \\
\cline { 2 - 7 } & Initial language score & 36 & 15 & 3 & 93 & 657 \\
\cline { 2 - 7 } & Initial math score & 42 & 17 & 6 & 94 & 656 \\
\cline { 2 - 7 } & Student age & 11 & 2 & 7 & 18 & 626 \\
\hline \multirow{5}{*}{$\begin{array}{l}\text { Soompled } \\
\text { Sample }\end{array}$} & Aggregated Initial Score & 44 & 16 & 1 & 95 & 2,436 \\
\cline { 2 - 7 } & Average class size & 50 & 26 & 5 & 159 & 2,439 \\
\cline { 2 - 7 } & Budget per Student** & 2,700 & 5,000 & 91 & 43,750 & 2,167 \\
\cline { 2 - 7 } & Initial language score & 47 & 18 & 2 & 100 & 2,363 \\
\cline { 2 - 7 } & Initial math score & 49 & 19 & 3 & 100 & 2,430 \\
\cline { 2 - 7 } & Student age & 11 & 2 & 7 & 20 & 2,361 \\
\hline
\end{tabular}

*unweighted averages; **variable is re-scaled and measured in thousands in the regressions

Table 13 presents the summary statistics of the dummy independent variables for each education sector and the pooled sample regressions. Again, the statistics reflect the marked variation in the characteristics of the students included in the sample across sectors.

The mean and mode statistics provided in Tables 12 and 13 are used to build the following profile of students in the pooled data.

- The majority of the students (about 70 per cent) are from the Francophone sector.

- The largest proportion of students: 
$\circ$ are male between ages 10 and 15 ;

- attend schools in rural areas, located in areas accessible by paved roads, and have an average budget close to 2,700 CFAF per student;

- are taught in classes with 50 students, on average, and have chalk (very few classes have electricity);

- are taught by male teachers who have been absent from school for at least a day in the month before the survey was administered and who reportedly earned at least 250,000 CFAF per month;

o live in homes without running water, electricity, fridges, televisions or computers;

- live with both parents in homes and both parents (or guardians) can read; and

- live in homes with no books and where the official language is not spoken. 
Table 13: Descriptive Statistics: Independent Variables, Dummy Variables ${ }^{32}$

\begin{tabular}{|c|c|c|c|c|}
\hline Sector & Variable & Mean & Mode & $\mathbf{N}$ \\
\hline \multirow{12}{*}{ Francophone } & Books & 0.42 & 0 & 1,735 \\
\hline & Class condition & 1 & 1 & 1,781 \\
\hline & Female student & 0.43 & 0 & 1,735 \\
\hline & Female teacher & 0.18 & 0 & 1,781 \\
\hline & Language & 0.28 & 0 & 1,781 \\
\hline & Living condition & 0.63 & 0 & 1,781 \\
\hline & Living status & 2.07 & 3 & 1,781 \\
\hline & Parent's reading ability & 2.11 & 3 & 1,781 \\
\hline & Rural & 0.5 & 1 & 1,781 \\
\hline & School access & 0.89 & 1 & 1,759 \\
\hline & Teacher absence & 0.73 & 1 & 1,781 \\
\hline & Teacher salary & 2.61 & 4 & 1,781 \\
\hline \multirow{12}{*}{ Anglophone } & Books & 0.7 & 1 & 626 \\
\hline & Class condition & 0.82 & 0 & 658 \\
\hline & Female student & 0.48 & 0 & 625 \\
\hline & Female teacher & 0.3 & 0 & 658 \\
\hline & Language & 0.48 & 0 & 658 \\
\hline & Living condition & 0.62 & 0 & 658 \\
\hline & Living status & 2.16 & 3 & 658 \\
\hline & Parent's reading ability & 2.21 & 3 & 626 \\
\hline & Rural & 0.66 & 1 & 658 \\
\hline & School access & 0.74 & 1 & 658 \\
\hline & Teacher absence & 0.49 & 0 & 658 \\
\hline & Teacher salary & 2.67 & 4 & 658 \\
\hline \multirow{12}{*}{ Pooled Sample } & Books & 0.5 & 0 & 2,361 \\
\hline & Class condition & 0.95 & 1 & 2,439 \\
\hline & Female student & 0.45 & 0 & 2,360 \\
\hline & Female teacher & 0.21 & 0 & 1,915 \\
\hline & Language & 0.33 & 0 & 2,407 \\
\hline & Living condition & 0.63 & 0 & 2,439 \\
\hline & Living status & 2.09 & 3 & 2,439 \\
\hline & Parent's reading ability & 2.13 & 3 & 2,407 \\
\hline & Rural & 0.55 & 1 & 2,439 \\
\hline & School access & 0.85 & 1 & 2,417 \\
\hline & Teacher absence & 0.67 & 1 & 2,439 \\
\hline & Teacher salary & 2.63 & 4 & 2,439 \\
\hline
\end{tabular}

32 Definition of the dummy variable categories is available in Table 10. 


\subsubsection{Estimation Approach and Results}

The adopted regression approach is the Ordinary Least Squares estimation technique. Prior to running the regressions, three tests are conducted: tests for normality, multicollinearity and heteroscedasticity.

The normality of the residuals is examined using the Shapiro-Francia test (due to the larger size of the pooled data). The null hypothesis that the residuals (both in the pooled sample and subject-specific regressions) are normally distributed is rejected. Also, skewness and kurtosis statistics shows that the distributions, particularly the aggregated scores, are moderately skewed and have a heavy tail (i.e. leptokurtic). It is important to keep in mind though that normality of residuals is only required for valid hypothesis testing and is not required to obtain unbiased estimates of the OLS regression coefficients. More importantly, the normality assumption is not needed with large sample sizes (as in this case) as estimation properties improve with sample size and the Central Limit Theorem applies.

A test for multicollinearity is also conducted. Multicollinearity is a concern because when high multicollinearity is present, standard errors are higher and independent variable coefficients will need to be larger to be statistically significant. The presence of data multicollinearity is detected by examining the Spearman correlation coefficients, Tolerances and Variance Inflation Factors (VIF). ${ }^{33}$ None of the pairwise correlations of

\footnotetext{
${ }^{33} \mathrm{VIF}$ measures the impact of collinearity among variables in a model and is equal to $1 /$ Tolerance.
} 
the independent variables are higher than 0.75. Also, all the VIFs are less than five and tolerances are greater than 0.20 , the commonly accepted thresholds for detecting multicollinearity. However, structural multicollinearity exists in the model due to the inclusion of interaction terms. It is important to re-iterate though that even in the presence of structural multicollinearity, OLS assumptions are not violated and the coefficient estimates remain unbiased. ${ }^{34}$

The presence of heteroscedasticity is detected using Breusch-Pagan test. Testing for heteroscedasticity is important as statistical inference assumes that the errors are homoscedastic. The null hypothesis of a constant variance is rejected at the 0.05 level for the mathematics regression only. The pair-wise correlation between regression residuals and the explanatory factors is examined to determine whether the violation is limited to specific variables but none of the correlation estimates are higher than 0.75 . As such, a general form of correction is applied and the "robust" command is used to correct the math regression standard errors for heteroscedasticity. Given the presence of heteroscedasticity, OLS is no longer expected to be BLUE as OLS no longer has the smallest variance with heteroscedastic errors. However, OLS is expect to remain unbiased.

Standard errors are not adjusted for clustering. Clustering adjustment is suggested to minimize the effect of within-group correlation arising from the two-stage sampling design. Abadie et al (2017) argue that

\footnotetext{
${ }^{34} \mathrm{~A}$ method for addressing structural multicollinearity by centering the affected explanatory variables is difficult to apply as most of the interaction variables are dummy variables.
} 
We take the view that clustering is in essence a design problem, either a sampling design or an experimental design issue. It is a sampling design issue when the sampling follows a two-stage process, where in the first stage, a subset of clusters is sampled randomly from a population of clusters, while in the second stage, units are sampled randomly from the sampled clusters. Although this clustered sampling approach is the perspective taken most often when a formal justification is given for clustering adjustments to standard errors, it actually rarely fits applications in economics....we show that, contrary to common wisdom, correlations between residuals within clusters are neither necessary, nor sufficient, for cluster adjustments to matter.....we show that the question whether, and at what level, to adjust standard errors for clustering is a substantive question that cannot be informed solely by the data. (p.1-2)

\subsubsection{Aggregated Score Regression Results}

The model for the aggregated scores (as well as each subject) is initially run with all the explanatory variables interacted with the education sector (i.e. Anglophone or Francophone) and school location (i.e. rural or urban) dummy variables to formally test the existence of interactions. The Contrast test of linear marginal linear predictions is conducted, which is similar to the Chow test but is more amendable to factor variables.

The following independent variables are grouped based on whether their effect is dependent on education sector, school location or both:

- Education sector (only) - teacher's absence;

- School location (only) - school access, living status, language spoken at home and teacher's salary; and

- Education sector and school location - initial assessment scores, budget per student, class condition and living condition.

Significant two-way interactions and related three-way interactions are included in the regression model. To conserve space, a truncated version of the results (without the 
included interaction terms) is presented in Table 14. The complete table (with all the included interaction terms) is available in Table B1 in Appendix B. The results for the aggregated score results are presented in the first column. Only statistically significant effects are discussed. In general, the explanatory power shows that the model explains about 34 per cent of the variation in aggregated test scores.

The results also support the hypothesis of a difference between sectors. The negative and significant coefficient (at the 0.01 level) on the Francophone dummy variable suggests that the final aggregate scores for Francophone students is 22 percentage points lower than their counterparts in the Anglophone sector, holding other factors fixed. In other words, there is a sizeable intercept shift between the Anglophone and Francophone systems.

On the surface, the community in which the school is located (i.e. rural or urban) does not appear to play a role in determining the final performance. While the coefficient on the rural variable is negative, suggesting that rural student's performance is lower than their urban counterparts, the coefficient is not statistically significant at conventional testing levels. However, that is only part of the story as the significant coefficient (at the 0.01 level) on rural* francophone suggests that student's education sector plays a role; the gap between the Anglophone and Francophone intercepts is now narrowed by about 17 percentage points for Francophone students in rural areas. 
Several results are consistent with prior expectations. First, the coefficient on the initial aggregate assessment score is positive and significant at the 0.05 level confirming the assertion that student's initial knowledge endowment is an important determinant of final performance. The results suggest that a per cent increase in initial performance of Anglophone students raises their final performance by about 0.4 percentage points.

The positive and significant coefficient (at the 0.05 level) on francophone * initial scores reveals a slope difference between the Anglophone and Francophone sectors, with the Francophone slope being higher by 0.2 percentage points. In other words, holding other factors fixed, aggregate final performance of Francophone students is lower than their Anglophone counterparts at lower levels of initial scores but the gap narrows as initial scores increases.

Second, the coefficient on school access is positive and statistically significant at the 0.01 level which suggests that, holding other factors fixed, easy access to schools (via paved roads) contributes positively to educational achievement. Final aggregate schools for urban students in schools that are accessible via paved roads is higher by an additional 11 percentage points. The size and significance (at the 0.01 level) of the coefficient on the rural* school access variable suggest that the effect of school location supersedes the accessibility effect, as rural students with better access to schools have lower final aggregate scores than their urban counterparts in schools with poorly paved roads. 
Third, the coefficient on classsize is negative and statistically significant at the 0.05 level, supporting the widely-documented assertion that higher pupil-teacher ratio contributes negatively to student's performance. Holding other factors fixed, an increase in pupilteacher ratio is estimated to lower final aggregate score and the effect is similar across both education sector and school location.

Finally, the coefficient on classcondition suggests that the level of classroom resourcing matters and plays an important role in the determination of educational achievement. The lack of individual resources (particularly chalk) are shown to have a detrimental effect but the joint availability of chalk and electricity in classrooms is beneficial.

Holding other factors fixed, final performance is estimated to be higher, by an additional 12 percentage points, for Anglophone urban students taught in classrooms with both chalk and electricity compared to their counterparts taught in classrooms where neither is available. The effect of class resources varies by school location and education sector. For example, the intercept for Francophone students in rural schools taught in classrooms where both chalk and electricity are present is higher than the one for Anglophone students in urban schools where neither resource is present by approximately 10 percentage points.

There are, however, several surprising results. First, the results suggest that higher levels of teacher's salary do not contribute positively to educational achievement. However, school location plays a role as the coefficient on teacher salary * rural suggests a positive 
and significant effect for rural students taught by teachers at the highest salary levels, compared to their urban counterparts taught by teachers earning the lowest salary range.

Second, there also does not appear to be a "wealth" effect as the coefficients on the socioeconomic indicator for families, living condition, are generally negative (and statistically significant at either 0.05 or 0.1 levels particularly in the aggregate score regression). However, the magnitude of the effect differs based on education sector and school location and reveals a positive wealth effect surprisingly, for Francophone students living in rural areas with three or more of the indicators present in their home compared to urban students in Anglophone schools living in homes with none of the indicators.

Third, the effect of parent's reading ability on educational achievement is negative and consistent across school location and education sector. In other words, the results suggest that there is no academic benefit from having parents (or guardians) who can read. Fourth, only the effect of living with dad is positive and statistically significant at the 0.1 level for urban students. By contrast, the effects of living with either or both parents are consistently negative and statistically significant (at conventional testing levels) for rural students.

Fifth, while the negative coefficient on teacher's absence is anticipated, what is surprising is the differential education sector effect. The results suggest that teacher's absence from school is only negative for Anglophone students. 
Finally, there is a minimal effect of age and gender. The coefficient on female (student) is positive while the coefficients on female (teacher) and student's age are negative. However, the coefficients are not statistically significant at conventional levels. Also, not statistically significant at conventional levels are the coefficients on budget, books and language.

\subsubsection{Individual Subject Score Regression Results}

The individual subject results are presented in the second and third columns in Table 14. Again, only the truncated results (without interaction terms) are contained in the table. The complete results (with all the interaction terms) are provided in Table B1 in Appendix B. Similar to the aggregate scores analysis, the Contrast test is conducted to identify the significant interactions.

The independent variables are once again grouped below based on whether their effect is dependent on education sector, school location or both. The assessment subject which the significant interaction exists is provided in parenthesis.

- Education Sector (only) - books (language), living status (language), parent's reading ability (language), living condition (math), teacher's absence (math), and class condition (math);

- School Location (only)- initial assessment (language), student's age (language), class condition (language), teacher's salary (language), living status (math), and language spoke at home (math); and 
- Education Sector and School Location- initial assessment (math), school access (both), budget (both), teacher's salary (math), female teacher (language) and living condition (math only).

From Table 14, it can be seen that the explanatory power of both models is consistent with the aggregate scores model, suggesting that the model does equally well at explaining determinants of both math and language assessment results. In general, the subject level results are consistent with the aggregate score results. In particular, the intercept for the Francophone students, holding other factors fixed, remains lower than Anglophone students especially in math. Also, the initial performance remains a strong and significant determinant of final performance for both subjects and magnitude of the effect differs by school location and education sector (particularly school location).

There are several interesting findings that are obscured in the aggregate results. First, the mathematics performance results include a significant (at the 0.1 level) and surprising gender difference with female students' final mathematics assessment score estimated to be higher than their male counterparts by around one percentage point. Second, there is now a significant and positive effect on final mathematics assessment scores associated with a student's access to books in their homes and this effect is similar across education sectors and school location.

Third, the language final assessment results include a significant (at the 0.01 level) and negative effect associated with age of students but shows that the effect differs by school 
location and is higher in urban schools. Fourth, the effect of the availability of financial resources, proxied by the monthly budget per student, on the performance of Anglophone students in urban schools though consistently positive, is now statistically significant in the language results. The effect of financing is different across education sector and school location and negative for Francophone students in rural schools.

Further, the results highlight a number of significant effects that are driven by a single subject (i.e. subject-driven effects). For example, classsize (only significant in math regression), and teacher's absence (only significant in math results). Finally, the subject specific regressions provide very little insight with respect to the surprising negative and significant relationship between parent's reading, living status, living condition, teacher's salary and student's final assessment scores.

Table 14: Final Score Regression Results 


\begin{tabular}{|c|c|c|c|c|}
\hline \multicolumn{2}{|c|}{ DV: Final Assessment Scores } & \multirow{2}{*}{$\begin{array}{c}\text { Aggregate } \\
40.38^{* * *} \\
(6.91)\end{array}$} & \multirow{2}{*}{$\begin{array}{c}\text { Math } \\
42.71^{* \star *} \\
(7.18)\end{array}$} & \multirow{2}{*}{$\begin{array}{c}\text { Language } \\
38.86^{* \star *} \\
(5.14)\end{array}$} \\
\hline & Constant & & & \\
\hline & Initial Scores & $\begin{array}{l}0.36^{* *} \\
(5.29)\end{array}$ & $\begin{array}{c}0.29^{* \star *} \\
(6.21)\end{array}$ & $\begin{array}{l}0.60^{\star \star *} \\
(17.41)\end{array}$ \\
\hline & Francophone & $\begin{array}{c}-21.65^{* * *} \\
(-3.99)\end{array}$ & $\begin{array}{c}-26.87^{* *} \\
(-4.49)\end{array}$ & $\begin{array}{l}-4.09 \\
(-0.57)\end{array}$ \\
\hline \multirow[t]{2}{*}{$\begin{array}{l}\text { Student } \\
\text { Factors }\end{array}$} & Female & $\begin{array}{c}0.82 \\
(1.45)\end{array}$ & $\begin{array}{l}1.12^{*} \\
(1.80)\end{array}$ & $\begin{array}{c}0.13 \\
(0.19)\end{array}$ \\
\hline & Age & $\begin{array}{c}-0.18 \\
(-1.02)\end{array}$ & $\begin{array}{c}0.11 \\
(0.57)\end{array}$ & $\begin{array}{l}-0.94^{* * *} \\
(-2.85) \\
\end{array}$ \\
\hline \multirow[t]{4}{*}{$\begin{array}{l}\text { School } \\
\text { Factors }\end{array}$} & Rural & $\begin{array}{l}-0.25 \\
(-0.04) \\
\end{array}$ & $\begin{array}{c}8.09 \\
(1.47) \\
\end{array}$ & $\begin{array}{l}-12.41 \\
(-1.58) \\
\end{array}$ \\
\hline & School access & $\begin{array}{c}10.68^{* * *} \\
(4.82)\end{array}$ & $\begin{array}{c}1.02 \\
(0.31)\end{array}$ & $\begin{array}{l}7.09^{*} \\
(1.71)\end{array}$ \\
\hline & Average class size & $\begin{array}{l}-0.03^{* *} \\
(-2.28) \\
\end{array}$ & $\begin{array}{c}-0.06^{\star \star \star} \\
(-4.09)\end{array}$ & $\begin{array}{c}-0.01 \\
(-0.75)\end{array}$ \\
\hline & Monthly budget per student & $\begin{array}{c}0.77 \\
(0.93)\end{array}$ & $\begin{array}{c}0.41 \\
(0.70)\end{array}$ & $\begin{array}{l}2.32^{* *} \\
(2.36)\end{array}$ \\
\hline \multirow[t]{3}{*}{$\begin{array}{l}\text { Class } \\
\text { Factors }\end{array}$} & Class condition-chalk only & $\begin{array}{l}-7.78^{* \star \star} \\
(-2.92) \\
\end{array}$ & $\begin{array}{c}-4.47^{\star \star *} \\
(-4.10)\end{array}$ & $\begin{array}{c}1.52 \\
(1.02) \\
\end{array}$ \\
\hline & Class condition-electricity only & $\begin{array}{l}-0.36 \\
(-0.12)\end{array}$ & $\begin{array}{l}-2.11 \\
(-1.20)\end{array}$ & $\begin{array}{c}3.27 \\
(1.25)\end{array}$ \\
\hline & $\begin{array}{l}\text { Class condition-chalk \& } \\
\text { electricity }\end{array}$ & $\begin{array}{c}11.88^{* * *} \\
(3.52)\end{array}$ & $\begin{array}{l}5.21^{*} \\
(1.73)\end{array}$ & $\begin{array}{l}4.85^{* *} \\
(2.61)\end{array}$ \\
\hline \multirow[t]{5}{*}{$\begin{array}{l}\text { Teacher } \\
\text { Factors }\end{array}$} & Female & $\begin{array}{l}-0.53 \\
(-0.67)\end{array}$ & $\begin{array}{l}-1.10 \\
(-1.21)\end{array}$ & $\begin{array}{l}0.99 \\
(0.34)\end{array}$ \\
\hline & $\begin{array}{l}\text { Teacher salary }-30,000 \text { to } \\
89,000 \text { CFAF }\end{array}$ & $\begin{array}{l}-2.83^{* *} \\
(-2.03)\end{array}$ & $\begin{array}{c}-12.31^{* * *} \\
(-5.35)\end{array}$ & $\begin{array}{l}-3.69^{* \star} \\
(-2.21)\end{array}$ \\
\hline & $\begin{array}{l}\text { Teacher salary - } \\
90,000 \text { to } 249,000 \mathrm{CFAF}\end{array}$ & $\begin{array}{l}-4.31 \\
(-1.45)\end{array}$ & $\begin{array}{c}-13.99^{* * *} \\
(-3.92)\end{array}$ & $\begin{array}{l}-8.59^{\star \star} \\
(-2.45)\end{array}$ \\
\hline & $\begin{array}{l}\text { Teacher salary - } \\
250,000 \text { CFAF and above }\end{array}$ & $\begin{array}{l}-3.87^{* * *} \\
(-3.53)\end{array}$ & $\begin{array}{c}-7.69^{\star \star \star} \\
(-3.17)\end{array}$ & $\begin{array}{l}-2.37^{*} \\
(-1.79)\end{array}$ \\
\hline & Absent Teacher & $\begin{array}{c}10.19^{* * *} \\
(-4.97)\end{array}$ & $\begin{array}{c}-5.66^{\star \star *} \\
(-5.13)\end{array}$ & $\begin{array}{c}0.19 \\
(0.23)\end{array}$ \\
\hline \multirow{10}{*}{$\begin{array}{l}\text { Home and } \\
\text { Family } \\
\text { Factors }\end{array}$} & Books & $\begin{array}{c}0.63 \\
(1.01)\end{array}$ & $\begin{array}{l}1.80^{\star \star \star} \\
(2.56)\end{array}$ & $\begin{array}{c}2.11 \\
(1.39)\end{array}$ \\
\hline & French/English spoken at home & $\begin{array}{l}-1.36 \\
(-1.45)\end{array}$ & $\begin{array}{l}-0.70 \\
(-0.67)\end{array}$ & $\begin{array}{c}-0.38 \\
(-0.47) \\
\end{array}$ \\
\hline & $\begin{array}{l}\text { Living condition - } \\
\text { one or two items }\end{array}$ & $\begin{array}{l}-7.10^{*} \\
(-1.89)\end{array}$ & $\begin{array}{l}-1.59 \\
(-1.20) \\
\end{array}$ & $\begin{array}{l}-6.75^{*} \\
(-1.65) \\
\end{array}$ \\
\hline & $\begin{array}{l}\text { Living condition - } \\
\text { three items or more }\end{array}$ & $\begin{array}{l}-9.11^{\star \star} \\
(-2.33)\end{array}$ & $\begin{array}{l}-1.83 \\
(0.99)\end{array}$ & $\begin{array}{l}-5.48 \\
(-1.30) \\
\end{array}$ \\
\hline & Parentsread -mom only & $\begin{array}{l}-4.32^{* * *} \\
(-2.82) \\
\end{array}$ & $\begin{array}{c}-6.02^{\star \star \star} \\
(-3.43)\end{array}$ & $\begin{array}{c}-10.07^{* * *} \\
(-3.33)\end{array}$ \\
\hline & Parentsread - dad only & $\begin{array}{l}-2.07^{\star \star} \\
(-2.15) \\
\end{array}$ & $\begin{array}{l}-2.54^{* *} \\
(-2.23) \\
\end{array}$ & $\begin{array}{l}-3.71^{*} \\
(-1.73) \\
\end{array}$ \\
\hline & Parentsread - mom and dad & $\begin{array}{l}-4.81^{* * *} \\
(-5.54) \\
\end{array}$ & $\begin{array}{l}-5.74^{\star * *} \\
(-5.58)\end{array}$ & $\begin{array}{l}-8.87^{* * *} \\
(-4.26) \\
\end{array}$ \\
\hline & Living with mom only & $\begin{array}{c}0.61 \\
(0.42)\end{array}$ & $\begin{array}{c}0.56 \\
(0.36)\end{array}$ & $\begin{array}{l}2.39 \\
(0.95)\end{array}$ \\
\hline & Living with dad only & $\begin{array}{l}3.57^{*} \\
(1.86)\end{array}$ & $\begin{array}{c}3.86 \\
(1.62) \\
\end{array}$ & $\begin{array}{c}-2.19 \\
(-0.68) \\
\end{array}$ \\
\hline & Living with both parents & $\begin{array}{l}-0.30 \\
(-0.26)\end{array}$ & $\begin{array}{c}0.41 \\
(0.35) \\
\end{array}$ & $\begin{array}{l}-2.08 \\
(-1.11) \\
\end{array}$ \\
\hline \multicolumn{2}{|c|}{ Number of Observations } & 2,093 & 2,087 & 2,090 \\
\hline \multicolumn{2}{|l|}{$\mathbf{R}^{2}$} & 0.34 & 0.29 & 0.32 \\
\hline \multicolumn{2}{|l|}{ F statistic } & $\begin{array}{l}18.99 \\
(0.00)\end{array}$ & $\begin{array}{l}23.33 \\
(0.00)\end{array}$ & $\begin{array}{l}16.74 \\
(0.00)\end{array}$ \\
\hline
\end{tabular}

Note: t-statistic reported in parentheses except F-statistic where p-value is reported. Two-tailed p-value: * significant at 0.1 level; ${ }^{* *}$ significant at the 0.05 level; ${ }^{* * *}$ significant at 0.01 level. Normal standard errors produced for aggregate and language regressions and robust standard error produced for math regression. Adjusted $R^{2}$ provided in the complete table in Appendix B. 


\subsubsection{Results Summary}

The anticipated and significant regression results (both in the aggregate and subjectspecific) offer several important findings:

- As suspected, there is a difference between educational achievement attributed solely to the education sector, holding other factors fixed. The intercept for the Anglophone sector is consistently higher than their Francophone counterparts in all three regressions (although more pronounced in mathematics scores and accordingly, aggregate scores).

- On the surface, school location does not appear to be an important driver of educational achievement. However, the education sector plays a role in moderating this effect (only for math and aggregate scores). Based on the aggregate results, Anglophone students in urban schools are relatively stronger performers compared to their Francophone counterparts in rural schools. However, the magnitude of the effect varies by assessment subject.

- Initial performance (the proxy for initial endowment and prior knowledge) is a positive and strong determinant of final performance but the magnitude of the effect is dependent on education sector, school location and assessment subject. The larger coefficient estimate on initial performance for the Francophone students (relative to the Anglophone students) in the aggregate results shows that 
Francophone student's final aggregate performance does tend to catch up to the aggregate final performance of Anglophone students, given the same initial score.

- While female students appear to be relatively stronger performers than their male counterparts, the statistical significance is dependent on assessment subject and only statistically significant for final math scores.

- The nature and significance of the effect of student's age on final achievement is not consistent and differs by school location and assessment subject. This effect is only statistically significant in the language regression where it is negative. The negative effect is consistent across school locations (although with differing magnitudes).

- The accessibility of schools (via paved roads) contributes positively to the academic performance for Anglophone students in urban schools. School location and education sector matter as the effect is reversed for Francophone students in rural students particularly in the mathematics assessment.

- The negative effect of a higher pupil-teacher ratio is dependent on subject, and only statistically significant in the aggregate and math results. 
- The effect of financial resources, though consistently positive, is surprisingly modest and dependent on assessment subject, school location and education sector and is only significant in the language regression.

- The effect of the availability of classroom resources differs by subject, school location and education sector. The results generally support the assertion that the importance of classroom resources, chalk and electricity, lie in their joint, rather than individual, availability. This finding speaks to the importance of resource adequacy and the quality of classroom conditions.

- The negative effect of a teacher's absence is evident in the Anglophone sector and reverses for the Francophone sector. The effect also differs by subject and is only significant in the math regression. The higher effect in the Anglophone section is particularly interesting as teacher absence is more pronounced in the data in the Francophone sector. Perhaps, a higher level of gradation is required to better hone in on the effect on the Francophone sector.

- The magnitude of the effect of the availability of reading materials in a student's home is dependent on subject (positive only in the mathematics regression) and education sector.

The results also include a number of surprising results with respect to the generally negative coefficient on select family-related factors (parent's reading ability, living 
condition and living status) as well as teacher's salary. The significant coefficients suggest that higher teacher salaries, parent's reading ability, income level, and parent's presence in the home all have a negative effect on educational achievement.

Some of these findings are reasonably consistent with the literature. For example, Hanushek (1997) notes that:

the vast number of estimated real resource effects gives little confidence that just adding more of any of the specific resources to schools will lead to a boost in student achievement.....there is very weak support for the notion that simply providing higher teacher salaries or greater overall spending will lead to improved student performance... (p.144)

Nonetheless, subsequent analysis will delve deeper into the surprising significant results for teacher's salary, living condition, living status, and parent's reading ability.

\subsection{Additional Analysis: Role of Student's Prior Knowledge and Learning}

The unexpected relationship between most family-related factors and final performance is explored within the context of their relationship with initial performance. The argument is that the contribution of family- (and student-) related factors to student's endowment, knowledge and academic motivation (proxied by initial performance) is expected to be largely constant over the course of the year. As such, it is likely that their effects on final performance are being masked and subsumed by the inclusion of initial performance in the model regressions. ${ }^{35}$

\footnotetext{
${ }^{35}$ An alternative specification of the main aggregate regression without initial assessment score is also estimated. The signs of the estimated coefficients are generally consistent and as expected, a number of coefficients are now statistically significant at conventional testing levels (particularly student age and
} 
To test this assertion, initial aggregate test scores at the beginning of the school year are regressed against student- and family-related factors. Similar to the full model specifications, significant Interactions based on school location and education sector are also included in the final specifications and the results are presented in Table 15.

Although the explanatory power of the model is much lower than the explanatory power of the final score regressions, the results still provide some interesting insights. First, the effect of gender is now significant (at the 0.1 level) and is more consistent with existing evidence on the gender disparity and under-education of girls. Holding other factors fixed, initial assessment scores for female students are estimated to be around one percentage point lower than male students.

In most SSA countries, a student's gender has an impact on school access as well as performance in schools with girls more likely to drop out than boys. Difference in drop-out rates is mainly a result of differential costs associated with gender opportunities by families and society. Gender-related difference between rural and urban areas is tested and although initial performance is lower for rural female students, compared to their male urban counterparts, this difference is not statistically significant.

Second, the student's age now has a negative and significant effect (at the 0.01 level) on initial test scores. An increase in student's age by a year is estimated to decrease assessment performance at the beginning of the school year by around one percentage

availability of books in the home). However, the explanatory power of the model is markedly lower (adjusted $\mathrm{R} 2$ is 0.17 compared to 0.33 ) so the results are not reported. 
point. The effect is slightly more pronounced for Francophone students which makes sense as Francophone students are older on average (by a year) than their Anglophone counterparts. This difference is consistent with the year difference in the official starting age of primary school between both sectors.

With respect to age, Michaelowa (2001) argues that the negative effect is likely due to the exclusion of repetition of lower grades. Since age and repetition are highly correlated, the negative relationship between lower grade repetition and test scores is likely wrongly attributed to age. Another factor which is also highly correlated with age that is excluded from the analysis is extended absences from school due to family's financial constraint or family responsibility (at home or on the farm). ${ }^{36}$ In essence, the lower performance of older age of students is arguably in part due to the exclusion of measures of repetition and/or extended absences from school.

The sign and significance on the coefficient on living condition supports the assertion that a family's wealth or socio-economic status plays a positive role in determining prior knowledge (particularly homes with higher number of the selected durable goods) for Francophone students. However, the evidence from the Anglophone sector (or rural areas) does not support this assertion. The enduring contradiction calls into question the suitability of this variable as a proxy for wealth and socio-economic status across sectors.

\footnotetext{
${ }^{36}$ Two- and three-way interactions between gender, age and rural are tested but none of the interactions are statistically significant.
} 
It ought to be noted that the available evidence on the wealth effect in SSA is not generally robust. For example, Michaelowa (2001) notes that the individual effects of wealth (using an index of durable goods such as a car, a fridge and a video recorder) have not yielded any statistically significant correlations.

Third, the results suggest that the effect of having parents (or guardians) who can read varies by education sector and school location. The effect remains largely negative and now generally not statistically significant. The extent to which this effect is driven by the language spoken at home or living status is explored. The parent literacy effect should arguably be stronger for students who speak one of the two official languages at home or live with either (or both parents). The interactions are tested but are not statistically significant at conventional testing levels.

This persistent negative effect of this variable calls into question its suitability as a proxy of parent's literacy level. The variable arguably suffers from measurement bias as it is derived from subjective assessment by students of their parents reading competencies. More importantly, students are only asked to indicate whether or not their parent or guardian can read and not how well their parents or guardians are able to read. In other words, the variable is not an indicator of quality as it does not assess or measure reading fluency or competency of parents. ${ }^{37}$

\footnotetext{
${ }^{37}$ No suitable alternative proxy is available in the data.
} 
Fourth, the effect of family living arrangement on prior learning and knowledge is similar across sectors and location and suggests a positive effect for both female- or maleheaded households (not both), but none of the coefficients are statistically significant at conventional testing levels.

Finally, the results suggest that availability of books in the home and the language spoken at home contribute strongly to prior learning and achievement. The significance of the language spoken at home (at the 0.01 level) is particularly important as it signals a parent's ability to support the development of the basic language skills required at school and help with homework. The effect of both factors is constant across education sector and school location. These significant results are contrary to the earlier regression results which suggest that both factors are not important determinants of final assessment scores.

In summary, evidence to support the assertion that the individual effects of the variables are being moderated in the earlier specification by initial assessment scores is stronger for student-related factors (age and gender) and select family-related factors (i.e. availability of books at home and language spoken at home). As such, their effect in the earlier specifications ought to be interpreted as reflecting their incremental contribution to final educational performance over and above their contribution to initial performance. The findings for the remaining family-related factors calls into question their suitability as proxies.

\section{Table 15: Initial Score Regression Results}




\begin{tabular}{|c|c|c|}
\hline \multicolumn{2}{|c|}{ DV: Initial Assessment Score } & \multirow{2}{*}{$\begin{array}{c}\text { Aggregate } \\
62.22^{* \star \star} \\
(8.88)\end{array}$} \\
\hline & Constant & \\
\hline & Francophone & $\begin{array}{l}-6.05 \\
(-0.78)\end{array}$ \\
\hline \multirow[t]{3}{*}{$\begin{array}{l}\text { Student } \\
\text { Factors }\end{array}$} & Female & $\begin{array}{l}-1.06^{*} \\
(-1.65)\end{array}$ \\
\hline & Age & $\begin{array}{c}-1.21^{* * *} \\
(-2.97)\end{array}$ \\
\hline & Francophone * Age & $\begin{array}{l}-0.57 \\
(-1.21) \\
\end{array}$ \\
\hline \multirow[t]{2}{*}{$\begin{array}{l}\text { School } \\
\text { Factor }\end{array}$} & Rural & $\begin{array}{l}-15.46^{* * *} \\
(-2.97) \\
\end{array}$ \\
\hline & Francophone * Rural & $\begin{array}{l}28.04^{\star \star \star} \\
(5.02)\end{array}$ \\
\hline \multirow{22}{*}{$\begin{array}{l}\text { Home and } \\
\text { Family } \\
\text { Factors }\end{array}$} & Books & $\begin{array}{c}4.04^{* * *} \\
(6.05)\end{array}$ \\
\hline & French/English spoken at home & $\begin{array}{c}2.22^{\star * *} \\
(2.98) \\
\end{array}$ \\
\hline & Living condition -one or two items & $\begin{array}{c}-14.66^{* * *} \\
(-4.15)\end{array}$ \\
\hline & Living condition -three items or more & $\begin{array}{l}-12.04^{* * *} \\
(-3.26)\end{array}$ \\
\hline & Francophone ${ }^{*}$ Living condition -one or two items & $\begin{array}{c}16.60^{* \star *} \\
(4.43)\end{array}$ \\
\hline & Francophone * Living condition -three items or more & $\begin{array}{c}18.43^{* * *} \\
(4.65)\end{array}$ \\
\hline & Rural * Living condition -one or two items & $\begin{array}{c}10.99^{* * *} \\
(2.84)\end{array}$ \\
\hline & Rural ${ }^{*}$ Living condition -three items or more & $\begin{array}{c}5.62 \\
(1.30) \\
\end{array}$ \\
\hline & Francophone *Rural ${ }^{*}$ Living condition -one or two items & $\begin{array}{c}-15.44^{* * *} \\
(-3.65)\end{array}$ \\
\hline & Francophone * Rural *Living condition -three items or more & $\begin{array}{l}-18.56^{* * *} \\
(-3.22)\end{array}$ \\
\hline & Parentsread -mom only & $\begin{array}{l}-1.20 \\
(-0.16) \\
\end{array}$ \\
\hline & Parentsread - dad only & $\begin{array}{l}-1.12 \\
(-0.18) \\
\end{array}$ \\
\hline & Parentsread - mom and dad & $\begin{array}{l}-1.56 \\
(-0.27) \\
\end{array}$ \\
\hline & Francophone * Parentsread -mom only & $\begin{array}{l}-1.05 \\
(-0.13) \\
\end{array}$ \\
\hline & Francophone * Parentsread - dad only & $\begin{array}{l}2.03 \\
(0.31) \\
\end{array}$ \\
\hline & Francophone * Parentsread - mom and dad & $\begin{array}{c}8.88 \\
(1.49) \\
\end{array}$ \\
\hline & Rural * Parentsread -mom only & $\begin{array}{l}5.29 \\
(0.67)\end{array}$ \\
\hline & Rural * Parentsread-dad only & $\begin{array}{c}6.90 \\
(1.09) \\
\end{array}$ \\
\hline & Rural * Parentsread - mom and dad & $\begin{array}{l}4.96 \\
(0.84)\end{array}$ \\
\hline & Francophone * Rural * Parentsread -mom only & $\begin{array}{c}-7.17 \\
(-0.80) \\
\end{array}$ \\
\hline & Francophone * Rural * Parentsread - dad only & $\begin{array}{l}-10.04 \\
(-1.45) \\
\end{array}$ \\
\hline & Francophone * Rural * Parentsread - mom and dad & $\begin{array}{l}-14.08^{* *} \\
(-2.23)\end{array}$ \\
\hline
\end{tabular}




\begin{tabular}{|l|l|c|}
\hline \multirow{2}{*}{} & Living with mom only & 0.39 \\
& & $(0.35)$ \\
\cline { 2 - 3 } & Living with dad only & 1.79 \\
& & $(1.17)$ \\
\cline { 2 - 3 } & Living with both parents & -1.10 \\
& & $(-1.25)$ \\
\hline Number of Observations & $\mathbf{2 , 3 5 9}$ \\
\hline F-statistic & $\mathbf{1 3 . 9 9}$ \\
& $\mathbf{0 . 0 0 )}$ \\
\hline $\mathbf{R}^{\mathbf{2}}$ & $\mathbf{0 . 1 6}$ \\
\hline Adjusted $\mathbf{R}^{\mathbf{2}}$ & $\mathbf{0 . 1 5}$ \\
\hline
\end{tabular}

Note: t-statistic reported in parentheses except F-statistic where p-value is reported. Twotailed p-values: * significant at 0.1 level; ${ }^{* *}$ significant at the 0.05 level; ${ }^{* * *}$ significant at 0.01 level. Robust standard errors reported. Adjusted R squared for the regression without robust standard errors is reported.

\subsection{Additional Analysis: Role of Teacher Remuneration}

According to the literature, the monthly salary of primary school teachers is expected to reflect the average teacher's ability, expertise, and productivity. Better teachers are more likely to help students hone their cognitive skills and improve their academic performance. These students, in turn, can apply their cognitive skills to future productive economic activities (Lee and Barro, 1997 and Hanushek ,1997). Accordingly, teacher's salary remains one of the most widely used proxies for teacher quality. Also, teacher salaries are arguably the biggest cost factor in educational finance.

The presented results suggest that teacher's salary is detrimental to student's educational achievement. The distribution of teacher salary is consistent with years of experience as relatively new teacher in the data generally earn less than their more experienced counterparts. However, the majority of teachers surveyed in both sectors have relatively nascent teaching experience. 
Figure 13 provides the distribution of surveyed teachers by years of experience. A majority of the teachers in the Anglophone sector have been teaching for five years or less. Similarly, in the Francophone sector, most of the surveyed have been teaching for ten years or less.

\section{Figure 13: Distribution of Surveyed Teachers by Years of Teaching Experience}

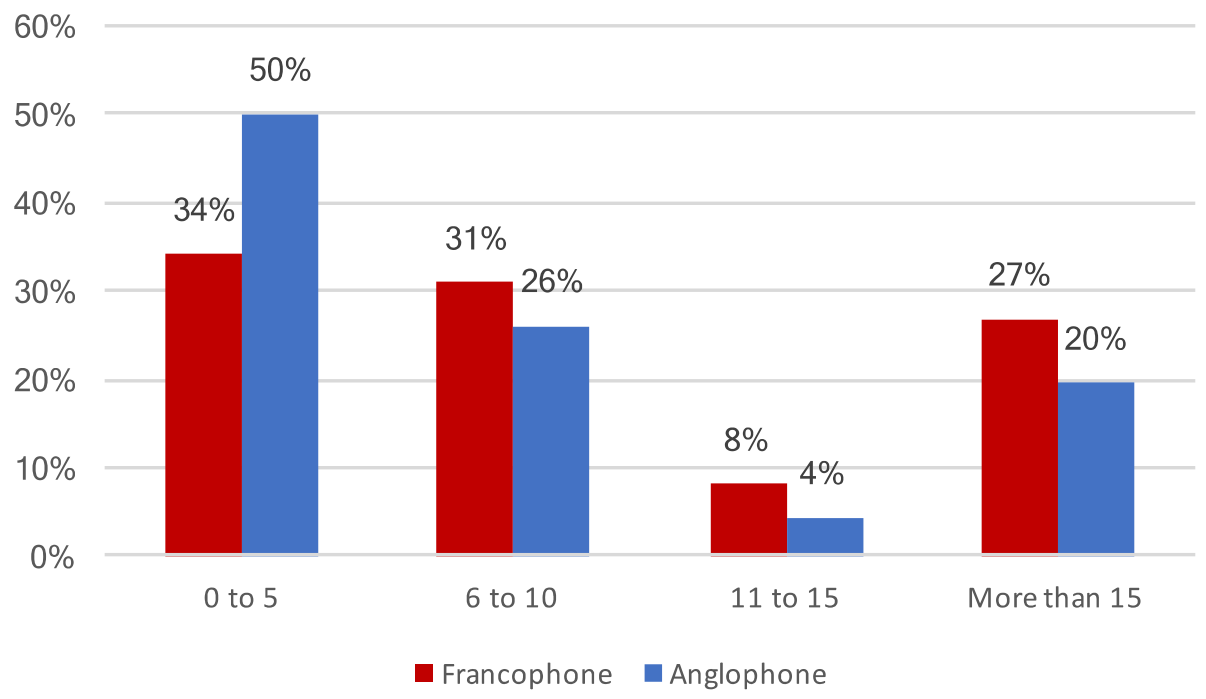

The relationship between student's final performance and teacher's years of experience is examined using t-tests. Surprisingly, the average student performance is slightly higher for relatively newer teachers in both sectors but the differences are not statistically significant at conventional testing levels. Education does not provide additional insight as the percentage of relatively new teachers reporting higher academic degrees is comparable to their counterparts with relatively more years of teaching experience.

Taken together, the results suggest that the teacher-related factors in the analysis do not contribute to educational achievement in a manner consistent with the literature 
presented above. It speaks to the complexity associated with the use of the variable as a proxy for quality of teaching. Naylor and Sayed (2014) notes:

...there is evidence to suggest that teacher quality is dependent on a combination of different factors such as classroom practices, subject knowledge, professional development, teaching experience and quality of teacher-student relationships which in turn impact on student outcomes. These findings signal that it cannot be automatically assumed that teacher certificates and qualifications lead to better teaching... (p.8)

In addition, educational policy reforms occurring in the country around the time of the survey and the state of the system further reduces its suitability as a strong proxy of quality of teaching.

\subsubsection{Survey Timing}

The timing of the survey coincides with a period of significant policy reform in the education sector in Cameroon and explains why a majority of teachers are relatively new. In the 1990s, there was a ban on recruiting teachers which was reversed in 2000 with the abolishment of school fees in primary schools. According to World Bank (2012), reduced allocations and re-defined priorities in the primary education sector resulted in increased enrollment and severe teacher shortages across the country.

The government introduced a contract teacher program in primary education in the 1990s which was further refined in 2000 . The program aimed to incorporate all non-civil servant teachers into a single group of contract teachers. There remained a shortage of qualified teachers in Cameroon during this time-period and a recruitment drive was put in place in 
the early 2000s to meet the Millennium Development Goal of Universal Primary Education and reduce pupil-teacher ratios (UNESCO, 2014).

The growth in the number of teachers in the primary sector between 1990 and 2010 is consistent with a period of expansion in the teaching force. Figure 14 shows an initial peak in the number of teachers between 2004 and 2006, around the survey time-period.

Figure 14: Number of Teachers in Primary Education, Cameroon

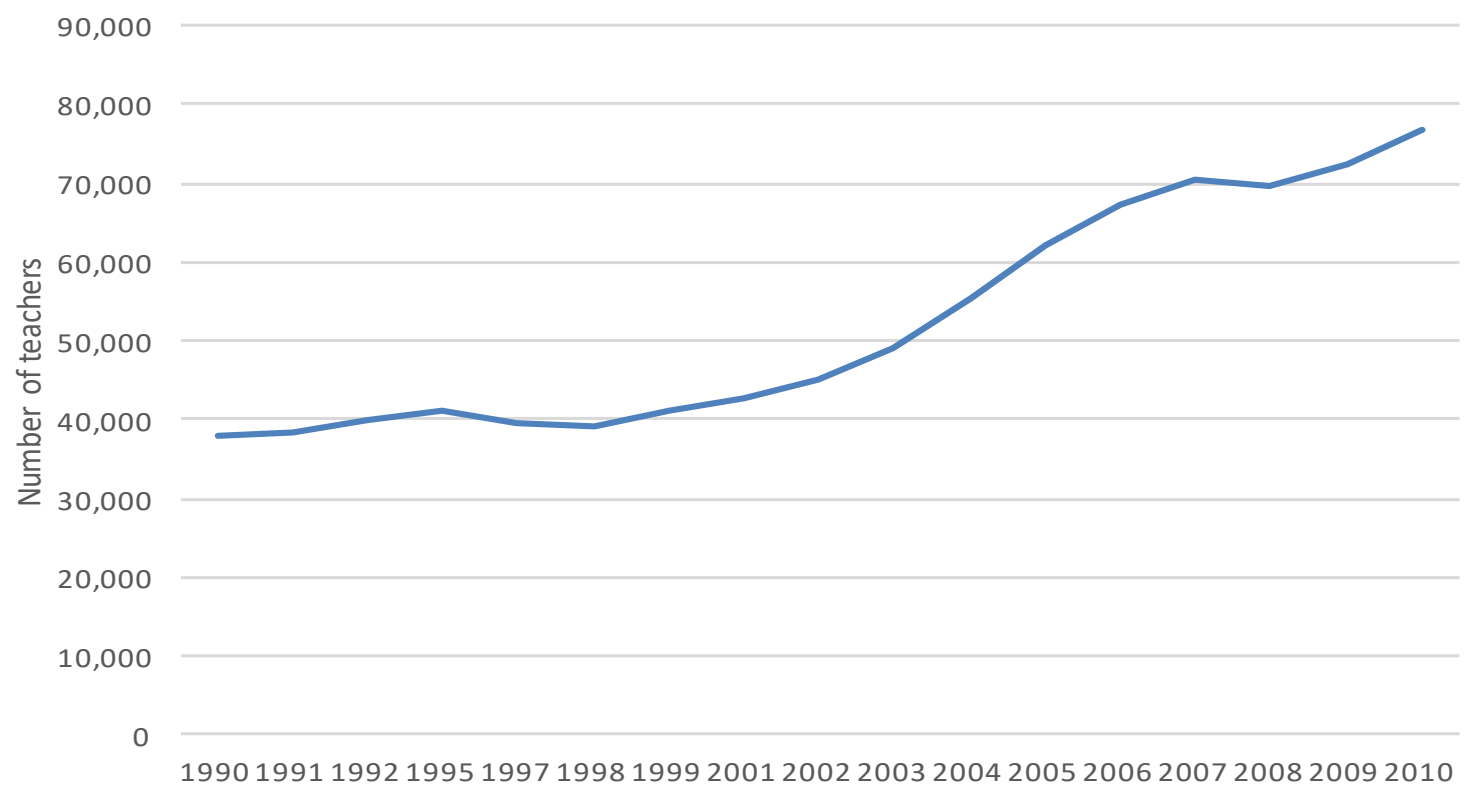

Source: World Bank Education Statistics

This context suggests that the findings of the full model are in part due to the nature of the underlying data. In other words, the cross-sectional data only captures a partial picture of the effect of the reforms and speaks to the importance of adopting a longitudinal study. 


\subsubsection{Differences in Salary Grid and Teacher Type}

According to World Bank (2012), there is inequity and arbitrariness in the salaries paid to teachers within the country and pay grids are not always connected to differences in qualifications or work effort. Also, there are different types of teachers in the primary sector with different pay grids: regular civil servant teachers hired by the federal government; contract teachers hired by regional administrations; and teachers hired by the Parent Teacher Associations (PTAs).

Regular (non-contract) civil servant teachers generally earn the highest salaries and the PTA teachers earn the lowest. Teachers hired by PTAs earn between CFA 35,000 and CFA 60,000 per month and teachers hired by the government receive a minimum of about CFA 150,000 per month (World Bank, 2012).

This contract structure suggests that salary distribution is highly correlated with teacher type. The variation in the reported salary ranges suggests a mix of different types of teachers in the sample. However, teacher type is excluded from the analysis (due to issues with data coding). As such, the variation in performance associated with teacher type is likely incorrectly attributed to salary.

\subsubsection{Issues with the Teacher Registration System}

Teacher salaries may also not be consistent with qualification and reflective of systematic issues and inefficiency in existing processes. According to World Bank (2012), the process of registration prior to receiving a first salary could be lengthy and as long as 
three years. During this period, teachers often do not receive any remuneration and could receive large lump sums which includes months of arrear payments. This argument is especially relevant in this case given that majority of the teachers included in the data are relatively new.

\subsection{Conclusion}

The main goal of this chapter is to extend the analysis in Chapter one by presenting a micro-level analysis of the determinants of educational quality using a single country case study. Cameroon is selected for this case study as it is identified as one of the outliers in Chapter one. In general, the results suggest that initial performance and included student, school-, and class- related factors have a nuanced effect on academic achievement that varies by education sector, school location and/or assessment subject.

The surprising effect of family-related factors on educational achievement is explored in subsequent analysis first by re-running student and family factors against student's assessment scores at the beginning of the school year. This analysis suggests that the inclusion of initial performance in the full model subsumes the importance of student's attributes (age and gender), particularly in the aggregate score regression, and two family-related determinants of educational quality (the availability of books in the home and language spoken at home). As such, their contribution in the original model ought to be interpreted as an incremental effect on final academic achievement, over and above their effect on initial performance. 
However, this analysis did little to address the generally negative effect of the remaining family-related factors (particularly parent's reading ability and living condition). The robust findings related to these variables are arguably due to the weakness of the variables as proxies for socio-economic status or parent's literacy level.

The analysis also presented contextual explanations for the surprising negative relationship between teacher's salary and educational achievement. Important policy reforms occurring around the time of the survey, omitted variable bias and inefficiencies in the education system all play a role in reducing the suitability of the variable as a measure of teaching quality.

What exactly can be learned from the Cameroon experience? The results do not provide definitive evidence of the prominence of the effect of one group of factors over another (i.e. school factors versus family factors). The results also do not necessarily provide a clear insight as to why Cameroon is an outlier in Chapter one. However, the results do provide evidence of the complexities associated with estimating the determinants of educational quality even at the micro-level and highlight the importance of locational and institutional context, as well as family and school characteristics. The results also highlight the importance of the assessment subject, strength of proxy measures and the interactions and interdependencies between the various explanatory factors.

Future micro-level studies (including longitudinal qualitative and quantitative analyses) are required, once more suitable data become available, to better hone in on key 
determinants of educational achievements and relevant policy levers, taking into consideration prevailing country-level contexts. In addition, different estimation techniques (for example, quantile regression) could also help uncover differences in determinants of educational achievement at different levels of student's performance. 


\section{References}

Abadie, A., Athey, S., Imbens, G. \& Wooldridge, J. (2017). When should you adjust standard errors for clustering? Available online at: https://economics.mit.edu/files/13927

African Development Bank Group (AfDG). (2019). Macroeconomic Performance and Prospects: Jobs, Growth and Firm Dynamism. Available online at: https://www.afdb.org/fileadmin/uploads/afdb/Documents/Publications/2019AEO/A EO_2019-EN.pdf

Badr, M. Morrissey, O. \& Appleton, S. (2012). Determinants of Educational Attainment in MENA. CREDIT Research Paper, No. 12/03.

Badr,M.Morrisey, O. \& Appleton, S. (2003). Determinants of Educational Attainment in MENA. CREDIT Research Paper, No.12/03.

Bashir, S., Lockheed, M., Ninan, E. \& Tan, JP. (2018). Facing Forward: Schooling for Learning in Africa. Washington,D.C.: World Bank.

Baum, C. (2013). Quantile Regression.Available online at: http://fmwww.bc.edu/ECC/S2013/823/EC823.S2013.nn04.slides.pdf

Bethell, G. (2016). Mathematics Education in Sub-Saharan Africa: Status, Challenges and Opportunities. Washington,D.C.: World Bank

Coleman, J.S. (1966). Equality of Educational Opportunity. National Center for Educational Statistics. Report Number OE-380001.

Chinapah, V. (2003). Monitoring Learning Achievement (MLA) Project in Africa. Association for the Development of Education in Africa Biennial Meeting Working Paper.

CONFEMEN (2007). Rapport PASEC Cameroun 2004/2005: Le defi de la scolarisation universelle de qualite. Available online at: http://www.pasec.confemen.org/wpcontent/uploads/2015/07/09-Cameroun-20071.pdf

. (2015). PASEC 2014 Education System Performance in Francophone SubSaharan Africa. Available online at: https://www.pasec.confemen.org/wpcontent/uploads/2015/12/Rapport_Pasec2014_GB_webv2.pdf

Eloundou-Enyegue, M. \& Williams, L. (2006). Family Size and Schooling and SubSaharan African Settings: A Reexamination. Demography, 43(1):25-52 
Frölich, M. \& Michaelowa, K. (2011). Peer Effects and Textbooks in Primary Education: Evidence from Francophone Sub-Saharan Africa. Labour Economics, 18(4):47486.

Firpo, S., Fortin, N. \& Lemieux, T. (2009). Unconditional Quantile Regressions. Econometric., 77(3):953-973.

Gleewe, P. (2013). Education Policy in Developing Countries. Chicago, I.L.: University of Chicago Press.

Glewwe, P., Hanushek,E., Humpage, S. \& Ravina,R. (2011). School Resources and Educational Outcomes in Developing Countries: A Review of the Literature from 1990 to 2010. NBER Working Paper No. 17554.

Glewwe, P. \& Kremer, M. (2006). Chapter 16- Schools, Teachers and Education Outcomes in Developing Countries. Handbook of the Economics of Education, Volume 2. Edited by Eric. A. Hanushek and Finis Welch. DOI: 10.1016/S15740692(06)02016-2

Grimm.M. (2011). Does Household Income Matter for Children's Schooling? Evidence for Rural Sub-Saharan Africa. Economics of Education Review, 30:740-54.

Handa, S. \& Simler, K. (2000). Quality or Quantity? The Supply-Side Determinants of Primary Schooling in Rural Mozambique. FCND Discussion Paper No. 83.

Hanushek,E.A. (1986). The Economics of Schooling: Production and Efficiency in Public Schools. Journal of Economic Literature, 24(3): 1141-77.

(1995). Interpreting Recent Research on Schooling in Developing Countries. The World Bank Research Observer, 10(2):227-46.

(1997). Assessing the Effects of School Resources on Student Performance: An Update. Educational Evaluation and Policy Analysis, 19(2):141164.

(2003). The failure of input-based schooling policies. The Economic Journal, 113:F64-F98.

online

.(2007). Education Production Functions. Palgrave Encyclopedia. Available

https://hanushek.stanford.edu/sites/default/files/publications/Hanushek\%202008

\%20PalgraveDict.pdf

Hanushek, E., Kim, D. (1995). Schooling, labor force quality and economic growth. NBER Working Paper No. 5399 
Hanushek,E. \& Woessman, L. (2007). The Role of School Improvement in Economic Development. National Bureau of Economic Research Working Paper no.12832.

Heyneman, S., and Loxley, W. (1983). The effect of primary- school quality on academic achievement across twenty-nine high- and low-income countries. American Journal of Sociology, 88(6),1162-1194.

Karugu, A.M, Kamere, I.M. \& Mugo, P. Chapter 11: The Education System of Cameroon mimeo. Available online at: https://irlibrary.ku.ac.ke/bitstream/handle/123456789/10018/the\%20education\%20system $\% 20$ of\%20cameroon..pdf?sequence=1

Kennedy, P. (2002). Oh No! I Got The Wrong Sign! What Should I Do? Simon Fraser University Department of Education Discussion $\mathrm{Pa}$ pers No. 02-3.

Koenker, R. \& Bassett, Jr. G. (29178). Regression Quantiles. Econometrica, 46(1):33-50

Koenker, R. \& Hallock. K. (2001). Quantile Regression. Journal of Economic Perspectives, 15(4):143-156.

Lee, J.W. \& Barro, R.J. (1997). Schooling Quality in a Cross Section of Countries. NBER Working Paper Series No. 6198

Lloyd, C. \& Blanc, A. (1996). Children's Schooling in sub-Saharan Africa: The Role of Fathers, Mothers and Others. Population and Development Review,22(2):265298.

Lockheed, M. \& Verspoor, A. (1991). Improving Primary Education in Developing Countries. Oxford, U.K: Oxford University Press for the World Bank.

Majaard,K. \& Mingat, A. (2012). Education in Sub-Saharan Africa: a comparative analysis. Washington, D.C.: World Bank.

Michaelowa, K. (2001). Primary Education Quality in Francophone Sub-Saharan Africa: Determinants of Learning Achievement and Efficiency Considerations. World Development, 29(10): 1699-1716.

(2003). Determinants of Primary Education Quality: What we Learn from PASEC for Francophone Sub-Saharan Africa? Association for the Development of Education in Africa Working Paper.

MINEDUB (2018). Annuaire statistique 2016/2017- 2016/2017 Statistical Yearbook. Available online at: http://www.minedub.cm/uploads/media/Annuaire_Statistiques_2017_-_Final.pdf 
Mioko, S. (1998). Gender versus socioeconomic status and school location differences in grade 6 reading literacy in five African countries. Harare: Ministry of Education and Culture.

Naylor, R. \& Sayed, Y. (2014). Teacher Quality: Evidence Review. Australian Government Department of Foreign Affairs and Trade. Available online at: https://dfat.gov.au/aid/how-we-measure-performance/ode/Documents/evidencereview-teacher-quality.pdf

OECD. (2005). School Factors Related to Quality and Equity: Results from PISA 2000. Available online at: http://www.oecd.org/education/school/programmeforinternationalstudentassessm entpisa/34668095.pdf

(2006). Cameroon: African Economic Outlook 2005-2006. Available online at: www.oecd.org/dev/publications/africanoutlook

Pritchett, L. (2001). Where has all the education gone? The World Bank Economic Review, 15(3), 367-391.

Simmons, J. \& Leigh, A. (1975). The Determinants of School Achievement in Developing Countries: A Review of the Research. Paper Prepared for the American Education Research Association Annual Meeting, Washington:D.C. Available online at: https://files.eric.ed.gov/fulltext/ED106173.pdf

The Centre for Global Education Monitoring (GEM). (2015). The Southern and Eastern Africa consortium for monitoring educational quality. Assessment GEM Series no. 8.

Thomson, S. (2018). Achievement at Social and Socioeconomic background - an Educational Perspective. NPJ Science of Learning 3(5).

Tosam, F.J. (1988). Implementing Educational Change in Cameroon Two Case Studies in Primary Education. Thesis submitted in partial fulfilment of the requirements for the degree of Doctor of Philosophy in the Institute of Education, University of London.

UNESCO. (2009). Universal Primary Education in Africa: The Teacher Challenge. Available online at : http://uis.unesco.org/sites/default/files/documents/universalprimary-education-in-africa-the-teacher-challenge-en.pdf

.(2014). Wanted: Trained Teachers to Ensure Every Child'

(2015). World TVET Database: Cameroon. Available online at: https://unevoc.unesco.org/wtdb/worldtvetdatabase_cmr_en.pdf 
Van Kerm,P. (2015). Influence Functions at Work. 2015 London Stata Users Group Meeting:London, U.K. Available online at: https://www.stata.com/meeting/uk15/abstracts/materials/uk15_vankerm.pdf

Woessman, L. (2003). Schooling resources, educational institutions and student performance: the international evidence. Oxford Bulletin of Economics and Statistics, 65(2), 117-170.

Wooldridge,J. (2003). Introductory Econometrics: A Modern Approach, 2E. Mason, Ohio:Thomson/South-Western.

World Bank.(2012). Cameroon - Governance and management in the education sector (English). Washington D.C. : The Worldbank. http://documents.worldbank.org/curated/en/874481468223463602/CameroonGovernance-and-management-in-the-education-sector

(2018). Cameroon Education Reform Support Project : Combined Project Information Documents/Integrated Safeguards Datasheet. Report No: PIDISDSA215537

. (2019a). Cameroon: Recent Developments. Macro Poverty Outlook. Available online at: http://pubdocs.worldbank.org/en/819481492188154977/mpocmr.pdf

Washington, D.C.

(2019b). World Development Indicators. Washington, D.C: The World Bank (2019c). EdStats: Education Statistics. Washington, D.C: The World Bank. 


\section{Chapter Three: A Study of the Effect of Educational Achievement on Economic Growth in Sub-Saharan Africa}

Human capital theory argues that education or training raises the productivity of workers by imparting useful knowledge and skills, thereby raising their future income and lifetime earnings (Becker, 1993). The link between human capital investment and economic growth lies in its ability to expand scientific and technical knowledge and subsequently, raise the productivity of labour and other factors of production.

Increases in educational investment from human capital theory were historically assumed in the literature to occur by increasing the quantity of schooling. More recent empirical evidence shows that theory is equally consistent with increases to the quality of schooling. However, robust evidence on the effect of quality of education on economic growth in SSA is presently sparse. Addressing this gap is important to ensure that subSaharan African governments, bilateral agencies and multilateral agencies develop and implement educational policies and funding priorities that promote and result in sustainable economic growth in the region.

To that end, this paper investigates the relative contribution of education, particularly educational quality, to economic growth in SSA. More precisely, this paper addresses the following question:

What is the specific effect of educational quality on economic growth in SSA? 


\subsection{Literature Review}

Two theories explain the link between education and growth: neoclassical and endogenous growth models. The neoclassical growth model dates back to the works of pioneering economists including Solow (1956), Swan (1956) and Becker (1964). Solow (1956) provides a standard neoclassical production function with decreasing returns to capital and postulates that rates of saving and labour growth, both assumed to be exogenous, determine the steady-state level of income per capita. Human capital investment is included as an additional explanatory variable in the augmented Solow model.

Endogenous growth theory, pioneered by Romer (1986) and Lucas (1988), challenges the neoclassical view by proposing channels through which the long-run rate of economic growth can be influenced by structural economic factors. According to the theory, growth of technology depends on economic decisions at least as much as capital accumulation.

Education is included in endogenous models as an input in the production function itself. According to the theory, education is seen as a process that: alters the production technology (for example, Romer, 1990, 1993; Nelson and Phelps, 1966); makes it easier to adopt foreign technology (for example, Barro and Sala-i-Martin, 1995); or enable transfer of resources to more technologically advanced sectors of the economy.

In the early 1990s, seminal papers re-ignited the debate on the role of education in promoting growth and development by providing evidence of the positive role of education on economic growth. One of the most pivotal studies which spurred the renaissance is 
Mankiw, Romer and Weil (1992) (hereafter referred to as MRW,1992). Based on a crosssectional sample of 88 countries (including about 40 SSA countries), MRW (1992) find that education has a positive and significant effect on the growth rate of income from 1960 to 1985 . They estimate an augmented neoclassical Solow growth model. The coefficient on investment in schooling (proxied using an estimate of the average percentage of the working-age population enrolled in secondary school) is found to be positive and significant, suggesting that international differences in income per capita can be explained, at least in part, by the introduction of education in the growth estimation.

Similarly, Barro (1991) examines the economic growth experience of a cross-section of 98 countries (including 40 SSA countries) from 1960 to 1985 . He tests both neoclassical and endogenous growth theories and one of his main findings of his analysis, from the neoclassical model, is that the growth rate of real per capita GDP is positively related to initial human capital (proxied by 1960 primary and secondary school enrolment rates). Results suggest that poor countries tend to catch up with rich countries if the poor countries have high human capital per person (in relation to their level of per capita GDP) but not otherwise.

However, by mid-1990s, several studies challenged the landmark results. For example, Benhabib and Spiegel (1994), building on Nelson and Phelps (1966), use a cross-country sample (including around 40 SSA countries) from 1965 to 1985 and show that education does not have a direct effect on economic growth but instead operates indirectly through its effect on productivity and technological diffusion. Consequently, while they find that there is a positive relationship between human capital and economic growth, they 
challenge the traditional role of human capital as a separate production factor contributing to growth. They propose an alternative approach based on endogenous growth theory in which education influences innovative capacity and growth, but only for the richest countries. In the poorest countries, the catch-up effect plays a bigger role, which education affects indirectly. The effect of education on growth thus varies according to a country's level of development.

Pritchett (2001) also questions the earlier optimism about the effect of education on growth. His cross-national analysis shows that on average, growth of educational capital per worker (derived using two measures of educational attainment including Barro and Lee, 1993) contributed much less to growth than is expected in the standard augmented Solow model. His estimated coefficient on educational capital per worker is negative (and statistically significant in a number of specifications). The negative coefficient estimate on educational capital per worker persists in alternate specifications including when SSA countries are excluded from the sample. He provides three possible explanations for this finding: poor political and institutional environments, excess supply of educated labour and low educational quality.

In addition, studies began to raise concerns regarding the econometric approaches used in the initial studies of education and economic growth. In earlier studies, causality is predicted to run from human capital investment to economic growth, however, the reverse direction is equally plausible as higher rate of economic growth can induce increased investments in education. For example, Bils and Klenow (2000) provide evidence of the endogeneity of school attainment in growth models. Using evidence from the labor literature and historical attainment data from UNESCO $(1977,1983)$ they calibrate a 
model to determine how much of the relationship describes causality running from schooling to growth. They argue that the relationship between schooling and growth is too weak to plausibly explain most of the observed relationship.

Another issue is dynamic misspecification in that investment in education may have a sizeable effect on economic growth over many years. Individuals usually work for many decades after school before the effect of human capital investment on economic growth unfolds. Specifying the wrong lag length may yield misleading estimates. However, increased availability of time-series databases (for example, Barro \& Lee, 1993, 1996, 2001; and Cohen and Soto, 2007) with measures of human capital have helped mitigate the effect of this issue.

The literature since 2000 has primarily focused on two of the arguably most serious econometric issues that plague the relationship: measurement error and omitted variable bias. Krueger and Lindhal (2001) investigate the apparent contradiction between microeconomic studies in labour economics, which generally show sizeable returns to education, and macroeconomic studies of growth, which sometimes find little or no relationship between education and economic growth. They focus on measurement error in the education variable in macroeconomic studies and suggest that both the initial stock of human capital and the change in that stock over time are positively correlated with economic growth.

Cohen and Soto (2007) also address the problems of measurement error by using a new education database for years of schooling across countries between 1960 and 2000 . The data set consists of 95 countries including 26 countries in SSA. The improved data 
produce significant effects of education on economic growth for countries included in their panel data estimation. Their results suggest that reducing measurement error in education variables yields results that show significant effects of education on economic growth.

Of relevance in the recent literature is the issue of omitted variable bias resulting from the exclusion of an important variable: education quality. The importance of accounting for the quality of education was raised in earlier studies. For example, Barro (1991) measures differences in the quality of education across countries using data on studentteacher ratios in the initial year, 1960. However, earlier studies tended to measure quality indirectly, using educational input measures. What is novel about studies such as Hanushek and Kimko (2000) is the direct measure of quality of education using outcome measures, specifically assessment scores.

Benos and Zotou (2014) examine the relationship between education and economic growth and apply a meta regression analysis to 57 empirical studies. They also do not find a consistent effect of education on economic growth and suggest that the effect is nuanced and dependent on several factors (including adopted education measures, type of data and model specification). With respect to educational quality, they note that

The lack of education quality data in most studies considering the relationship between education and growth may be the biggest challenge in this area of research. The quantity of education is an inadequate measure of human capital differences, since school systems vary across countries in terms of resources, organization, and duration (p.672).

Hanushek and Kimko (2000) use data on similar mathematics and science test scores from six international assessments for over 30 countries (including two SSA 
countries). They construct normalized test scores and use the results as measures of labour force quality on economic growth from 1960 to 1990 . They show that the inclusion of the quality measure causes the coefficient on the quantity of schooling variable to lose its statistical significance. In other words, the effect of cognitive skills, i.e. educational quality, is more important than the effect of years of schooling on economic growth.

Hanushek and Woessmann (2008) expand the results of Hanushek and Kimko (2000) using the expanded Cohen-Soto years of education data, updated test scores data, and a longer time period (1960 to 2000). They confirm the findings of Hanushek and Kimko (2000) in that their results show that the coefficient on the included measure of schooling quantity loses its significance when the quality of schooling is accounted for. Their results also hold when regional dummy variables and two policy variables (trade openness and protection of property rights) are included. In addition, the results hold when the sample is limited to developing countries. Similarly, the analysis in Barro and Lee (2015) generally finds a positive effect of educational quality on economic growth, when average number of schooling years is controlled for.

To summarize the general literature, earlier studies use cross-country data and generally show that the quantity of education is positively related to economic growth, though a few studies find little, zero or even a negative association. Some studies did attempt to explore the effect of quality of schooling but it was often not a primary consideration of earlier studies. More recent studies have been focused on addressing the omitted variable bias and measurement error in the literature by accounting for the effect of educational achievement on economic growth. While these studies are based on international 
assessments that only include a handful of SSA countries, they generally show that the quality of education matters more than the quantity of education. Recent evidence of the relationship between cognitive skills and economic growth suggest strong returns within developing countries. Barro and Lee (2015) note that the magnitude of the estimates from available evidence suggest that educational quality concerns are real for developing countries.

The African growth literature typically focuses on a number of different explanatory variables; for example, ethnic diversity (Easterly and Levine, 1997) and geography and demography (Bloom and Sachs, 1998). Hoeffler (2002) uses panel data to examine Africa's growth performance using an augmented Solow model. Although the paper does not emphasize the effect of education, it does include a measure of the quantity of education as one of the regressors. The coefficient on the schooling variable is generally not significant and is negative in two of the five specifications. The author concludes that the augmented Solow model can account for low growth in SSA provided that unobserved country specific effects and the endogeneity of investment are allowed in the estimation of the parameters of the model.

Only a handful of studies have explicitly examined the role of education. Bloom et al (2006) explore the role of higher education in promoting economic growth in SSA from 1960 to 2000 and suggest that increasing tertiary education may be important in promoting technological catch-up and improving a country's ability to increase economic output. Gyimah-Brempong, Paddison and Mitiku (2006) use panel data, from 1960 to 2000 , to investigate the effect of higher education on economic growth in African 
countries. The role of tertiary education is investigated using an expanded neoclassical growth equation similar to the one developed by MRW (1992). The authors' most relevant extensions are the use of an African only data set and the inclusion of three levels of education- higher, secondary and primary- as individual regressors. The measures of education are based on Barro \& Lee (2001) estimates of educational attainment (i.e. the average years of higher, secondary and primary education completed by the adult population in a country). Their results suggest that all levels of education have a positive and statistically significant effect on the growth rate of per capita income in African countries.

As far as I am aware, the only study that examined the effect of the quality of education on growth is Gleewe, Maiga and Zheng (2014). The main focus of the study is to highlight recent studies on the effect of education on economic growth and present new estimates using SSA data. This study also attempts to use test score results to show that Africa's poor performance in economic growth is due in part to low education quality. However, their analysis is based on a single measure of educational quality, the results of the 2003 Trends in International Mathematics and Science Study which only includes three SSA countries.

The most relevant study on education quality is from the Latin American literature. Hanushek and Woessman (2012) examine Latin America's economic development puzzle: the lagging economic growth in the region despite relatively high initial growth and school attainment levels. They argue that level of educational achievement is extremely important for long-term growth. Educational achievement is measured using regional 
assessment results for the Labratorio Latinoamericano de Evaluacion de la Calidad de la Educacion (LLECE) and the Segundo Estudio Regional Comparativo Explicativo (SERCE) allowing for the inclusion of 16 Latin American countries into the analysis.

The tests are "spliced" into the worldwide assessments. The initial results show that economic growth during the studied time frame was significantly lower in Latin America than in the rest of the world. However, once differences in educational achievement are taken into consideration, the results suggest that Latin American countries do not show significantly lower long-run growth than the rest of the world. In fact, in the basic specification, test scores that are larger than one standard deviation or 100 PISA points are associated with an average annual growth rate in GDP per capita that is about 1.95 percentage points higher during the entire 40-year period. Further, the coefficient on years of schooling loses its significance and drops close to zero once educational achievement is accounted for, supporting the assertion that educational quality is a more important driver of economic growth. They then run the extended version using regional test results, and the results are similar to the analysis on the worldwide test. The novelty of this study is the introduction of regional test assessment into the analysis of worldwide growth performance.

From this review, it is apparent that a crucial gap remains in the SSA literature in explaining the effect of educational quality on economic growth that is based on robust regional data. Therefore, the goal of this paper is to contribute to the SSA growth literature by presenting evidence of the central role of educational achievement in economic development. This objective will be achieved by applying the metrics developed in 
Chapter one to conduct a more in-depth analysis of the role of cognitive skills on economic growth in SSA.

\subsection{Adopted Theoretical Model}

The neoclassical model predicts that each country will converge to its own steady state and that the speed of the convergence relates inversely to the distance from the steady state. In other words, the model predicts "conditional convergence" in the sense that a lower starting value of income tends to generate higher growth rate, once other determinants of the steady state have been controlled for.

In endogenous growth models, there is no steady-state level of income; differences among countries in income per capita can persist indefinitely, even if the countries have the same saving and population growth rates.

Coulombe and Tremblay (2009), provide a summary of the difference between the two models, neoclassical ("level approach") and endogenous growth ("growth approach"), with respect to education:

According to the level approach (Lucas, 1988, and Mankiw et al., 1992), human capital is modelled as an input in the production function and has a level effect on output. In this approach, only continuous improvements in education will exert a sustained effect on the growth rate of output in the long run. In the growth approach, often referred to as the Nelson and Phelps (1966) approach, education is an essential input in the innovation process. Consequently, an increase in education level increases innovation and the long-run growth rate of the economy (p.6).

A model based on a direct and level effect of education on economic growth is more consistent with a study of cross-country income growth as such the neoclassical theory 
is chosen as the theoretical framework for this paper. The selection does not imply that the neoclassical model provides a complete theory of growth; rather, it simply provides a more appropriate explanation for the main research question in this chapter.

\subsection{Theoretical Framework}

This section provides a brief synopsis of the theoretical framework adopted for this analysis.

\subsubsection{Theory}

The human capital-augmented Solow model of economic growth derived by MRW (1992) is the theoretical framework for this research. The model assumes a neoclassical, CobbDouglas, aggregate production function with production at time $t$ given by:

$$
Y(t)=K(t)^{\alpha} H(t)^{\beta}[A(t) L(t)]^{1-\alpha-\beta}
$$

Where: $\mathrm{Y}$ is output, $\mathrm{K}$ is capital, $\mathrm{L}$ is labour, $\mathrm{A}$ is the level of technology (i.e. labour productivity), and $\mathrm{H}$ is the stock of human capital.

The same production function is assumed to apply to human capital, physical capital and consumption. Human capital is assumed to depreciate at the same rate, $\delta$, as physical capital. ${ }^{38}$ Decreasing returns is assumed to apply to all capital (i.e. $\alpha+\beta<1$ ). Also, the rates of saving, population growth, and technological progress are assumed to be exogenous.

\footnotetext{
${ }^{38}$ Physical capital and human capital are typically assumed to depreciate at the same constant rate as it
} helps simplify the algebra. 
The two inputs, $L$ and $K$, are expected to be paid their marginal products. $L$ and $A$ are assumed to grow exogenously at rates $n$ and $g$ given by:

$$
\begin{aligned}
& L(t)=L(0) e^{n t} \\
& A(t)=A(0) e^{g t}
\end{aligned}
$$

Therefore, the number of "effective" units of labour (also referred to in the literature as "effective worker" or "productivity- augmented worker"), A(t)L(t), grows at rate $n+g$.

The model assumes that a fraction of income: $\mathbf{s k}_{\mathrm{k}}$, is invested in physical capital; and $\mathbf{S h}$, is invested in human capital. Therefore, the evolution of the economy is governed by:

$$
\begin{gathered}
\dot{k}(t)=s_{k} y(t)-(n+g+\delta) k(t) \\
\dot{h}(t)=s_{h} y(t)-(n+g+\delta) h(t)
\end{gathered}
$$

Where: $\mathrm{y}=\mathrm{Y} / \mathrm{AL}, \mathrm{k}=\mathrm{K} / \mathrm{AL}, \mathrm{h}=\mathrm{H} / \mathrm{AL}$ are quantities per effective unit of labour, and $\delta=$ depreciation rate.

Model also assumes that $g$ and $\delta$ are exogenous and constant across countries: $g$ reflects knowledge advancement which is expected to be equal across countries; and depreciation rate, $\delta$, is assumed to not vary across countries. Given both $\mathrm{g}$ and $\delta$ are assumed to be constant, then it is expected that the sign of $n+g+\delta$ is negative as the only variable factor is $\mathrm{n}$. According to the model, high population growth lowers income per capita as both physical and human capital would need to a distributed across a larger population. 
On the other hand, $\mathrm{A}(0)$ captures technology progress and additional factors including resource endowments, climate and institutions which are expected to differ across countries:

$$
\ln A(0)=a+\epsilon
$$

Where: $a$ is a constant and $\epsilon$ is a country-specific shock.

In a steady-state, physical and human capitals per effective worker are constant. The steady- state conditions from equations ( $4 a$ and $b$ ) along with the production function are used to derive the economy's steady state. Substituting the steady state values back into the production function and taking logs results in:

$\ln \left[\frac{Y(t)}{L(t)}\right]=\ln \mathrm{A}(0)+\mathrm{gt}-\frac{\alpha+\beta}{1-\alpha-\beta} \ln (\mathrm{n}+\mathrm{g}+\delta)+\frac{\alpha}{1-\alpha-\beta} \ln \left(s_{k}\right)+\frac{\beta}{1-\alpha-\beta} \ln \left(s_{h}\right)$

Capital share in income, $\alpha$, is estimated to be roughly one third and model implies an elasticity of income per capita with respect to saving rate of approximately 0.5 and an elasticity with respect to $\mathrm{n}+\mathrm{g}+\delta$ of approximately -0.5 . Saving rate and population growth are assumed to be independent of country-specific factors shifting the production function, i.e. $s$ and $n$ are independent of $\epsilon$.

Given the goal of this analysis is to examine cross-country differences in income growth, it is necessary to transform equation (5) from a level equation to a growth equation. The Solow model prediction on the growth of an economy is based on out-of-steady state dynamics and conditional convergence, the prediction that countries reach different 
steady states and converge only after all determinants of their steady state have been controlled (MRW, 1992).

The speed of convergence is given by:

$$
\frac{d \ln (y(t))}{d t}=\lambda\left[\ln \left(y^{*}\right)-\ln (y(t))\right]
$$

Where: $\lambda=(n+g+\delta)(1-\alpha-\beta)$ and $y^{*}$ is the steady state output per effective worker

Equation (6) implies an out-of-steady-state dynamics such that:

$$
\ln (y(t))=\left(1-e^{-\lambda t}\right) \ln \left(y^{*}\right)+e^{-\lambda t} \ln (y(0))
$$

Where: $y(0)$ is the income per effective worker at an initial date.

Subtracting $\ln (\mathrm{y}(0))$ and substituting for $\mathrm{y}^{*}$ gives:

$$
\begin{aligned}
\ln (y(t))-\ln ( & y(0)) \\
& =\left(1-e^{-\lambda t}\right) \frac{\alpha}{1-\alpha-\beta} \ln \left(s_{k}\right)+\left(1-e^{-\lambda t}\right) \frac{\beta}{1-\alpha-\beta} \ln \left(s_{h}\right) \\
& -\left(1-e^{-\lambda t}\right) \frac{\alpha+\beta}{1-\alpha-\beta} \ln (n+g+\delta)-\left(1-e^{-\lambda t}\right) \ln (y(0))
\end{aligned}
$$

Equation (8), commonly referred to as the augmented Solow model, implies that the growth of income is a function of steady state determinants and the initial level of income. In addition to MRW (1992) cross-sectional analysis, this equation has also been used as the framework of panel analysis of growth empirics for example, Islam (1995) and Hoeffler (2002). 
This equation is the foundation of the analysis in this paper and is used to investigate whether real income is higher in countries with higher saving rate and lower in countries with higher values of $n+g+\delta$. More importantly, this equation is used to investigate whether real income is higher in countries with higher human capital accumulation.

\subsection{Model}

The augmented Solow model speaks to the importance of accounting for initial income, population growth, physical and human capital investments in a model of economic growth. However, it is also important to account for specificities of the countries located within SSA. Accordingly, an additional variable, resource dependency is added to the model.

\subsubsection{Human Capital Investment}

Human capital investment is measured using two proxies intended to capture both the role of educational quality as well as educational quantity in promoting economic growth. Educational quality is measured using two quality indicators developed in Chapter one:

- The primary measure is the Combined Assessment Score (CAS) which is a combination of the average numeracy and literacy scores from MLA, PASEC and SACMEQ data; and

- The Combined Numeracy Score (CNAS) which is a combination of mathematics (PASEC and SACMEQ) and numeracy (MLA) assessment scores. ${ }^{39}$

\footnotetext{
${ }^{39} \mathrm{~A}$ third measure, the Combined Literacy Scores which is a combination of reading English/French (SACMEQ and PASEC) and English reading and writing (MLA) is also developed in the chapter. See Chapter one for more information.
} 
The adopted educational quantity variable is intended to capture the stock of human capital available at each level for production. Consequently, the rate of human capital investment is measured as the average years of schooling for the working population. Given that measure of educational quality is based on achievement tests conducted at the primary level, the comparable measure educational quantity variable, average years of schooling at the primary level is used in the analysis.

The use of educational measures at the primary level in an analysis of economic growth is justified to a large extent as it is consistent with research in this area. Nonetheless, it is important to keep in mind that approach used to measure educational quality has a number of limitations. These limitations include a failure to capture the effect of: additional social benefits that likely accrue to the society from higher educational attainment; the proportion of the educated population that are employed; and the emigration of educated persons.

\subsubsection{Resource Dependency}

Two types of countries are considered, resource dependent countries and non-resource dependent countries. Accounting for resource dependency is particularly crucial as it is expected that the standard growth model will not account for measured GDP in those countries. In line with Thomas and Treviño (2013), resource dependent countries are defined as those countries where natural resource exports (agricultural raw materials, 
fuel, ore and metals) exceed 25 per cent of average total merchandise export from 1960 to 2010. SSA countries deemed to be resource dependent are identified in Table A2 in the Appendix.

It is therefore expected that: 1) there would be a significant difference in the mean of per worker income of the two samples; and 2) the average per worker income in resource dependent countries will be less correlated with measures of educational quality and educational quantity.

Before testing the first hypothesis, a variance ratio $\mathrm{F}$ test for equal variance is conducted. Based on the F statistic, I fail to reject the null hypothesis of equal variance ratio at the 0.05 significance level. A two-sample t-test with equal variance is then conducted and I also fail to reject the null hypothesis of equal means at the 0.05 significance level. In other words, the difference in mean income per worker, though higher for resource dependent countries, is not statistically significant.

However, the conditional correlation between per worker income and the measures of educational quality and quantity are markedly lower for resource dependent countries. For example, the correlation between per worker income and educational quality is 0.29 and 0.66 for resource and non-resource dependent countries respectively. This difference in correlations lends some credence to existing evidence of the role of natural resources in distorting traditional channels of economic growth. As such, a resource dependency dummy variable is added to the model. 


\subsubsection{Estimated Equation}

Accordingly, the modified version of equation (8) estimated in this analysis is:

$$
\begin{aligned}
\ln (y(t))-\ln & (y(0)) \\
& =\beta_{1}+\beta_{2} \ln (y(0))+\beta_{3} \ln \left(s_{k}\right)+\beta_{4} \ln (n+g+\delta)+\beta_{5} \ln \left(s_{h}^{\text {quality }}\right) \\
& +\beta_{8} \ln \left(l s_{h}^{\text {quantity }}\right)+\beta_{9} \text { resource }+u
\end{aligned}
$$

Where: $y(0)$ initial income per effective worker, $s_{k}$ is physical capital investment, $n+g+\delta$

adjusted population growth rate, $s_{h}^{\text {quality }}$ educational quality, $s_{h}^{\text {quantity }}$ education quantity and resource is a dummy variable for resource dependency.

In accordance with the empirical literature, it is expected that the estimated coefficients on: $s_{k}, s_{h}^{\text {quality }}$, and $s_{h}^{\text {quantity }}$, resource will be positive; $n+g+\delta$, and $y(0)$ (provided conditional convergence holds for SSA) will be negative.

\subsubsection{Estimated Approach}

The analysis is approached on two fronts. First, the widely adopted cross-sectional approach for studying economic growth is used to derive a baseline which is compared to prevailing evidence and theory. However, this approach has some limitations. First, utilizing a single (average) observation masks important cross-sectional and temporal variations that exist between and across countries.

Second, cross-section regressions are more likely to suffer from omitted variable bias as they do not accommodate differences in initial levels of technology across countries allowing the error term to be correlated with one or more of the included explanatory variables. 
Finally, one or more of the independent variables are likely to be endogenous. Barro and Lee (2000) note that education increases with the level of per capita income across countries and through time for a given country, making education an endogenous variable. In addition, time-invariant country characteristics such as demographics are likely to be correlated with the explanatory variables.

Therefore, a panel data analysis is also conducted to mitigate the effect of these issues. Panel data provides a means of addressing: omitted variable bias, time and country effects, and endogeneity issues. The panel data approach for studying the relationship between education and income growth is consistent with the approach adopted in a number of studies including Islam (1995), Hoeffler (2002) and Gyimah-Brempong et al (2006).

Panel data is typically analysed using either the Fixed Effect (FE) or Random Effect (RE) model. The Hausman test is conducted to determine whether the FE or RE model is appropriate for this analysis. I fail to reject the null hypothesis at the 0.05 significance level meaning that the RE model is more likely to produce consistent estimates.

Given the unbalanced nature of the data set, the Breusch-Pagan Larange multiplier test for random effects is conducted to confirm the validity of the panel estimation approach. The result reveals no significant difference across units (i.e. no panel effect). As such, a pooled OLS model is also estimated to validate the results of the RE model. ${ }^{40}$

\footnotetext{
${ }^{40}$ A third estimation approach, Arellano-Bover/Blundell-Bond (Arellano and Bover 1995; Blundell and Bond 1998) was considered to enable the exploitation of intertemporal variation using lagged independent values. However, this approach is not estimated given the highly unbalanced nature of the data set.
} 


\subsubsection{Data and Sample}

The dependent variable is proxied using percent change in income per worker. According to the Solow model, it is more appropriate to use per worker income and the growth of the adult workforce (as opposed to per capita income and growth of the population) given that the model is based on a production function and not every person contributes to production.

This distinction is particularly important for SSA where the population growth rate has been on average higher than the growth of the working population. ${ }^{41}$ Per worker income is measured as the natural logarithm of the Real GDP per working age population (i.e. population aged 15 to 64 years).

The quality of human-capital is measured is the natural logarithm of CAS or CNAS. Given the cross-sectional nature of the quality measure, two additional explanatory variables found to be relatively strong predictors of educational quality in Chapter one are considered as instruments in the panel estimation. The results of the reduced model analysis in Chapter one suggests that two group of factors: family factors and school factors matter in determining educational assessment outcomes. However, the magnitude of each effect depends largely on the assessment subject used in the analysis.

\footnotetext{
${ }^{41}$ Hoeffler (2002) estimate a growth equation using both per worker and per capita values and the results did not appear to be sensitive to the choice of dependent variable. She concludes that the result may likely be due to data quality.
} 
For CAS, family effects (measured by adult literacy rate and GDP per capita) and school effects (measured by the percentage of trained primary school teachers) play a more important role in determining educational achievement. The adult literacy rate is included in the panel analysis as the only proxy for educational quality (due to larger data availability and to prevent the introduction of multicollinearity). The rate of human-capital accumulation is measured as the natural logarithm of the average number of years of primary education completed by the adult population (15 years or older). In the panel estimation, education quantity is measured at the beginning of a period.

Physical capital investment is measured using the natural logarithm of the gross capital formation as a percentage of GDP in a period. Similar to MRW (1992), technological progress and the depreciation rate are assumed to be constant across countries and sum up to $0.05 .{ }^{42}$ The adjusted working population growth is therefore the natural logarithm of the sum of the population growth rate of the working population and 0.05 . Initial income is measured as the natural logarithm of the real per worker GDP at the beginning of a period or the earliest year within the period for which data is available. ${ }^{43}$

Data on income, adult literacy, population, physical investment are obtained from the World Bank Development Indicators and the education quantity data is obtained from

\footnotetext{
42 The chosen value of depreciation is critical to the estimation and is chosen by MRW (1992) to match available data; Romer (1989) uses a larger sample size and derives a comparable estimate. While it is possible to validate the value, such a validation would be difficult given the issue of data availability for SubSaharan African countries.

${ }^{43}$ For countries with missing income information for 1960, estimates for as late as 1980 are used.
} 
Barro and Lee (2010). Additional information on the source, definition and description of each variable is provided in Table C1 in Appendix C.

Additional explanatory variables explored for possible inclusion to the model include the trade per cent of GDP, agriculture value added (as a per cent of GDP), HIV prevalence and foreign aid dependency. However, these variables are not added to keep the model parsimonious due to the small sample size.

The first stage, cross-sectional analysis, is based on a data set with 18 countries (due to data availability) averaged over 1960 to $2010 .{ }^{44}$ Ideally, the second stage, panel analysis, should include all 48 SSA countries with data from 1960 to $2010 .{ }^{45}$ In accordance with the practice in the empirical growth literature, and to avoid the undue influence of temporary shocks, a five-year average of each variable is taken and ought to result in 10 time periods and 480 observations. However, data are not available for all variables, for all countries and for all ten periods, so the data set is an unbalanced panel and a total of 59 country-years of data are included in the panel and pooled OLS regressions limiting the generalizability of the results.

\footnotetext{
${ }^{44}$ Full list of countries available in Table C.2 in Appendix C.
}

${ }^{45}$ Full list of countries available in Table C.2 in Appendix C. 


\subsection{Cross-Section Regression Analysis}

Summary statistics of the explanatory variables are presented in Table 16 and generally shows a marked variation in range of performance on various indicators across SSA countries.

Table 16: Descriptive Statistics

\begin{tabular}{|l|c|c|c|c|c|}
\hline Variable & Mean $^{*}$ & Std. Dev & Minimum & Maximum & N \\
\hline $\begin{array}{l}\text { Real GDP per worker } \\
\text { (2000 US\$) }\end{array}$ & 2,902 & 3,471 & 429 & 18,138 & 47 \\
\hline $\begin{array}{l}\text { Initial income (2000 } \\
\text { US\$) }\end{array}$ & 2,031 & 2,028 & 361 & 8,740 & 39 \\
\hline Capital formation (\%) & 20 & 10 & 0 & 69 & 47 \\
\hline $\begin{array}{l}\text { Working Population } \\
\text { growth (\%) }\end{array}$ & 3 & 0.4 & 2 & 3.52 & 48 \\
\hline CAS & 46 & 9 & 25 & 62.56 & 33 \\
\hline $\begin{array}{l}\text { Total number of primary } \\
\text { school (years) }\end{array}$ & 1 & 1 & 0.1 & 3.43 & 32 \\
\hline Adult Literacy Rate & 55 & 21 & 19 & 89.46 & 46 \\
\hline $\begin{array}{l}\text { Trained Primary } \\
\text { Teachers }\end{array}$ & 75 & 18 & 37 & 100 & 41 \\
\hline
\end{tabular}

*unweighted averages

Prior to running the regressions, a series of tests are conducted. First, the normality condition of the dependent variable is examined. The Shapiro-Wilk test (considered more appropriate for small samples) is conducted and the result shows that the dependent variable is normally distributed. More importantly, the Shapiro-Wilk test is also conducted on the residuals and not surprisingly, the result show that the residuals are also normally distributed.

Second, the presence of multicollinearity is detected by examining the Variance Inflation Factors (VIF). When high multicollinearity is present, coefficients of explanatory variables 
will have to be larger in order to be statistically significant. Multicollinearity is deemed to not be of concern as all VIFs are less than 5 (and all Tolerances are greater than 0.20 ). ${ }^{46}$

Finally, the presence of heteroscedasticity is detected using Breusch-Pagan test. Testing for heteroscedasticity is crucial as statistical inference (i.e. t-test and F-test) is based on the assumption of homoscedasticity. I fail to reject the null hypothesis of homoscedastic error terms at the 0.05 significant level. Accordingly, reported standard errors are not corrected for heteroscedasticity. Based on the results of the tests, OLS is expected to be BLUE. The results of the regressions are presented in Table 17.

The estimation begins with the augmented Solow model which includes only initial income to test the convergence prediction of the Solow model. The result is presented in Column 1. The second column presents the result with educational quantity. The third column provides the results with educational quality and the final column contains the full model.

The result with initial income per capita as the only regressor cannot be reported due to the low predictive power of the model (i.e. unable to reject the null hypothesis of the Ftest). In Column 2, the estimated coefficient on the initial level of income is negative, though it is not at all close to being statistically significant. In other words, there is no significant tendency for poor SSA countries to conditionally converge and grow faster on average than their richer SSA counterparts.

\footnotetext{
${ }^{46} \mathrm{~A}$ smaller threshold for VIF and tolerance is used than the more widely used cut-off (10 and 0.10 respectively) because of the small sample size.
} 
The coefficient on adjusted population growth is also negative and is statistically significant at the 0.01 level. The results suggest that, over the 40 -year time-period, a one per cent increase in the adjusted population is estimated to decrease growth by approximately seven per cent. The coefficients on physical capital investment and resource dependency both have the expected positive signs but only the coefficient estimate of the former is statistically significant at the 0.01 level. Over the 40 -year period, a one per cent increase in physical capital investment is estimated to increase growth by around six per cent. The hypothesis associated with human capital theory receives no support from the estimation as the coefficient on educational attainment, while positive, is not statistically significant at conventional testing levels.

The specification with the educational quality measure presented in Column 3 did not result in any changes to the sign and significance level of the coefficients on initial income, physical capital formulation, adjusted population or resource dependency dummy. Most importantly though, the sign of the coefficient estimates on the CAS variable, while positive, is also not statistically significant at conventional testing levels.

The full model results presented in Column 4 is consistent with the previous two model specifications with respect to initial income, physical capital accumulation, adjusted population and resource dependency. Also, the coefficients on both measures of education remain positive, but are still not statistically significant at conventional testing levels. ${ }^{47}$

${ }^{47}$ Both measures of education are interacted with the resource dummy variable. The results suggest a higher intercept for resource dependent countries and lower slope for resource dependent countries 
Overall, these results are generally in line with existing research and support existing evidence of the positive contribution of physical capital accumulation to economic growth in SSA. The results also highlight the negative effect of population growth on the growth capacity of an economy. Most importantly though, the results do not provide strong evidence of the importance of both educational quality and quantity in promoting growth. However, the low power of the regressions is arguably due to the small sample size of the data. As such, the next phase of the research involves conducting a panel data analysis, intended to strengthen the results by using a relatively larger sample size.

(given similar levels of educational quantity or quality). However, none of the results are statistically significant at conventional testing levels and the explanatory power of the model is also not improved so these results are not reported. 
Table 17: Cross-Sectional OLS Regression Results

\begin{tabular}{|l|c|c|c|c|}
\hline Dependent Variable & \multicolumn{4}{|c|}{ In(GDP per working population 2010)- In (GDP } \\
& per working population 1960) & \\
\hline & $(\mathbf{1})$ & $\mathbf{2})$ & $\mathbf{3})$ & $\mathbf{( 4 )}$ \\
\hline Ln(Initial Income) & 0.56 & -0.18 & -0.08 & -0.21 \\
& $(1.62)$ & $(-0.85)$ & $(-0.46)$ & $(-0.97)$ \\
\hline Ln(CAS) & & & 0.50 & 0.64 \\
& & & $(0.64)$ & $(0.82)$ \\
\hline Ln (Total number of primary & & 0.43 & & 0.50 \\
school, years) & & $(0.91)$ & & $(1.03)$ \\
\hline Ln(Physical Capital & & $5.71^{* * *}$ & $5.87^{* * *}$ & $5.51^{* * *}$ \\
Formation) & & $(7.34)$ & $(7.84)$ & $(6.71)$ \\
\hline Ln(Adjusted Working & & $-7.47^{* *}$ & $-6.24^{* *}$ & $-7.12^{* *}$ \\
Population) & & $(-2.84)$ & $(-2.43)$ & $(-2.63)$ \\
\hline Resource Dependency & & -0.43 & -0.59 & -0.28 \\
& & $(-1.00)$ & $(-1.59)$ & $(-0.59)$ \\
\hline Constant & 2.67 & $-28.57^{* * *}$ & $-28.01^{* * *}$ & $-29.45^{* * *}$ \\
& $(1.05)$ & $(-4.17)$ & $(-4.06)$ & $(-4.19)$ \\
\hline $\mathbf{R}^{2}$ & $\mathbf{0 . 1 4}$ & $\mathbf{0 . 8 8}$ & $\mathbf{0 . 8 8}$ & $\mathbf{0 . 8 9}$ \\
\hline Adjusted R & $\mathbf{0 . 0 9}$ & $\mathbf{0 . 8 4}$ & $\mathbf{0 . 8 3}$ & $\mathbf{0 . 8 3}$ \\
\hline F-statistic & $\mathbf{2 . 6 3}$ & $\mathbf{1 8 . 3 1}$ & $\mathbf{1 7 . 6 4}$ & $\mathbf{1 4 . 9 4}$ \\
& $\mathbf{0 . 1 2}$ & $\mathbf{( 0 . 0 0 )}$ & $\mathbf{( 0 . 0 0 )}$ & $\mathbf{( 0 . 0 0 )}$ \\
\hline $\mathbf{N}$ & $\mathbf{1 8}$ & $\mathbf{1 8}$ & $\mathbf{1 8}$ & $\mathbf{1 8}$ \\
\hline
\end{tabular}

Note: t-statistic reported in parentheses except F-statistic where p-values are reported. Two-tailed p-values: * significant at 0.1 level; ${ }^{* *}$ significant at the 0.05 level; ${ }^{* * *}$ significant at 0.01 level.

\subsection{Panel Regression Analysis}

A series of tests are conducted prior to running the panel and pooled regressions. A test for heteroscedasticity is performed using a Modified Wald test for group wise heteroscedasticity. The null hypothesis of homoscedastic error terms is rejected at the 0.01 significant level. Therefore, all reported standard errors are corrected for 
heteroscedasticity. A general form of correction is applied and the "robust" command is used to correct the regression standard errors for heteroscedasticity.

A test for serial correlation, autocorrelation, is also conducted. Autocorrelation is more of a concern for macro panels with relatively long time series, where it causes standard errors of the coefficients to be small and $R^{2}$ to be high. The function, xtserial, which implements Wooldridge (2002) test for serial correlation in panel data, is conducted. Based on the results, I fail to reject the null hypothesis of no first-order autocorrelation at the 0.10 level.

Finally, the presence of a unit-root is determined. A stationary dependent variable minimises the possibility of capturing spurious relationships. In addition, if variables are not stationary, then standard assumptions for analysis will not likely be valid. For example, t-ratios will not follow a t-distribution so it will not be possible to undertake hypothesis testing on the regression coefficients. The presence of a unit-root is determined using the Fisher test. The Fisher test is based on an augmented Dickey-Fuller test and is chosen because it does not require a balanced panel. The null hypothesis is rejected at the 0.01 significance level; at least one of the included country panels is stationary. ${ }^{48}$ Under the random effects assumptions, the estimator is expected to be consistent, not unbiased and asymptotically normally distributed as the sample size increases over a finite time period.

${ }^{48} \mathrm{Admittedly,} \mathrm{the} \mathrm{Dickey-Fuller} \mathrm{test} \mathrm{is} \mathrm{relatively} \mathrm{weak} \mathrm{but} \mathrm{the} \mathrm{unbalanced} \mathrm{nature} \mathrm{of} \mathrm{the} \mathrm{data} \mathrm{makes} \mathrm{it}$ difficult to run alternate panel unit root tests (including the Breitung, Harris-Tzavalis and Levin-Lin-Chu). 
The results of the panel regressions are presented in Table 18. Similar to the crosssectional results, the first column presents the results of the test of convergence prediction of the Solow model with initial income as the only explanatory variable. The second column presents the results of the model with the measure of educational quantity. The third contains the results of the regression with educational quality's proxy. The fourth is the full model and includes all explanatory variables.

All panel regressions include time dummies. While some of the coefficients of the included time dummies are statistically significant at the 0.1 level of significance, all estimated coefficients are not reported to conserve space. The result of the panel regression with the log of initial income per capita as the only regressor in Column 1 is consistent with the cross-sectional analysis as the coefficient is also positive but is now statistically significant at the 0.05 level. In other words, not only is there no evidence of a tendency for poor SSA countries to grow faster on average than their rich SSA counterparts, there is now evidence of conditional divergence.

Column 2 presents the results with the educational quantity measure included along with other key variables of the model. The coefficient on initial income remains positive but is no longer statistically significant at conventional levels. The coefficient estimate for the variable measuring physical investment is also positive and is statistically significant at 0.05 level. A one per cent change in physical capital investment (across countries and time) is estimated to increase growth, on average, by around two per cent. This estimate is about four percentage points lower than the cross-section regression estimates. 
Also, similar to the cross-section results, the coefficient estimate on both the adjusted working population growth and resource dependency dummy are negative, however, only the coefficient on working population growth is statistically significant at the 0.05 level. A one per cent increase in adjusted population working population (across countries and time) is estimated to decrease growth, on average, by approximately five per cent (two percentage points lower than the cross-section analysis results). More importantly, the coefficient estimate on years of primary schooling is positive, though is also not statistically significant at conventional testing levels in this specification.

The results of the replacement of the educational quantity measure with the proxy for educational quality is presented in Column 3. The estimated coefficient on adult literacy rate is positive but is also not statistically significant at conventional testing levels. The signs and level of statistical significance of the other explanatory variable coefficients remain unchanged. The inclusion of both measures of educational quality and quantity in a single regression is presented in Column 4 and while the coefficients on both measures are positive, they are still not statistically significant at conventional testing levels. Again, the size and signs of the remaining explanatory variables remain consistent. Also, the explanatory powers remain relatively unchanged with the inclusion of the different education variables. ${ }^{49}$

\footnotetext{
49 The results of the pooled OLS regression are generally consistent with the panel and cross-sectional OLS regression results and so are not reported.
} 
Table 18: Panel Regression Results

\begin{tabular}{|l|c|c|c|c|}
\hline Dependent Variable & \multicolumn{4}{|c|}{ In(GDP per working population) } \\
\hline & $\mathbf{( 1 )}$ & $\mathbf{( 2 )}$ & $\mathbf{( 3 )}$ & $\mathbf{( 4 )}$ \\
\hline Ln(Initial Income) & $0.60^{* *}$ & 0.07 & 0.08 & 0.06 \\
& $(2.45)$ & $(0.29)$ & $(0.31)$ & $(0.24)$ \\
\hline Ln(Total number of & & 0.25 & & 0.14 \\
primary school, & & $(0.71)$ & & $(0.33)$ \\
years) & & & & \\
\hline Ln(Adult Literacy & & & 0.33 & 0.20 \\
Rate) & & & $(0.74)$ & $(0.36)$ \\
\hline Ln(Physical Capital & & $1.53^{* *}$ & $1.51^{* *}$ & $1.52^{* *}$ \\
Formation) & & $(2.49)$ & $(2.39)$ & $(2.38)$ \\
\hline Ln(Adjusted Working & & $-5.19^{* *}$ & $-5.12^{* *}$ & $-5.16^{* *}$ \\
Population) & & $(-2.42)$ & $(-2.43)$ & $(-2.43)$ \\
\hline Resource & & -0.15 & -0.14 & -0.13 \\
Dependency & & $(-0.38)$ & $(-0.34)$ & $(-0.32)$ \\
\hline Constant & & $-14.80^{* * *}$ & $-14.12^{* * *}$ & $-13.73^{* * *}$ \\
& & $(-2.80)$ & $(-2.57)$ & $(-2.30)$ \\
\hline $\mathbf{N}$ & $\mathbf{5 9}$ & $\mathbf{5 9}$ & $\mathbf{5 9}$ & $\mathbf{5 9}$ \\
\hline $\mathbf{R}^{\mathbf{2}}$ & $\mathbf{0 . 2 4}$ & $\mathbf{0 . 4 3}$ & $\mathbf{0 . 4 4}$ & $\mathbf{0 . 4 4}$ \\
\hline
\end{tabular}

Note: $t$ statistic reported in parentheses. Two-tailed p-value: * significant at 0.1 level; ${ }^{* *}$ significant at the 0.05 level; ${ }^{* * *}$ significant at 0.01 level. Adjusted $\mathrm{R}$ squared is produced for the random effect model.

Two possible alternative explanations for this result are investigated. First, the presence of an interaction between both educational measures may modify the results. The interaction effect reflects the notion that the quality effect on economic growth varies according to the quantity of education that exist within the country. The inclusion of an interaction term is also intended to capture the idea that the relationship between both measures of education and economic growth is not strictly additive. The coefficient on the interaction term in the Random Effect model is negative surprisingly suggesting that the effect of educational quality on economic growth decreases with higher level of 
educational quantity. However, the coefficient is not statistically significant at conventional testing levels. Also, its inclusion does not result in a change in the sign and significance of the other explanatory variables.

Second, and given the small sample size, there is a strong likelihood of outlier countries influencing the results. The residual plot for the full model regression is produced and interestingly, Mauritania, considered the most problematic outlier in Chapter one does not display a similar trait here. Accordingly, its exclusion did not significantly change the results or lead to a positive coefficient on the measure of education quantity. The exclusion of South Africa though, which appears to be the most influential outlier in Figure 15 , does changes the result slightly; the estimated coefficient on educational quality is now negative (although it is still not statistically significant at conventional testing levels). 
Figure 15: Full Regression Model Residual Plot

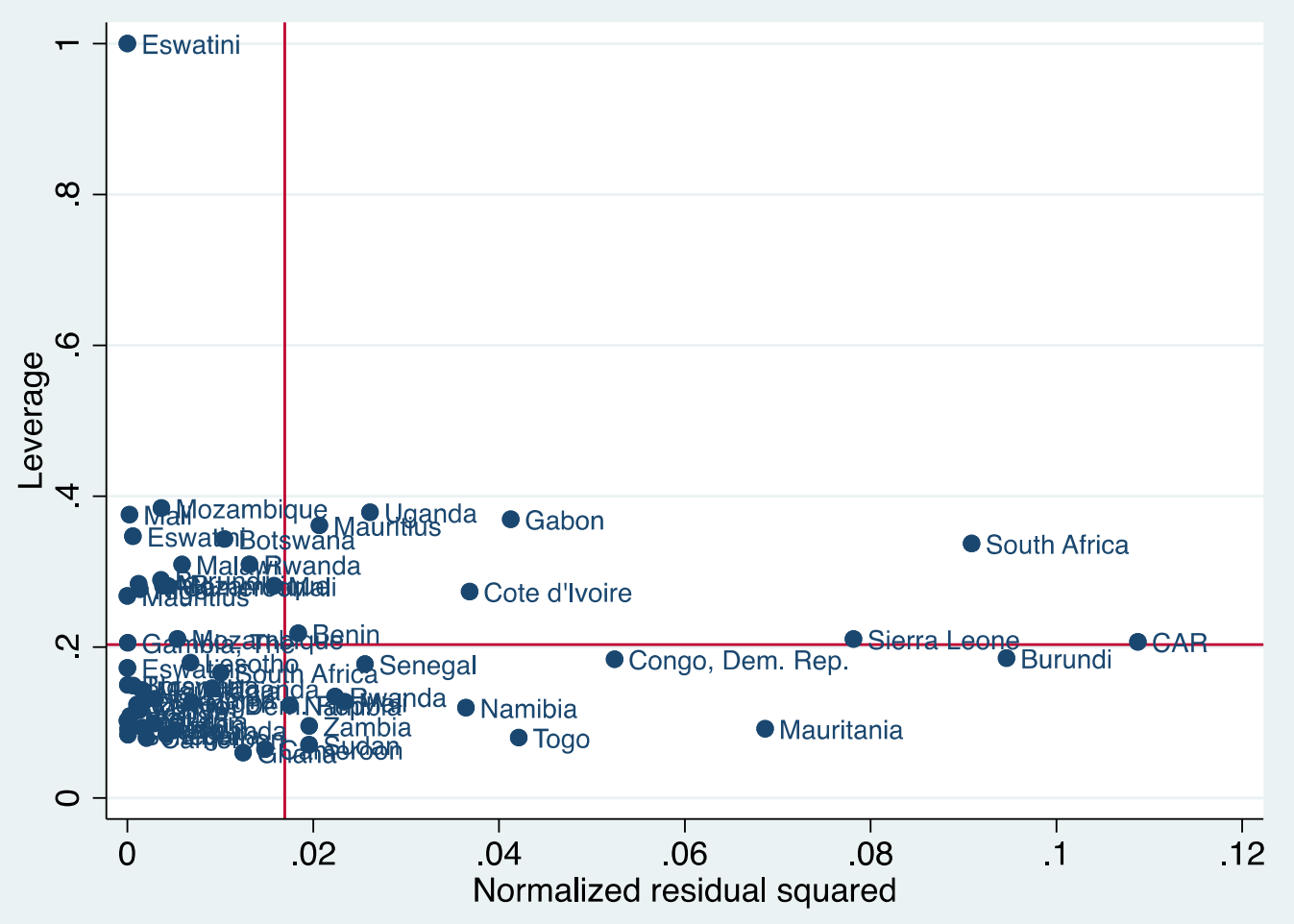

\subsection{Global Analysis}

A possible extension of the results is to emulate the approach adopted by Hanushek and Woessman (2012) and splice the regional results into the global assessment data. This extension challenges the fundamental premise of this study, i.e. that the relationship between education and economic growth in SSA is best understood within a regional context using assessments specifically designed for SSA countries. This extension is explored in the following section to better understand the extent to which a larger sample size and a more direct measure of educational quality can refine and strengthen the findings from the previous sections. 


\subsubsection{Educational Quality Measure}

This analysis is solely based on TIMSS data and only three SSA countries have ever participated in TIMSS: Botswana, Ghana, and South Africa. Due to data availability for SSA participants, only grade eight numeracy TIMSS results are spliced with CNAS data, derived from regional data in Chapter one. The comparison is deemed valid given that both assessments are curriculum-based. However, there is concern with respect to merging TIMSS grade eight results with CNAS grades four to six results. Like Hanushek and Woessman (2012), this concern is partly mitigated by assuming that the performance across grades within a country are consistent.

TIMSS numeracy data since inception to 2007 are used incorporating four iterations of the assessment. This time period roughly matches the time period of the regional assessments. Both Botswana and Ghana participated in 2003 and 2007 grade eight assessments and South Africa also participated in the grade eight assessments in 1995,1999 and 2003 . The performance of all three countries were generally consistent lending credence to the approach of utilizing the overall average over all four years.

Situating SSA's performance on an international scale involved a number of steps, same as those adopted by Hanushek and Woessman (2012) and similar to Chapter one. First, the derived average CNAS score is standardized to match the mean and standard deviation of the TIMSS scale. Next, the average CNAS score for each country is re-scaled based on the equalized average for TIMSS and CNAS scores for South Africa and 
Botswana. ${ }^{50}$ Also, the re-scaled CNAS results for South Africa and Botswana are used in place of their TIMSS results based on the idea that regional assessment results are more reliable for SSA than their international counterparts. For Ghana, the TIMSS result is used as regional data is not available.

The final step involves re-scaling the regional test scores such that scores of South Africa and Botswana in the regional and the global assessments have the same standard deviation. In other words, the distributional information of the regional assessment is replaced with the global assessment information while using the regional test scores to situate each SSA country within the region. Tables A2 and A3 in the Appendix provide the international and derived scores, respectively. The similarity between the final regional and international assessment scores for Botswana and South Africa is arguably due to the use of only data for both countries in the conversion. Table 20 presents the geographical distribution of the countries including 19 SSA countries. ${ }^{51}$

Table 19: Regional Distribution of Countries

\begin{tabular}{|l|c|c|}
\hline Region & Count & Per cent \\
\hline Sub-Saharan Africa & 19 & $31 \%$ \\
\hline Middle East and North Africa & 9 & $15 \%$ \\
\hline Latin America and Caribbean & 3 & $5 \%$ \\
\hline Europe and Central Asia & 20 & $32 \%$ \\
\hline East Asia and Pacific & 9 & $15 \%$ \\
\hline North America & 2 & $3 \%$ \\
\hline Total & $\mathbf{6 2}$ & \\
\hline
\end{tabular}

${ }^{50}$ Ghana was excluded as a benchmark country given the lack of CNAS data for the country.

51 The full list of SSA countries provided in Table C.2 in Appendix C. 
Equation (8) is modified by removing the resource dependency dummy as the variable is no longer relevant within the broader global context. Prior to estimating the equation, a series of tests are conducted. First, the presence of multicollinearity is examined using the Variance Inflation Factors (VIF). Multicollinearity is deemed to not be of concern for most variables as their VIFs are less than 10 (and all Tolerance are greater than 0.10 ).

Second, the presence of heteroscedasticity is tested for using the Breusch-Pagan test. I reject the null hypothesis of homoscedastic error terms at the 0.05 significant level. Accordingly, reported standard errors are corrected for heteroscedasticity. A general form of correction is applied and the "robust" command is used to correct the regression standard errors for heteroscedasticity. OLS remains unbiased in the presence of heteroscedasticity albeit is no longer BLUE.

The results of the regression are presented in Table 20. All regressions include regional dummy variables, with SSA being the excluded regional indicator and thus the base case. The result with initial income per capita as the only regressor also suggests a rejection of the income convergence hypothesis as the estimated coefficient on the variable is positive and statistically significant at the 0.10 level. In other words, not only is there is no evidence of a tendency for poor SSA countries to grow faster on average than their SSA rich counterparts, there is again evidence of conditional divergence with rich countries growing faster.

In Column 2, the estimated coefficient on the initial level of income becomes negative but it is no longer statistically significant. As in the SSA regional regressions, the coefficient estimate for adjusted population growth is also negative and statistically significant at the 
0.05 level. Over the 40 -year period, a one per cent increase in the adjusted population is estimated to decrease growth by around four per cent. The estimated coefficient on physical capital investment is positive and statistically significant at the 0.01 level. Again, over the 40-year period, a one per cent increase in physical capital investment is estimated to increase growth by around three percent. Size of the estimated coefficients on physical capital investment and adjusted population are lower in this specification compared to the regional cross-sectional regression (estimated coefficient on physical capital is about 50 per cent lower). The difference in magnitude is likely reflective of the differences in the dependent variable and sample composition.

More importantly, unlike the results of the regional analyses, the estimated coefficients on educational attainment is positive and now statistically significant at the 0.05 level. Over the 40-year period, a one per cent increase in educational quantity is estimated to increase growth by one per cent. Not surprisingly, the region dummy variable suggests that all included regions have a higher intercept, i.e. higher income per working population, compared to SSA, but the coefficient estimates are only statistically significant (at conventional testing levels) for Europe and Central Asia, East Asia and the Pacific and North America.

The specification with the educational achievement measure presented in Column 3 did not result in any changes to the sign and significance level of the coefficients on initial income, and physical capital formulation. Also, the sign of the estimated coefficient on adjusted population remains consistent albeit is no longer statistically significant at 
conventional testing levels. The sign of the estimated coefficient on the educational quality is positive, more than double the size of the estimated coefficient on educational quantity, and is statistically significant at the 0.01 level. Over the 40 -year period, a one per cent increase in test scores is estimated to increase growth by approximately three percent. This time, none of the regional dummies relative to SSA are statistically significant at conventional levels.

The full model results presented in Column 4 is consistent with the previous two model specifications with respect to initial income, physical capital accumulation and adjusted population. Also, the coefficients on both measures of education are positive and statistically significant at either 0.01 or 0.1 levels. The size of both coefficients remains generally consistent with the models where either variable is included. More importantly though, the size of the educational quality remains about three times larger than the educational quality variable supporting the assertion of its larger role in promoting economic growth. Also, the statistical significance of both measures of education suggests a joint and complementary role of both measures.

Finally, Column 5 presents the results with an education interaction term added to the full model. The inclusion of the interaction term has an impact on a number of explanatory variables. First, the effect of adjusted population though still negative but is no longer statistically significant at conventional testing levels. Also, the estimated coefficient on initial income is now negative but is still not statistically significant. More importantly though, the interaction term is positive and statistically significant (at the 0.1 level) 
suggesting that the greater the level of educational quantity, the stronger the effect of educational quality on growth. However, the estimated coefficients on both educational measures are now surprisingly negative (though only the educational quality coefficient is statistically significant at the 0.1 level).

Overall, these results are generally in line with existing research and the previous two specifications with respect to the positive contribution of physical capital accumulation to economic growth. The results also highlight the negative effect of population growth on the growth capacity of an economy. Most importantly, the results provide stronger evidence of the importance of both educational quality and quantity and their combined role in promoting economic growth. The results also highlight the pivotal role of educational quality in promoting economic growth. Finally, the fact that these results emerge from a global sample while they are not apparent in the SSA sample analysis reaffirms the exceptional nature of SSA growth and importance of basing the analysis on a larger sample. 
Table 20: International OLS Regression Results

\begin{tabular}{|c|c|c|c|c|c|}
\hline \multirow[t]{2}{*}{ Dependent Variable } & \multicolumn{5}{|c|}{$\begin{array}{l}\text { In(GDP per working population 2010)- In (GDP per working } \\
\text { population 1960) }\end{array}$} \\
\hline & (1) & $(2)$ & (3) & (4) & (5) \\
\hline Ln(Initial Income) & $\begin{array}{l}0.46^{\star *} \\
(2.29)\end{array}$ & $\begin{array}{c}-0.04 \\
(-0.17)\end{array}$ & $\begin{array}{c}0.20 \\
(1.11)\end{array}$ & $\begin{array}{c}0.01 \\
(0.05)\end{array}$ & $\begin{array}{c}-0.10 \\
(-0.43)\end{array}$ \\
\hline Ln(CAS/TIMSS) & & & $\begin{array}{l}2.96^{* * *} \\
(3.18)\end{array}$ & $\begin{array}{l}2.55^{* * *} \\
(2.72)\end{array}$ & $\begin{array}{c}-0.15 \\
(-0.09)\end{array}$ \\
\hline $\begin{array}{l}\text { Ln (Total number of primary } \\
\text { school,years) }\end{array}$ & & $\begin{array}{l}1.17^{* *} \\
(2.37)\end{array}$ & & $\begin{array}{l}0.87^{*} \\
(1.95)\end{array}$ & $\begin{array}{r}-13.34^{*} \\
(-1.73)\end{array}$ \\
\hline Ln(Physical Capital Formation) & & $\begin{array}{l}3.10^{* * *} \\
(3.55)\end{array}$ & $\begin{array}{l}2.94^{* * *} \\
(2.93)\end{array}$ & $\begin{array}{l}2.80^{* * *} \\
(2.97)\end{array}$ & $\begin{array}{l}2.96^{* * *} \\
(3.40)\end{array}$ \\
\hline $\begin{array}{l}\text { Ln(Adjusted Working } \\
\text { Population) }\end{array}$ & & $\begin{array}{l}-3.70^{* *} \\
(-2.44)\end{array}$ & $\begin{array}{l}-2.22 \\
(-1.63)\end{array}$ & $\begin{array}{l}-2.38^{*} \\
(-1.68)\end{array}$ & $\begin{array}{c}-1.95 \\
(-1.29)\end{array}$ \\
\hline $\begin{array}{l}\mathrm{Ln}(\mathrm{CAS} / \mathrm{TIMSS}){ }^{*} \text { Ln (Total } \\
\text { number of primary school,years) }\end{array}$ & & & & & $\begin{array}{l}2.44^{*} \\
(1.84)\end{array}$ \\
\hline Constant & $\begin{array}{l}3.53^{* *} \\
(2.27)\end{array}$ & $\begin{array}{c}-12.63^{* * *} \\
(-2.70)\end{array}$ & $\begin{array}{c}-25.98^{* * *} \\
(-5.68)\end{array}$ & $\begin{array}{c}-23.06^{* * *} \\
(-4.89)\end{array}$ & $\begin{array}{c}-6.06 \\
(-0.59)\end{array}$ \\
\hline Middle East and North Africa & $\begin{array}{c}1.00^{*} \\
(1.96)\end{array}$ & $\begin{array}{c}0.54 \\
(1.24) \\
\end{array}$ & $\begin{array}{c}-0.39 \\
(-0.94)\end{array}$ & $\begin{array}{c}-0.18 \\
(-0.43) \\
\end{array}$ & $\begin{array}{c}-0.07 \\
(-0.18)\end{array}$ \\
\hline Latin America and Caribbean & $\begin{array}{c}0.79 \\
(1.08)\end{array}$ & $\begin{array}{c}0.92 \\
(1.54)\end{array}$ & $\begin{array}{c}0.76 \\
(1.34)\end{array}$ & $\begin{array}{c}0.61 \\
(1.07)\end{array}$ & $\begin{array}{c}0.81 \\
(1.53)\end{array}$ \\
\hline Europe and Central Asia & $\begin{array}{c}2.39^{* \star *} \\
(3.84)\end{array}$ & $\begin{array}{l}1.21^{* *} \\
(2.48)\end{array}$ & $\begin{array}{c}0.45 \\
(0.97)\end{array}$ & $\begin{array}{c}0.46 \\
(0.99)\end{array}$ & $\begin{array}{c}0.44 \\
(0.91)\end{array}$ \\
\hline East Asia and Pacific & $\begin{array}{l}2.20^{* * *} \\
(3.68)\end{array}$ & $\begin{array}{l}0.94^{\star *} \\
(2.03)\end{array}$ & $\begin{array}{c}0.06 \\
(0.15) \\
\end{array}$ & $\begin{array}{c}-0.04 \\
(-0.09) \\
\end{array}$ & $\begin{array}{c}-0.27 \\
(-0.65) \\
\end{array}$ \\
\hline North America & $\begin{array}{l}2.34^{\star *} \\
(3.40)\end{array}$ & $\begin{array}{l}1.93^{\star * \star} \\
(3.80)\end{array}$ & $\begin{array}{c}0.95 \\
(1.63)\end{array}$ & $\begin{array}{c}0.94 \\
(1.65)\end{array}$ & $\begin{array}{c}0.76 \\
(1.41)\end{array}$ \\
\hline Number of Observations & 62 & 62 & 62 & 62 & 62 \\
\hline F-statistic & $\begin{array}{l}25.45 \\
(0.00)\end{array}$ & $\begin{array}{l}34.05 \\
(0.00)\end{array}$ & $\begin{array}{l}29.86 \\
(0.00)\end{array}$ & $\begin{array}{l}36.62 \\
(0.00)\end{array}$ & $\begin{array}{l}35.82 \\
(0.00)\end{array}$ \\
\hline $\mathbf{R}^{2}$ & 0.67 & 0.80 & 0.81 & 0.83 & 0.84 \\
\hline Adjusted $\mathbf{R}^{2}$ & 0.63 & 0.76 & 0.78 & 0.79 & 0.80 \\
\hline
\end{tabular}

Note: $t$ statistic reported in parentheses except F-statistic where $p$-values are reported. Two-tailed $p$-values:

* significant at 0.1 level; ${ }^{* *}$ significant at the 0.05 level; ${ }^{* * *}$ significant at 0.01 level.

Regional dummy variables result are relative to SSA (dummy variable excluded from the regression).

Reported adjusted R squared from regressions not corrected for heteroscedasticity. 


\subsection{Discussion}

The focus of the discussion in this section is the implication of the findings on initial income, a core tenet of the Solow model. This section also provides context for the presented evidence regarding the role of education in promoting economic growth.

\subsubsection{Initial Income}

MRW (1992) provides the following explanation for the apparent lack of convergence of income in Sub-Saharan Africa.

If countries have permanent differences in their production function, that is differences in $A(0)$, then these $A(0)$ 's would enter as part of the error term and would be positively correlated with initial income. ${ }^{52}$ Hence, variation in $A(0)$ would bias the coefficient on initial income toward zero. In other words, permanent crosscountry differences in the production function would lead to differences in initial income uncorrelated with subsequent growth rates and therefore, would bias the results against finding convergence. (p.424)

I offer two additional explanations. First, many developing countries, particularly those in SSA, have growth experiences that are far from the conditions of a steady state so it is difficult to expect them to exhibit the behaviour of out of steady state dynamics, the basis of conditional convergence of the Solow model.

Second, according to the conditional convergence hypothesis, countries with relatively lower initial income should have experienced higher than average growth rates, ceteris paribus. Barro (1991) suggests that poor countries tend to catch up with rich countries if

${ }^{52}$ The term $A(0)$ reflects other factors beyond technology including resource endowments, climate and institutions. 
the poor countries have high human capital per person (in relation to their level of GDP per capita) but not vice versa.

However, this assumption does not necessarily hold. In 1960, for example, compared to countries in the regional cross-sectional analysis sample with above average initial income, SSA countries in the sample with below average initial income, on average, had: lower physical capital investments; lower years of total schooling; lower life expectancy at birth; and higher fertility rate (see Table 21). It is therefore no longer surprising that the evidence suggests conditional divergence rather than convergence, with poorer countries growing more slowly than their richer counterparts, a process reinforced by their poorer performance based on other growth-enhancing indicators.

Table 21: Descriptive Statistics based on Initial Income (in 1960)*

\begin{tabular}{|c|c|c|c|c|c|c|}
\hline 1960 & Variable & Mean* & $\begin{array}{l}\text { Std. } \\
\text { Dev }\end{array}$ & Min & Max & $\mathbf{N}$ \\
\hline \multirow{4}{*}{$\begin{array}{l}\text { Below } \\
\text { Average } \\
\text { Initial Income }\end{array}$} & $\begin{array}{l}\text { Physical Capital } \\
\text { formation (\%) }\end{array}$ & 12 & 7 & 2 & 23 & 13 \\
\hline & $\begin{array}{l}\text { Total number of total } \\
\text { schooling (years) }\end{array}$ & 1 & 1 & 0.2 & 3 & 13 \\
\hline & $\begin{array}{l}\text { Life Expectancy at Birth } \\
\text { (years) }\end{array}$ & 41 & 6 & 28 & 51 & 13 \\
\hline & $\begin{array}{l}\text { Fertility Rate (births per } \\
\text { woman) }\end{array}$ & 7 & 1 & 6 & 8 & 13 \\
\hline \multirow{4}{*}{$\begin{array}{l}\text { Above } \\
\text { Average } \\
\text { Initial Income }\end{array}$} & $\begin{array}{l}\text { Physical Capital } \\
\text { formation (\%) }\end{array}$ & 38 & 22 & 22 & 53 & 5 \\
\hline & $\begin{array}{l}\text { Total number of total } \\
\text { schooling (years) }\end{array}$ & 3 & 2 & 1 & 4 & 5 \\
\hline & $\begin{array}{l}\text { Life Expectancy at Birth } \\
\text { (years) }\end{array}$ & 49 & 7 & 40 & 59 & 5 \\
\hline & $\begin{array}{l}\text { Fertility Rate (births per } \\
\text { woman) }\end{array}$ & 6 & 1 & 4 & 6 & 5 \\
\hline
\end{tabular}

*unweighted averages; * data for 1960 is not available for all countries particularly for physical capital investment. 


\subsubsection{Education}

Three results from the analyses are the focus of this discussion. First, the sign on the coefficient on the measure of educational quality is positive in all the estimations, though it is only statistically significant in the global rather than the regional analyses. Also, the estimated coefficients of both education quality and quantity are positive and statistically significant in the larger world-wide analysis.

The literature provides evidence of the pivotal role of educational quality in promoting growth and development. For example, Hanushek and Woessmman (2012) suggest that the inclusion of educational achievement in their estimations fully accounts for the poor growth performance of Latin American countries.

The fact that the educational quantity variable coefficient estimate remained statistically significant in the world-wide regression after the inclusion of the educational quality measure suggests a more complementary role of both measures of education in promoting growth.

Pritchett (2006) provides a possible explanation for the lack of significance of the education variables in the SSA regional regression and the joint significance of both measures of education in the world-wide regressions. He raises the possibility of a "threshold" effect (i.e. minimum threshold over which a country's quality of education needs to exceed prior to it translating into a significant improvement in productivity or cognitive skills). In other words, it just might be the case that the level of educational quality in most SSA countries has yet to reach the required threshold and this may be the 
reason why educational quality coefficient estimate is not statistically significant in the regional regressions. ${ }^{53}$

In the world-wide regressions, the coefficient of the educational quality variable is consistently larger than the educational quantity variable providing corroborating evidence of a more superior role of educational quality. In other words, the nature of the relationship between both educational measures and their subsequent effect on economic growth is fluid and nuanced, subject to historical levels of both that exist within a country.

However, it would be remiss not to note the negative coefficients on the measures of education in the global analysis when an education interaction term is introduced. As expected, the interaction term is positive and statistically significant. However, it is not immediately clear why both educational measures are negative (although only the estimated coefficient on educational quantity is statistically significant).

The effect of the presence an outlier is investigated. The outlier explanation carries some weight as the exclusion of the identified outlier, South Africa, caused some changes in the results. It is not immediately clear why South Africa and Mauritania in Chapter one have a strong influence on the results in the two stages of this analyses. The sample size and composition of both analyses likely played a role as the coefficient of the educational quality variable remained consistently positive in the international regressions despite the inclusion of both countries.

${ }^{53}$ Formal testing to confirm the presence of a threshold effect is not been conducted and will be addressed in future research. 
Further, the need to keep the estimated model parsimonious likely led to omitted variable bias. For example, Pritchett (2001) argues that poor political and institutional environments and excess supply of schooling growth are important explanatory factors for explaining a country's economic performance. Benhabib and Spiegel (1994) suggest that the direct effect of education on innovative capacity may be a more important explanatory factor for rich countries, while in the poorest countries, the catch-up effect plays a bigger role. In other words, it is likely that the effect of education on growth varies according to a country's level of development. As such, the inclusion of additional economic, political and institutional variables to better reflect each country's position on the economic and political development spectrum may have helped increased the explanatory power of the estimated models.

\subsection{Conclusion}

This paper investigates the effect of education, primarily educational quality, on economic growth in select Sub-Saharan African countries. The findings from the regional SSA analyses provide evidence of the importance of physical capital and population growth in the determination of a country's growth performance. However, the results with respect to the contribution of education to a country's growth performance is relatively weak. While both measures of educational quality and quantity are consistently positive in the various iterations of the regional analyses, the estimated coefficients on both variables are not statistically significant in any of the specifications. 
On the other hand, the findings from the analysis based on the global sample provides evidence that lend credence to the existing literature of the importance of education in promoting growth. The evidence also suggest that educational quality and educational quantity are distinct yet complementary components of human capital development and explain different aspects of the educational process. Finally, the results provide corroborating evidence of the pivotal role of educational quality in promoting growth.

Admittedly, the weak results from the regional SSA analysis challenges the underlying premise of this thesis of the importance of incorporating regional context in an analysis of the growth experience of SSA countries. However, the weak regional results are arguably due to the low data availability and threshold effect noted in Pritchett (2001). It is very likely that the positive effect of educational quality on economic growth in SSA will become more apparent in regional analysis once additional regional assessment data become available and more SSA countries exceed their "threshold" in educational quality. 


\section{References}

Arellano,M. and Bond, S. (1991). Some tests of specification for panel data: Monte Carlo evidence and an application to employment equations. Review of Economic Studies, 58, 277-97.

(1998). Dynamic panel data estimation using DPD98 for GAUSS: a guide for users. Institute for Fiscal Studies, London Working Paper no. $88 / 15$.

Arellano, M. and Bover, O. (1995). Another look at the instrumental variable estimation of error-components models. Journal of Econometrics, 68, 29-52.

Barro,R. (1991). Economic growth in a cross-section of countries. Quarterly Journal of Economics, 106(2),407-443.

Barro, R.J. \& Lee, J.W. (1993). International comparisons of educational attainment. Journal of Monetary Economics, 32:363-94.

.(1994). Sources of economic growth. Carnegie-Rochester Conference Series on Public Policy, 40, 1-46.

(1996). International measures of schooling years and schooling quality. American Economic Review, 86:218-23.

(2000). International data on educational attainment: updates and

Implications. CID Working Paper No. 42.

(2001). International data on educational attainment: updates and implications. Oxford Economic Papers, 53:3.

. (2010). A new data set of educational attainment in the world, 19502010. NBER Working Paper no. 5902.

(2015).Education matters: global schooling gains from the $19^{\text {th }}$ to the $21^{\text {st }}$ century. Oxford, UK: Oxford University Press.

Barro, R. \& Sala-i-Martin. (1995). Technological diffusion, convergence, and growth. NBER Working Paper no. 5151.

Basu, P. \&, Guariglia, A. (2008). Does low education delay structural transformation? Southern Economic Journal, 75(1),104-127.

Becker, G. (1962.) Investment in human capital: a theoretical analysis. Journal of Political Economy, 70(5), 9-49. 
Becker, G. (1964). Human capital: a theoretical and empirical analysis. New York: Columbia University Press.

Becker, G.S. (1993). Human capital, 3rd ed University of Chicago Press: Part 1.

Benhabib, J. \& Spiegel, M. (1994). The role of human capital in economic development: evidence from aggregate cross-country data. Journal of Monetary Economics 34, 143-173.

Benos, N. \& Zotou, S. (2014). Education and economic growth: a meta-regression analysis. World Development, 64:669-689.

Bloom, D., Canning, D. and Chan, K. (2006). Higher education and economic development in Africa. World Bank Human Development Sector Africa Region Paper

Bloom, D. \& Sachs, J. (1998). Geography, demography, and economic growth in Africa. Brookings Papers on Economic Activity, 2:207-273.

Bils, M. \& Klenow, P. (2000). Does schooling cause growth? American Economic Review, $90,1160-83$

Bishop, J. (1992). The impact of academic competencies of wages, unemployment and job performance. Carnegie-Rochester Conference Series on Public Policy, $37: 127-94$.

Blundell, R. \& Bond, S. (1998). Initial conditions and moment restrictions in dynamic panel data models. Journal of Econometrics, 87:115-143.

Boccanfuso, D., Savard, L. \& Elvire, B. (2013). Human capital and growth: new evidences from African data. International Economic Journal, 27(1), 55-77

Cazzavilan, G., Donadelli, M., \& Persha, L. (2013). Economic growth and poverty traps in Sub-Saharan Africa: the role of education and TFP shocks. Research in Economics, 67(3), 226-242.

Cohen, D. and Soto, M. (2007). Growth and human capital: good data, good results. Journal of Economic Growth, 12, 51-76.

Coleman, J.S. (1966). Equality of Educational Opportunity. National Center for Educational Statistics. Report Number OE-380001.

Glewwe, P., Maiga, E. and Zheng, H. (2014). The contribution of education to economic growth in Sub-Saharan Africa: a review of the evidence, with special attention and an application to sub-Saharan Africa. World Development, 59: 379-393. 
Glewwe, P. and Jacoby, H. (1995). An economic analysis of delayed primary school enrolment in a low income country: the role of early childhood nutrition. The Review of Economics and Statistics, 77(1): 156-69.

Gyimah-Brempong,K., Paddison, O. and Mitiku, W. (2006). Higher education and economic growth in Africa, Journal of Development Studies, 42(3), 509-529.

Gyimah-Brempong, K. (2010). Education and economic development in Africa. Paper prepared for the $4^{\text {th }}$ African Economic Conference, 2010, Tunisia.

Hanushek, E. \& D. Kimko. (2000). Schooling, labor force quality, and the growth of nations." American Economic Review. 90,1184-1208.

Hanushek, E. and Woessmann, L. (2007).The role of education quality for economic growth. Policy Research Working Paper Series 4122, The World Bank.

(2008). The role of cognitive skills in economic development. Journal of Economic Literature, 46 (3), 607-668.

(2008). The role of cognitive skills in economic development. Journal of Economic Literature, 46 (3), 607-668.

(2012). Schooling, educational achievement, and the Latin American growth puzzle. Journal of Development Economics, doi:10.1016/j.jdeveco.2012.06.004

Hoeffler, A. (2002). The augmented Solow model and the African growth debate. Oxford Bulletin of Economics and Statistics, 64(2):135-158.

Islam, N. (1995). Growth empirics: a panel data approach. The Quarterly Journal of Economics,110(4):1127-1170.

Klenow, P.,\& Rodriguez-Clare, A. (2001). The neoclassical revival in growth economics: has it gone too far?" NBER Macroeconomics Annual.

Knutsson, B. \& Lindberg, J. (2012). Education, development and the imaginary global consensus: reframing educational planning dilemmas in the South. Third World Quarterly, 33 (5), 807-824.

Krueger, A. \& Lindahl, M. (2001). Education for growth: why and for whom?" Journal of Economic Literature, 39, 1101-136.

Levine, R. \& Renelt, D. (1992). A sensitivity analysis of cross-country growth regressions. American Economic Review, 82(4),942-963. 
Lucas, R. (1988). On the mechanics of economic development. Journal of Monetary Economics,22,3-42.

Mankiw, N. G., Romer, D. \& Weil D.N. (1992). A contribution to the empirics of economic Growth. Quarterly Journal of Economics, 107 (2), 407-437.

Nelson, R. \& Phelps, E. (1966). Investment in humans, techonological diffusion and economic growth. The American Economic Review,56(no.1/2):69-75.

Oyelere, R. (2010). Africa's education enigma? The Nigerian story. Journal of Development Economics, 91(1), 128-139.

Pritchett, L. (2001). Where has all the education gone? The World Bank Economic Review, 15(3), 367-391.

.(2006). Does learning to add up add up? The returns to schooling in aggregate data. Handbook of the Economics of Education, 1:635-695.

Romer, P. (1986). Increasing returns and long-run growth. Journal of Political Economy, 94(5), 1002-1037.

.(1989). Capital accumulation in the theory of long run growth. Modern Business Cycle Theory, Barro, R. Ed. Cambridge, MA: Harvard University Press.

(1990). Human capital and growth: theory and evidence. Carnegie-Rochester

Conference Series on Public Policy,32, 251-286.

.(1993). Idea gaps and object gaps in economic development. Journal of Monetary Economics:S71-S102.

Smith, A. (1776). An inquiry into the nature and causes of the wealth of nations. London: Methuen \& Co., Ltd.

Solow, R. M. (1956). A contribution to the theory of economic growth. Quarterly Journal of Economics, 70 (1), 65-94.

Swan, T.(1956). Economic growth and capital accumulation. Economic Record, 32(2):334-361.

Thomas, A. and Trevino, J. (2013). Resource dependence and fiscal effort in SubSaharan Africa. IMF Working Paper, no.188

Tikly, L. (2011). Towards a framework for researching the quality of education in lowincome countries. Comparative Education, 47(1), 1-23. 
United Nations Education, Scientific, and Cultural Organization (UNESCO). (1977). Statistics of educational attainment and literacy, 1945-1974. Paris, France: United Nations.

.(1983). Statistics of educational attainment and literacy, 1970-1980. Paris, France: United Nations.

United Nations International Children's Emergency Fund (UNICEF). (2000). Defining quality in education. A paper presented by UNICEF at the meeting of The International Working Group on Education Florence, Italy, June.

Wong, J. (2012). Effects of education on sub-Saharan Africa. University of Gothenburg, master of science in economics project.

Wooldridge, J.M. (2002). Econometrics analysis of cross section and panel data. Cambridge, MA: MIT Press.

World Bank (2019a). World Development Indicators. Washington, D.C: The World Bank Washington, D.C.

(2019b). EdStats: Education Statistics. Washington, D.C: The World Bank. 


\section{Thesis Conclusion}

This thesis examines the role of human capital theory in explaining the development and growth experience in SSA. The earlier literature on human capital theory assumed that increasing the number of years of schooling attained within a population, the quantity of schooling, would lead to improved growth performance. However, recent evidence shows that increasing the cognitive skills and ability of the population, the educational achievements or quality of schooling, is also important for economic growth. The central premise of this thesis is that the apparent lack of a strong causal relationship in SSA (after controlling for other explanatory factors) between education and economic growth is due to the imperfect measurement of education.

Chapter one presents a unique measure of educational quality in SSA developed from assessment results of two large-scale regional assessments in SSA: Le Programme d'Analyse des Systèmes Educatifs de la CONFEMEN and the Southern and Eastern Africa Consortium for Monitoring Educational Quality. A third large-scale assessment with sizeable SSA participation is the Monitoring Learning Project is also utilized in the development of the measure.

The resulting measures are applied in a cross-sectional macro-level regression analysis of the determinants of educational quality. The results show that both family and school factors play a role in the determination of education quality, though the magnitude of each effect depends largely on assessment subject. While there remains considerable unexplained variance in educational outcomes, the analysis identifies some areas of possible policy leverage for SSA governments. 
Chapter two refines the understanding of the determinants of educational quality by presenting a micro-level case study. The case study is conducted on a country identified as an outlier in Chapter one, Cameroon. The results suggest that both school and family factors matter in the determinants of educational quality in the country but the relationship is quite nuanced, complex and dependent on locational and institutional context, family characteristics and school resource. Results also depend assessment subject and the interactions and interdependencies between the various explanatory factors. In other words, understanding of student performance, and thus their presumed capacity to contribute to their own productivity and that of their community, needs to be nuanced and understood within the context of their communities and families.

Chapter three presents the application of the educational quality metrics developed in Chapter one in the empirical analysis of aggregate country growth in SSA. The regional SSA analyses did not provide strong evidence of the importance of educational quality in explaining the growth experience of SSA countries. However, the evidence is stronger in the world-wide analysis of the relationship between educational quality and economic growth, highlighting the exceptional nature of the SSA education-growth experience. The results of the global analysis suggest that both educational quality and quantity have important and complementary roles to play in explaining growth generally, but their effect in the SSA growth experience remains inexplicably weak.

In summary, this thesis provides evidence of the factors contributing to educational quality in SSA, and of its potential role in promoting growth in the region and lends credence to the focus on educational quality in the fourth SDG. This does not mean that educational 
quality is the panacea for all the ills that currently plague the region. The analysis does suggest that educational quality potentially has an important role to play in facilitating growth in general (as seen in the global analysis) even if it remains unclear how to unlock this potential in SSA. 


\section{APPENDIX A}

Table A1: Participation of SSA Countries by Assessment: 1995 to 2010

\begin{tabular}{|l|c|c|c|c|}
\hline Country Name & MLA & PASEC & SACMEQ & TIMSS \\
\hline Angola & & & & \\
\hline Benin & & 2005 & & \\
\hline Botswana & 1999 & & $2000 \& 2007$ & $2003 \& 2007$ \\
\hline Burkina Faso & dna & 2007 & & \\
\hline Burundi & & 2009 & & \\
\hline Cabo Verde & dna & 2005 & & \\
\hline Cameroon & & & & \\
\hline Central African Republic & & $2004 \& 2010$ & & \\
\hline Chad & & 2009 & & \\
\hline Comoros & & 2010 & & \\
\hline Congo, Dem. Rep. & & 2009 & & \\
\hline Congo, Rep. & dna & 2009 & & \\
\hline Cote d'Ivoire & & & & \\
\hline Equatorial Guinea & & & $2000 \& 2007$ & \\
\hline Eswatini & & & & \\
\hline Eritrea & & & & \\
\hline Ethiopia & dna & & & \\
\hline Gabon & & & & \\
\hline Gambia, The & & 2006 & & \\
\hline Ghana & & & & \\
\hline Guinea & & & $2000 \& 2007$ & \\
\hline Guinea-Bissau & 1999 & 2006 & $2000 \& 2007$ & \\
\hline Kenya & 1999 & 2005 & & \\
\hline Lesotho & & & $2000 \& \& 2007$ & \\
\hline Liberia & 1996 & & & \\
\hline Madagascar & & dna & & \\
\hline Malawi & & & & \\
\hline Mali & & & & \\
\hline Mauritania & & & \\
\hline Mauritius & & & \\
\hline Mozambique & & & \\
\hline Namibia & & & \\
\hline Niger & & & \\
\hline Nigeria & & & \\
\hline Rwanda & & & \\
\hline
\end{tabular}




\begin{tabular}{|l|c|c|c|c|}
\hline Country Name & MLA & PASEC & SACMEQ & TIMSS \\
\hline Sao Tome and Principe & & dna & & \\
\hline Senegal & 1999 & 2007 & & \\
\hline Seychelles & & dna & $2000 \& 2007$ & \\
\hline Sierra Leone & & & & \\
\hline Somalia & & & & \\
\hline South Africa & 1999 & & $2000 \& 2007$ & $\begin{array}{c}1995,1999 \& \\
2003\end{array}$ \\
\hline South Sudan & & & & \\
\hline Sudan & & & & \\
\hline Tanzania & & & $2000 \& 2007$ & \\
\hline Togo & & 2010 & & \\
\hline Uganda & 1999 & & $2000 \& 2007$ & \\
\hline Zambia & 1999 & & $2000 \& 2007$ & \\
\hline Zimbabwe & & & 2007 & \\
\hline Total & 12 & 16 & 14 & 3 \\
\hline Sum & 42 & & & \\
\hline Unique sum & 34 & & & \\
\hline
\end{tabular}

\section{Notes}

Blank - no assessment information available; dna--participated in the survey but country result is not available; SACMEQ data for 2005 is incomplete and excluded from the analysis 
Table A2: Regional and International Average Assessment Scores, SSA Countries ${ }^{54}$

\begin{tabular}{|c|c|c|c|c|c|c|c|c|}
\hline Country & $\begin{array}{l}\text { Resource } \\
\text { Dependent }\end{array}$ & $\begin{array}{l}\text { PASEC: } \\
\text { 5th Grade } \\
\text { Mean } \\
\text { French, } \\
\text { Total } \\
\end{array}$ & $\begin{array}{l}\text { PASEC: } \\
\text { 5th Grade } \\
\text { Mean } \\
\text { Math, } \\
\text { Total }\end{array}$ & $\begin{array}{l}\text { SACMEQ: } \\
\text { 6th Grade } \\
\text { Mean Math } \\
\text {, Total }\end{array}$ & $\begin{array}{l}\text { SACMEQ: } \\
\text { 6th Grade } \\
\text { Mean } \\
\text { Reading } \\
\text { Total } \\
\end{array}$ & $\begin{array}{l}\text { MLA: 4th } \\
\text { Grade Mean } \\
\text { Literacy, } \\
\text { Total }\end{array}$ & $\begin{array}{l}\text { MLA: 4th } \\
\text { Grade } \\
\text { Mean } \\
\text { Numeracy } \\
\text {, Total } \\
\end{array}$ & $\begin{array}{l}\text { TIMSS } \\
\text { Average } \\
\text { Score }\end{array}$ \\
\hline Benin & 1 & 31.60 & 32.50 & & & & & \\
\hline Botswana & 1 & & & 516.70 & 527.85 & 48.00 & 51.00 & 365 \\
\hline Burkina Faso & 1 & 37.82 & 41.70 & & & & & \\
\hline Burundi & 0 & 41.71 & 47.48 & & & & & \\
\hline Cameroon & 1 & 53.40 & 46.80 & & & & & \\
\hline Chad & 1 & 34.62 & 35.28 & & & & & \\
\hline Comoros & 0 & 31.49 & 36.02 & & & & & \\
\hline Congo, Dem. Rep. & 1 & 42.45 & 48.16 & & & & & \\
\hline Congo, Rep. & 1 & 37.16 & 38.83 & & & & & \\
\hline Cote d'Ivoire & 1 & 37.42 & 29.76 & & & & & \\
\hline Eswatini & 0 & & & 528.65 & 539.50 & & & \\
\hline Gabon & 1 & 60.14 & 48.21 & & & & & \\
\hline Ghana & 1 & & & & & & & 293 \\
\hline Guinea & 1 & 37.97 & 37.03 & & & & & \\
\hline Kenya & 0 & & & 560.05 & 544.80 & & & \\
\hline Lesotho & 0 & & & 462.05 & 459.55 & & & \\
\hline Liberia & 1 & & & & & 40 & 41.8 & \\
\hline Madagascar & 0 & 36.90 & 52.60 & & & 55.00 & 44.00 & \\
\hline Malawi & 0 & & & 439.95 & 431.20 & 35.00 & 43.00 & \\
\hline Mali & 1 & & & & & 51.82 & 43.62 & \\
\hline Mauritania & 1 & 19.86 & 22.84 & & & & & \\
\hline Mauritius & 0 & 50.59 & 41.81 & 603.95 & 554.95 & 61.20 & 58.52 & \\
\hline
\end{tabular}

${ }^{54}$ Adopted gendered regional assessment scores available upon request. 


\begin{tabular}{|c|c|c|c|c|c|c|c|c|}
\hline Country & $\begin{array}{l}\text { Resource } \\
\text { Dependent }\end{array}$ & $\begin{array}{l}\text { PASEC: } \\
\text { 5th Grade } \\
\text { Mean } \\
\text { French, } \\
\text { Total } \\
\end{array}$ & $\begin{array}{l}\text { PASEC: } \\
\text { 5th Grade } \\
\text { Mean } \\
\text { Math , } \\
\text { Total } \\
\end{array}$ & $\begin{array}{l}\text { SACMEQ: } \\
\text { 6th Grade } \\
\text { Mean Math } \\
\text {, Total } \\
\end{array}$ & $\begin{array}{l}\text { SACMEQ: } \\
\text { 6th Grade } \\
\text { Mean } \\
\text { Reading , } \\
\text { Total } \\
\end{array}$ & $\begin{array}{l}\text { MLA: 4th } \\
\text { Grade Mean } \\
\text { Literacy , } \\
\text { Total }\end{array}$ & $\begin{array}{l}\text { MLA: 4th } \\
\text { Grade } \\
\text { Mean } \\
\text { Numeracy } \\
\text {, Total } \\
\end{array}$ & $\begin{array}{l}\text { TIMSS } \\
\text { Average } \\
\text { Score }\end{array}$ \\
\hline Mozambique & 1 & & & 506.75 & 496.05 & & & \\
\hline Namibia & 1 & & & 450.95 & 472.85 & & & \\
\hline Niger & 1 & & & & & 41.12 & 37.31 & \\
\hline Nigeria & 1 & & & & & 25.1 & 32.2 & \\
\hline Senegal & 1 & 40.66 & 45.69 & & & 48.86 & 39.73 & \\
\hline Seychelles & 0 & & & 552.50 & 578.55 & & & \\
\hline South Africa & 1 & & & 490.55 & 494.10 & 48.10 & 30.00 & 272 \\
\hline Tanzania & 1 & & & 537.55 & 561.85 & & & \\
\hline Togo & 1 & 32.26 & 36.41 & & & & & \\
\hline Uganda & 0 & & & 494.10 & 480.55 & 59.00 & 50.00 & \\
\hline Zambia & 1 & & & 435.10 & 437.30 & 43.00 & 36.00 & \\
\hline Zimbabwe & 1 & & & 519.80 & 507.70 & & & \\
\hline Count & & 16 & 16 & 14 & 14 & 12 & 12 & 3 \\
\hline Average & & 39.13 & 40.07 & 507.05 & 506.20 & 46.35 & 42.27 & 309.81 \\
\hline Standard Deviation & & 9.54 & 7.96 & 49.00 & 46.70 & 10.25 & 8.13 & 48.85 \\
\hline Skewness & & 0.46 & -0.45 & 0.19 & -0.12 & -0.54 & 0.44 & 1.39 \\
\hline Kurtosis & & 1.11 & -0.15 & -0.39 & -1.09 & 0.30 & 0.08 & \\
\hline
\end{tabular}

\section{Notes}

Countries with multiple survey results. PASEC: Chad( 2004 and 2010)

SACMEQ: Botswana (2000 and 2007); Lesotho ( 2000 and 2007); Mauritius (2000 and 2007); Mozambique ( 2000 and 2007);

Namibia ( 2000 and 2007); Seychelles ( 2000 and 2007); South Africa (2000 and 2007); Eswatini (2000 and 2007); Tanzania ( 2000 and 2007);Uganda ( 2000 and 2007) and Zambia ( 2000 and 2007).

Regional scores are 1995 to 2010 averages. TIMSS scores are 1995 to 2007 averages.

Sources: World Bank Education Statistics, CONFEMEN and UNESCO 
Table A3: Derived Assessment Scores, SSA Countries

\begin{tabular}{|c|c|c|c|c|c|c|c|c|c|c|}
\hline Country & $\begin{array}{l}\text { Combined } \\
\text { Numeracy } \\
\text { Assessment } \\
\text { Score ( on } \\
\text { MLA scale), } \\
\text { female } \\
\text { (CNAS_f) }\end{array}$ & $\begin{array}{l}\text { Combined } \\
\text { Numeracy } \\
\text { Assessment } \\
\text { Score ( on } \\
\text { MLA scale), } \\
\text { male } \\
\text { (CNAS_m) }\end{array}$ & $\begin{array}{l}\text { Combined } \\
\text { Numeracy } \\
\text { Assessment } \\
\text { Score ( on } \\
\text { MLA scale), } \\
\text { total (CNAS) }\end{array}$ & $\begin{array}{l}\text { Combined } \\
\text { Literacy } \\
\text { Assessment } \\
\text { Score ( on } \\
\text { MLA scale), } \\
\text { female(CLAS } \\
\text { f) }\end{array}$ & $\begin{array}{l}\text { Combined } \\
\text { Literacy } \\
\text { Assessment } \\
\text { Score ( on } \\
\text { MLA scale), } \\
\text { male } \\
\text { (CLAS_m) }\end{array}$ & $\begin{array}{l}\text { Combine } \\
\text { d Literacy } \\
\text { Assessm } \\
\text { ent Score } \\
\text { ( on MLA } \\
\text { scale), } \\
\text { total } \\
\text { (CLAS) }\end{array}$ & $\begin{array}{l}\text { Combined } \\
\text { Assessment } \\
\text { Score (on } \\
\text { MLA } \\
\text { scale),female } \\
\text { (CAS_f) }\end{array}$ & $\begin{array}{l}\text { Combined } \\
\text { Assessment } \\
\text { Score (on } \\
\text { MLA } \\
\text { scale),male } \\
\text { (CAS_m) }\end{array}$ & $\begin{array}{l}\text { Combined } \\
\text { Assessment } \\
\text { Score (on } \\
\text { MLA } \\
\text { scale),total } \\
\text { (CAS) }\end{array}$ & $\begin{array}{l}\text { CNASI } \\
\text { TIMSS } \\
\text { Score }\end{array}$ \\
\hline Benin & 30.23 & 34.57 & 32.91 & 41.61 & 45.50 & 43.09 & 35.01 & 38.91 & 36.97 & 244 \\
\hline Botswana & 50.81 & 48.94 & 49.78 & 54.33 & 49.75 & 53.11 & 52.22 & 48.70 & 50.78 & 365 \\
\hline Burkina Faso & 39.73 & 44.66 & 42.31 & 47.04 & 54.36 & 49.77 & 42.83 & 49.29 & 45.65 & 311 \\
\hline Burundi & 44.56 & 50.64 & 48.21 & 50.92 & 57.48 & 53.94 & 47.43 & 54.37 & 51.09 & 354 \\
\hline Cameroon & 46.26 & 47.70 & 47.52 & 62.35 & 70.40 & 66.48 & 54.65 & 59.06 & 57.28 & 349 \\
\hline Chad & 33.96 & 36.70 & 35.75 & 44.75 & 52.38 & 46.34 & 38.64 & 43.59 & 40.24 & 265 \\
\hline Comoros & 36.07 & 43.51 & 36.51 & 44.20 & 48.44 & 42.98 & 39.40 & 45.66 & 38.89 & 270 \\
\hline $\begin{array}{l}\text { Congo, Dem. } \\
\text { Rep. }\end{array}$ & 46.60 & 49.87 & 48.91 & 50.03 & 60.11 & 54.74 & 47.97 & 55.23 & 51.89 & 359 \\
\hline Congo, Rep. & 38.32 & 39.72 & 39.38 & 47.25 & 51.53 & 49.06 & 42.23 & 44.96 & 43.66 & 290 \\
\hline Cote d'Ivoire & 29.04 & 30.94 & 30.12 & 48.19 & 51.02 & 49.34 & 38.07 & 39.50 & 38.71 & 224 \\
\hline Eswatini & 49.47 & 51.69 & 50.84 & 59.02 & 59.69 & 60.88 & 54.29 & 55.64 & 55.85 & 373 \\
\hline Gabon & 46.41 & 50.39 & 48.95 & 67.37 & 79.46 & 73.71 & 57.51 & 65.16 & 61.87 & 359 \\
\hline Ghana & & & & & & & & & & 293 \\
\hline Guinea & 34.78 & 39.42 & 37.54 & 45.29 & 55.46 & 49.93 & 39.35 & 46.73 & 43.11 & 277 \\
\hline Kenya & 53.75 & 59.28 & 56.83 & 59.15 & 62.11 & 62.09 & 56.67 & 61.03 & 59.76 & 415 \\
\hline Lesotho & 38.26 & 37.81 & 38.14 & 42.86 & 40.55 & 42.64 & 40.41 & 38.99 & 40.20 & 282 \\
\hline Liberia & & & 41.80 & & & 40.00 & & & 40.90 & 308 \\
\hline Madagascar & 47.03 & 49.29 & 48.72 & 51.85 & 52.01 & 51.89 & 49.31 & 50.33 & 50.09 & 357 \\
\hline Malawi & 37.12 & 40.32 & 38.46 & 34.81 & 35.39 & 35.58 & 36.39 & 38.66 & 37.60 & 284 \\
\hline Mali & 42.79 & 44.58 & 43.62 & 49.76 & 54.42 & 51.82 & 46.28 & 49.50 & 47.72 & 321 \\
\hline
\end{tabular}




\begin{tabular}{|c|c|c|c|c|c|c|c|c|c|c|}
\hline Country & $\begin{array}{l}\text { Combined } \\
\text { Numeracy } \\
\text { Assessment } \\
\text { Score ( on } \\
\text { MLA scale), } \\
\text { female } \\
\text { (CNAS_f) }\end{array}$ & $\begin{array}{l}\text { Combined } \\
\text { Numeracy } \\
\text { Assessment } \\
\text { Score ( on } \\
\text { MLA scale), } \\
\text { male } \\
\text { (CNAS_m) }\end{array}$ & $\begin{array}{l}\text { Combined } \\
\text { Numeracy } \\
\text { Assessment } \\
\text { Score ( on } \\
\text { MLA scale), } \\
\text { total (CNAS) }\end{array}$ & $\begin{array}{l}\text { Combined } \\
\text { Literacy } \\
\text { Assessment } \\
\text { Score ( on } \\
\text { MLA scale), } \\
\text { female(CLAS } \\
\text { f) }\end{array}$ & $\begin{array}{l}\text { Combined } \\
\text { Literacy } \\
\text { Assessment } \\
\text { Score ( on } \\
\text { MLA scale), } \\
\text { male } \\
\text { (CLAS_m) }\end{array}$ & $\begin{array}{l}\text { Combine } \\
\text { d Literacy } \\
\text { Assessm } \\
\text { ent Score } \\
\text { ( on MLA } \\
\text { scale), } \\
\text { total } \\
\text { (CLAS) }\end{array}$ & $\begin{array}{l}\text { Combined } \\
\text { Assessment } \\
\text { Score (on } \\
\text { MLA } \\
\text { scale),female } \\
\text { (CAS_f) }\end{array}$ & $\begin{array}{l}\text { Combined } \\
\text { Assessment } \\
\text { Score (on } \\
\text { MLA } \\
\text { scale),male } \\
\text { (CAS_m) }\end{array}$ & $\begin{array}{l}\text { Combined } \\
\text { Assessment } \\
\text { Score (on } \\
\text { MLA } \\
\text { scale),total } \\
\text { (CAS) }\end{array}$ & $\begin{array}{l}\text { CNASI } \\
\text { TIMSS } \\
\text { Score } \\
\end{array}$ \\
\hline Mauritania & 23.16 & 23.05 & 23.05 & 32.41 & 29.94 & 30.50 & 26.32 & 24.36 & 24.93 & 174 \\
\hline Mauritius & 56.85 & 53.29 & 55.38 & 66.64 & 58.34 & 63.02 & 62.05 & 56.34 & 59.54 & 405 \\
\hline Mozambique & 44.79 & 47.85 & 46.67 & 48.98 & 50.91 & 50.97 & 46.90 & 49.42 & 48.87 & 343 \\
\hline Namibia & 35.91 & 36.10 & 36.02 & 45.74 & 43.59 & 45.67 & 40.52 & 39.42 & 40.43 & 266 \\
\hline Niger & 38.07 & 36.74 & 37.31 & 41.33 & 40.79 & 41.12 & 39.70 & 38.77 & 39.22 & 276 \\
\hline Nigeria & & & 32.20 & & & 25.10 & & & 28.65 & 239 \\
\hline Senegal & 41.12 & 44.37 & 43.06 & 48.92 & 53.14 & 50.84 & 44.49 & 47.45 & 46.03 & 317 \\
\hline Seychelles & 57.45 & 52.31 & 55.39 & 72.45 & 62.54 & 69.79 & 65.11 & 57.30 & 62.56 & 405 \\
\hline South Africa & 36.85 & 36.23 & 36.79 & 50.37 & 47.26 & 49.31 & 42.25 & 40.71 & 41.68 & 272 \\
\hline Tanzania & 48.91 & 55.98 & 52.54 & 61.07 & 68.08 & 65.98 & 54.98 & 61.93 & 59.18 & 385 \\
\hline Togo & 35.02 & 38.02 & 36.91 & 42.17 & 46.44 & 43.80 & 37.74 & 41.42 & 39.55 & 273 \\
\hline Uganda & 45.64 & 47.93 & 47.13 & 49.71 & 49.82 & 53.21 & 48.61 & 49.92 & 51.62 & 346 \\
\hline Zambia & 33.84 & 34.21 & 34.50 & 40.37 & 39.03 & 40.28 & 37.73 & 37.01 & 37.98 & 256 \\
\hline Zimbabwe & 48.35 & 49.46 & 49.15 & 52.76 & 51.65 & 53.62 & 50.66 & 50.67 & 51.51 & 360 \\
\hline Count & 31 & 31 & 33 & 31 & 31 & 33 & 31 & 31 & 33 & 34 \\
\hline Average & 41.65 & 43.73 & 42.50 & 50.12 & 52.31 & 50.32 & 45.67 & 47.74 & 46.18 & 312.21 \\
\hline $\begin{array}{l}\text { Standard } \\
\text { Deviation }\end{array}$ & 8.15 & 8.14 & 8.11 & 9.25 & 10.26 & 10.75 & 8.68 & 8.95 & 9.32 & 57.24 \\
\hline Skewness & -0.02 & -0.37 & -0.16 & 0.57 & 0.34 & 0.05 & 0.29 & -0.20 & -0.04 & -0.13 \\
\hline Kurtosis & -0.28 & -0.10 & -0.47 & 0.26 & 0.90 & 0.30 & -0.08 & 0.19 & -0.37 & -0.42 \\
\hline
\end{tabular}

Note: Table contains scores derived by the author. See Chapter 1 for more information.

Sources: World Bank Education Statistics, CONFEMEN and UNESCO 
Table A3: Variable Description and Data Source

\begin{tabular}{|c|c|c|}
\hline Variable & Definition & Source \\
\hline $\begin{array}{l}\text { Adjusted net enrolment rate, primary, both sexes } \\
(\%)\end{array}$ & $\begin{array}{l}\text { Total number of students of the official primary school age } \\
\text { group who are enrolled at primary, expressed as a percentage } \\
\text { of the corresponding population. }\end{array}$ & UNESCO Institute for Statistics \\
\hline $\begin{array}{l}\text { Barro-Lee: Average years of primary schooling, } \\
\text { age } 15+, \text { total }\end{array}$ & $\begin{array}{l}\text { Average years of primary schooling, } 15+\text {, total is the average } \\
\text { years of primary education completed among people over age } \\
15 .\end{array}$ & $\begin{array}{l}\text { Robert J. Barro and Jong-Wha } \\
\text { Lee: http://www.barrolee.com/ }\end{array}$ \\
\hline $\begin{array}{l}\text { Cumulative drop-out rate to the last grade of } \\
\text { primary education, both sexes (\%) }\end{array}$ & $\begin{array}{l}\text { Proportion of pupils from a cohort enrolled in a given grade at } \\
\text { a given school year who are no longer enrolled in the following } \\
\text { school year. Cumulative dropout rate in primary education is } \\
\text { calculated by subtracting the survival rate from } 100 \text { at a given } \\
\text { grade. }\end{array}$ & UNESCO Institute for Statistics \\
\hline DHS: Net attendance rate. Primary. Urban & $\begin{array}{l}\text { Net attendance rate. Primary. Urban is the proportion of urban } \\
\text { children of the official primary school age who are attending } \\
\text { primary school. The primary school age is based on the } \\
\text { parameters of the educational system: starting age and } \\
\text { duration of primary school. }\end{array}$ & $\begin{array}{l}\text { Demographic and Health Surveys } \\
\text { (DHS) }\end{array}$ \\
\hline
\end{tabular}




\begin{tabular}{|l|l|l|}
\hline Variable & Definition & Source \\
\hline DHS: Net attendance rate. Primary & $\begin{array}{l}\text { Net attendance rate. Primary. Total is the proportion of } \\
\text { children of the official primary school age who are attending } \\
\text { primary school. The primary school age is based on the } \\
\text { parameters of the educational system: starting age and } \\
\text { duration of primary school. }\end{array}$ & $\begin{array}{l}\text { Demographic and Health Surveys } \\
\text { (DHS) }\end{array}$ \\
\hline $\begin{array}{l}\text { Enrolment in primary education, both sexes } \\
\text { (number) }\end{array}$ & $\begin{array}{l}\text { Total number of students enrolled in public and private primary } \\
\text { education institutions regardless of age. }\end{array}$ & UNESCO Institute for Statistics \\
\hline GDP per capita (constant 2010 US\$) & $\begin{array}{l}\text { GDP per capita is gross domestic product divided by midyear } \\
\text { population. GDP is the sum of gross value added by all } \\
\text { resident producers in the economy plus any product taxes and } \\
\text { minus any subsidies not included in the value of the products. } \\
\text { It is calculated without making deductions for depreciation of } \\
\text { fabricated assets or for depletion and degradation of natural } \\
\text { resources. Data are in constant 2010 U.S. dollars. }\end{array}$ & $\begin{array}{l}\text { World Bank national accounts } \\
\text { data, and OECD National } \\
\text { Accounts data files. }\end{array}$ \\
\hline $\begin{array}{l}\text { Government expenditure on primary education as } \\
\% \text { of GDP (\%) }\end{array}$ & $\begin{array}{l}\text { Total general (local, regional and central) government } \\
\text { expenditure on primary education (current, capital, and } \\
\text { transfers), expressed as a percentage of GDP. It includes } \\
\text { expenditure funded by transfers from international sources to } \\
\text { government. Divide total government expenditure for a given } \\
\text { level of education (for example, primary, secondary, or all } \\
\text { levels combined) by the GDP, and multiply by 100. }\end{array}$ & UNESCO Institute for Statistics \\
\hline
\end{tabular}




\begin{tabular}{|l|l|l|}
\hline Variable & Definition & Source \\
\hline $\begin{array}{l}\text { Government expenditure per primary student } \\
\text { constant US\$) }\end{array}$ & $\begin{array}{l}\text { Average total (current, capital and transfers) general } \\
\text { government expenditure per student in the given level of } \\
\text { education, expressed in US\$ at market exchange rates, in } \\
\text { constant prices. The constant prices base year is normally } \\
\text { three years before the year of the data release. Divide total } \\
\text { government expenditure (in constant US\$) for a given level of } \\
\text { education (for example, primary, secondary) by total enrolment } \\
\text { in that same level. This indicator is useful to compare average } \\
\text { spending on one student between levels of education, over } \\
\text { time, or between countries. Constant US\$ allow comparing } \\
\text { absolute values using a common currency, and considering } \\
\text { the effect of inflation. This indicator should not be considered a } \\
\text { unit cost, since it only includes what the government spends, } \\
\text { and not total spending per student (including household } \\
\text { contributions). Since it is a simple division of total government } \\
\text { expenditure by the number of students at a given level, } \\
\text { whether they attend public or private institutions, in countries } \\
\text { where private provision and/or funding of education is higher } \\
\text { the average amount per student will appear lower. }\end{array}$ \\
\hline
\end{tabular}




\begin{tabular}{|c|c|c|}
\hline Variable & Definition & Source \\
\hline $\begin{array}{l}\text { Net enrolment rate (NER), primary, both sexes } \\
(\%)\end{array}$ & $\begin{array}{l}\text { Total number of students in the theoretical age group for } \\
\text { primary education enrolled in that level, expressed as a } \\
\text { percentage of the total population in that age group. Divide the } \\
\text { number of students enrolled who are of the official age group } \\
\text { for primary education by the population for the same age } \\
\text { group and multiply the result by } 100 \text {. NER at each level of } \\
\text { education should be based on enrolment of the relevant age } \\
\text { group in all types of schools and education institutions, } \\
\text { including public, private and all other institutions that provide } \\
\text { organized educational programmes. A high NER denotes a } \\
\text { high degree of coverage for the official school-age population. } \\
\text { The theoretical maximum value is } 100 \% \text {. Increasing trends can } \\
\text { be considered as reflecting improving coverage at the } \\
\text { specified level of education. When the NER is compared with } \\
\text { the Gross enrolment ratio (GER), the difference between the } \\
\text { two highlights the incidence of under-aged and over-aged } \\
\text { enrolment. If the NER is below } 100 \% \text {, then the complement, } \\
\text { i.e. the difference with } 100 \% \text {, provides a measure of the } \\
\text { proportion of children not enrolled at the specified level of } \\
\text { education. However, since some of these children/youth could } \\
\text { be enrolled at other levels of education, this difference should } \\
\text { in no way be considered as indicating the percentage of } \\
\text { students not enrolled. To measure universal primary } \\
\text { education, for example, adjusted primary NER is calculated on } \\
\text { the basis of the percentage of children in the official primary } \\
\text { school age range who are enrolled in either primary or } \\
\text { secondary education. A more precise complementary indicator } \\
\text { is the Age-specific enrolment ratio (ASER) which shows the } \\
\text { participation in education of the population of each particular } \\
\text { age, regardless of the level of education. }\end{array}$ & UNESCO Institute for Statistics \\
\hline
\end{tabular}




\begin{tabular}{|c|c|c|}
\hline Variable & Definition & Source \\
\hline Mortality rate, under-5 (per 1,000 live births) & $\begin{array}{l}\text { Under-five mortality rate is the probability per } 1,000 \text { that a } \\
\text { newborn baby will die before reaching age five, if subject to } \\
\text { age-specific mortality rates of the specified year. }\end{array}$ & $\begin{array}{l}\text { Estimates Developed by the UN } \\
\text { Inter-agency Group for Child } \\
\text { Mortality Estimation (UNICEF, } \\
\text { WHO, World Bank, UN DESA } \\
\text { Population Division) at } \\
\text { wwW.childmortality.org. Projected } \\
\text { data are from the United Nations } \\
\text { Population Division's World } \\
\text { Population Prospects; and may in } \\
\text { some cases not be consistent with } \\
\text { data before the current year. }\end{array}$ \\
\hline $\begin{array}{l}\text { Percentage of teachers in primary education who } \\
\text { are trained, both sexes }(\%)\end{array}$ & $\begin{array}{l}\text { Number of teachers who have received the minimum } \\
\text { organized teacher training (pre-service or in-service) required } \\
\text { for teaching at the primary level in the given country, } \\
\text { expressed as a percentage of the total number of teachers at } \\
\text { the primary level. }\end{array}$ & UNESCO Institute for Statistics \\
\hline Population growth (annual \%) & $\begin{array}{l}\text { Annual population growth rate for year } t \text { is the exponential rate } \\
\text { of growth of midyear population from year } t-1 \text { to } t \text {, expressed } \\
\text { as a percentage. Population is based on the de facto } \\
\text { definition of population, which counts all residents regardless } \\
\text { of legal status or citizenship. }\end{array}$ & $\begin{array}{l}\text { Derived from total population. } \\
\text { Population source: (1) United } \\
\text { Nations Population Division. World } \\
\text { Population Prospects, (2) Census } \\
\text { reports and other statistical } \\
\text { publications from national } \\
\text { statistical offices, (3) Eurostat: } \\
\text { Demographic Statistics, (4) United } \\
\text { Nations Statistical Division. } \\
\text { Population and Vital Statistics } \\
\text { Reprot (various years), (5) U.S. } \\
\text { Census Bureau: International } \\
\text { Database, and (6) Secretariat of } \\
\text { the Pacific Community: Statistics } \\
\text { and Demography Programme. }\end{array}$ \\
\hline
\end{tabular}




\begin{tabular}{|c|c|c|}
\hline Variable & Definition & Source \\
\hline Primary completion rate, both sexes (\%) & $\begin{array}{l}\text { Total number of new entrants in the last grade of primary } \\
\text { education, regardless of age, expressed as percentage of the } \\
\text { total population of the theoretical entrance age to the last } \\
\text { grade of primary. This indicator is also known as "gross intake } \\
\text { rate to the last grade of primary education." The ratio can } \\
\text { exceed } 100 \% \text { due to over-aged and under-aged children who } \\
\text { enter primary school late/early and/or repeat grades. }\end{array}$ & UNESCO Institute for Statistics \\
\hline $\begin{array}{l}\text { Pupil/qualified teacher ratio in primary education } \\
\text { (headcount basis) }\end{array}$ & $\begin{array}{l}\text { Average number of pupils per qualified teacher at a given level } \\
\text { of education, based on headcounts of both pupils and } \\
\text { teachers. Divide the total number of pupils enrolled at the } \\
\text { specified level of education by the number of qualified } \\
\text { teachers at the same level. A qualified teacher is one who has } \\
\text { the minimum academic qualifications necessary to teach at a } \\
\text { specific level of education in a given country. This is usually } \\
\text { related to the subject(s) they teach. In computing and } \\
\text { interpreting this indicator, one should take into account the } \\
\text { existence of part-time teaching, school-shifts, multi-grade } \\
\text { classes and other practices that may affect the precision and } \\
\text { meaningfulness of pupil-teacher ratios. When feasible, the } \\
\text { number of part-time teachers is converted to 'full-time } \\
\text { equivalent' teachers; a double-shift teacher is counted twice, } \\
\text { etc. Teachers are defined as persons whose professional } \\
\text { activity involves the transmitting of knowledge, attitudes and } \\
\text { skills that are stipulated in a formal curriculum programme to } \\
\text { students enrolled in a formal educational institution. }\end{array}$ & UNESCO Institute for Statistics \\
\hline $\begin{array}{l}\text { Repetition rate in primary education (all grades), } \\
\text { both sexes (\%) }\end{array}$ & $\begin{array}{l}\text { Number of repeaters in primary education in a given school } \\
\text { year, expressed as a percentage of enrolment in primary } \\
\text { education in the previous school year. Divide the number of } \\
\text { repeaters in primary education in school year } t+1 \text { by the } \\
\text { number of pupils from the same cohort enrolled in primary } \\
\text { education in the previous school year t. }\end{array}$ & UNESCO Institute for Statistics \\
\hline
\end{tabular}




\begin{tabular}{|c|c|c|}
\hline Variable & Definition & Source \\
\hline $\begin{array}{l}\text { School life expectancy, primary, both sexes } \\
\text { (years) }\end{array}$ & $\begin{array}{l}\text { Number of years a person of school entrance age can expect } \\
\text { to spend within the specified level of education. For a child of a } \\
\text { certain age, the school life expectancy is calculated as the } \\
\text { sum of the age specific enrolment rates for the levels of } \\
\text { education specified. The part of the enrolment that is not } \\
\text { distributed by age is divided by the school-age population for } \\
\text { the level of education they are enrolled in, and multiplied by } \\
\text { the duration of that level of education. The result is then added } \\
\text { to the sum of the age-specific enrolment rates. A relatively } \\
\text { high SLE indicates greater probability for children to spend } \\
\text { more years in education and higher overall retention within the } \\
\text { education system. The expected number of years does not } \\
\text { necessarily coincide with the expected number of grades of } \\
\text { education completed, because of repetition. Since school life } \\
\text { expectancy is an average based on participation in different } \\
\text { levels of education, the expected number of years of schooling } \\
\text { may be pulled down by the magnitude of children who never } \\
\text { go to school. Those children who are in school may benefit } \\
\text { from many more years of education than the average. }\end{array}$ & UNESCO Institute for Statistics \\
\hline Polity & $\begin{array}{l}\text { It is the modified Polity variable (Polity 2) computed by } \\
\text { subtracting the autocracy score from the democratic score. }\end{array}$ & $\begin{array}{l}\text { Polity IV Project: Center for } \\
\text { Systematic Peace }\end{array}$ \\
\hline
\end{tabular}




\section{APPENDIX B}

Table B1: Full Final Assessment Regression Results 


\begin{tabular}{|c|c|c|c|c|}
\hline \multicolumn{2}{|r|}{ DV: Final Assessment Scores } & \multirow{2}{*}{$\begin{array}{c}\text { Aggregate } \\
40.38^{\star \star \star} \\
(6.91)\end{array}$} & \multirow{2}{*}{$\begin{array}{l}\text { Math } \\
42.71^{\text {** }} \\
(7.18)\end{array}$} & \multirow{2}{*}{$\begin{array}{c}\text { Language } \\
38.86^{\star \star \star} \\
(5.14)\end{array}$} \\
\hline & Constant & & & \\
\hline & Initial Scores & $\begin{array}{l}0.36^{* *} \\
(5.29)\end{array}$ & $\begin{array}{l}0.29^{\star * *} \\
(6.21)\end{array}$ & $\begin{array}{c}0.60^{* * *} \\
(17.41)\end{array}$ \\
\hline & Rural * Initial Scores & $\begin{array}{c}-0.06 \\
(-0.70)\end{array}$ & $\begin{array}{c}-0.19^{\star \star *} \\
(-3.24)\end{array}$ & $\begin{array}{c}-0.22^{\star * *} \\
(-5.02)\end{array}$ \\
\hline & Francophone * Initial Scores & $\begin{array}{l}0.19^{* *} \\
(2.55)\end{array}$ & $\begin{array}{c}0.08 \\
(1.36)\end{array}$ & \\
\hline & Rural * Francophone * Initial Scores & $\begin{array}{c}-0.14 \\
(-1.42)\end{array}$ & $\begin{array}{c}0.08 \\
(1.01) \\
\end{array}$ & \\
\hline & Francophone & $\begin{array}{c}-21.65^{\star * *} \\
(-3.99)\end{array}$ & $\begin{array}{c}-26.87^{* *} \\
(-4.49)\end{array}$ & $\begin{array}{c}-4.09 \\
(-0.57)\end{array}$ \\
\hline \multirow[t]{3}{*}{$\begin{array}{l}\text { Student } \\
\text { Factors }\end{array}$} & Female & $\begin{array}{c}0.82 \\
(1.45) \\
\end{array}$ & $\begin{array}{c}1.12^{*} \\
(1.80)\end{array}$ & $\begin{array}{c}0.13 \\
(0.19) \\
\end{array}$ \\
\hline & Age & $\begin{array}{c}-0.18 \\
(-1.02)\end{array}$ & $\begin{array}{c}0.11 \\
(0.57)\end{array}$ & $\begin{array}{c}-0.94^{* * *} \\
(-2.85)\end{array}$ \\
\hline & Rural * Age & & & $\begin{array}{l}0.90^{* *} \\
(2.06)\end{array}$ \\
\hline \multirow[t]{11}{*}{$\begin{array}{l}\text { School } \\
\text { Factors }\end{array}$} & Rural & $\begin{array}{c}-0.25 \\
(-0.04) \\
\end{array}$ & $\begin{array}{c}8.09 \\
(1.47)\end{array}$ & $\begin{array}{l}-12.41 \\
(-1.58) \\
\end{array}$ \\
\hline & Rural * Francophone & $\begin{array}{c}16.99^{* * *} \\
(2.83)\end{array}$ & $\begin{array}{c}17.02^{* \star} \\
(2.56)\end{array}$ & \\
\hline & School access & $\begin{array}{c}10.68^{\star * *} \\
(4.82)\end{array}$ & $\begin{array}{c}1.02 \\
(0.31) \\
\end{array}$ & $\begin{array}{c}7.09^{*} \\
(1.71) \\
\end{array}$ \\
\hline & Rural * School access & $\begin{array}{c}-11.96^{* * *} \\
(-4.81)\end{array}$ & $\begin{array}{l}-7.12^{\star *} \\
(-2.01)\end{array}$ & $\begin{array}{c}-2.01 \\
(-0.44)\end{array}$ \\
\hline & Francophone * School access & & $\begin{array}{c}17.61^{* * *} \\
(4.09) \\
\end{array}$ & $\begin{array}{c}-1.29 \\
(-0.23) \\
\end{array}$ \\
\hline & Rural * Francophone * School access & & $\begin{array}{c}-15.50^{\star \star *} \\
(-3.24)\end{array}$ & $\begin{array}{c}-4.99 \\
(-0.81)\end{array}$ \\
\hline & Average class size & $\begin{array}{l}-0.03^{* *} \\
(-2.28)\end{array}$ & $\begin{array}{c}-0.06^{* * *} \\
(-4.09)\end{array}$ & $\begin{array}{c}-0.01 \\
(-0.75)\end{array}$ \\
\hline & Budget & $\begin{array}{c}0.77 \\
(0.93)\end{array}$ & $\begin{array}{c}0.41 \\
(0.70)\end{array}$ & $\begin{array}{l}2.32^{* *} \\
(2.36)\end{array}$ \\
\hline & Rural * Budget & $\begin{array}{c}0.77 \\
(0.85) \\
\end{array}$ & $\begin{array}{c}-0.16 \\
(-0.28) \\
\end{array}$ & $\begin{array}{c}-1.03 \\
(-1.03) \\
\end{array}$ \\
\hline & Francophone * Budget & $\begin{array}{c}-1.04 \\
(-1.26) \\
\end{array}$ & $\begin{array}{c}-0.75 \\
(-1.28) \\
\end{array}$ & $\begin{array}{c}-2.47^{\star \star *} \\
(-2.53)\end{array}$ \\
\hline & Rural * Francophone * Budget & $\begin{array}{c}-1.45 \\
(-1.53) \\
\end{array}$ & $\begin{array}{c}-0.50 \\
-(0.75) \\
\end{array}$ & $\begin{array}{c}-0.58 \\
(-0.55) \\
\end{array}$ \\
\hline \multirow[t]{9}{*}{$\begin{array}{l}\text { Class } \\
\text { Factors }\end{array}$} & Class condition-chalk only & $\begin{array}{c}-7.78^{\star * *} \\
(-2.92)\end{array}$ & $\begin{array}{c}-4.47^{* * *} \\
(-4.10)\end{array}$ & $\begin{array}{c}1.52 \\
(1.02) \\
\end{array}$ \\
\hline & Class condition-electricity only & $\begin{array}{c}-0.36 \\
(-0.12) \\
\end{array}$ & $\begin{array}{c}-2.11 \\
(-1.20) \\
\end{array}$ & $\begin{array}{c}3.27 \\
(1.25) \\
\end{array}$ \\
\hline & Class condition-chalk \& electricity & $\begin{array}{c}11.88^{* * *} \\
(3.52)\end{array}$ & $\begin{array}{l}5.21^{*} \\
(1.73)\end{array}$ & $\begin{array}{l}4.85^{* \star} \\
(2.61)\end{array}$ \\
\hline & Rural * Class condition-chalk only & $\begin{array}{l}7.47^{* *} \\
(2.47)\end{array}$ & & $\begin{array}{l}4.30^{* *} \\
(2.33)\end{array}$ \\
\hline & Rural * Class condition-electricity only & $\begin{array}{c}-0.50 \\
(-0.11)\end{array}$ & & $\begin{array}{c}4.06 \\
(0.88)\end{array}$ \\
\hline & Rural * Class condition-chalk \& electricity & $\begin{array}{c}-30.65^{\star * *} \\
(-2.82)\end{array}$ & & $\begin{array}{c}2.58 \\
(0.65)\end{array}$ \\
\hline & Francophone * Class condition-chalk only & $\begin{array}{c}10.71^{* * *} \\
(3.55) \\
\end{array}$ & $\begin{array}{l}8.03^{\star \star \star} \\
(5.40) \\
\end{array}$ & \\
\hline & Francophone * Class condition-electricity only & $\begin{array}{c}1.81 \\
(0.44) \\
\end{array}$ & $\begin{array}{c}0.08 \\
(0.03)\end{array}$ & \\
\hline & $\begin{array}{l}\text { Francophone * Class condition-chalk \& } \\
\text { electricity }\end{array}$ & $\begin{array}{l}-9.89^{* *} \\
(-2.60)\end{array}$ & $\begin{array}{c}-3.21 \\
(-0.93)\end{array}$ & \\
\hline
\end{tabular}




\begin{tabular}{|c|c|c|c|c|}
\hline & $\begin{array}{l}\text { Rural * Francophone * Class condition一chalk } \\
\text { only }\end{array}$ & $\begin{array}{c}-4.83 \\
(-1.38)\end{array}$ & & \\
\hline & $\begin{array}{l}\text { Rural }{ }^{*} \text { Francophone }{ }^{*} \text { Class condition- } \\
\text { electricity only }\end{array}$ & & & \\
\hline & $\begin{array}{l}\text { Rural * Francophone * Class condition-chalk \& } \\
\text { electricity }\end{array}$ & $\begin{array}{l}38.31 \\
(3.38) \\
\end{array}$ & & \\
\hline $\begin{array}{l}\text { Teacher } \\
\text { Factors }\end{array}$ & Female & $\begin{array}{c}-0.53 \\
(-0.67)\end{array}$ & $\begin{array}{l}-1.10 \\
(-1.21)\end{array}$ & $\begin{array}{c}0.99 \\
(0.34)\end{array}$ \\
\hline & Rural * Female & & & $\begin{array}{c}3.41 \\
(0.91)\end{array}$ \\
\hline & Francophone ${ }^{*}$ Female & & & $\begin{array}{l}-5.82^{*} \\
(-1.76) \\
\end{array}$ \\
\hline & Rural * Francophone * Female & & & $\begin{array}{c}2.76 \\
(0.63)\end{array}$ \\
\hline & Teacher salary $-30,000$ to $89,000 \mathrm{CFAF}$ & $\begin{array}{l}-2.83^{* *} \\
(-2.03)\end{array}$ & $\begin{array}{c}-12.31^{* * *} \\
(-5.35)\end{array}$ & $\begin{array}{l}-3.69^{* *} \\
(-2.21)\end{array}$ \\
\hline & $\begin{array}{l}\text { Teacher salary - } \\
90,000 \text { to } 249,000 \text { CFAF }\end{array}$ & $\begin{array}{c}-4.31 \\
(-1.45)\end{array}$ & $\begin{array}{c}-13.99^{* \star *} \\
(-3.92)\end{array}$ & $\begin{array}{l}-8.59^{* *} \\
(-2.45)\end{array}$ \\
\hline & $\begin{array}{l}\text { Teacher salary - } \\
250,000 \text { CFAF and above }\end{array}$ & $\begin{array}{c}-3.87^{* * *} \\
(-3.53)\end{array}$ & $\begin{array}{c}-7.69^{* * *} \\
(-3.17)\end{array}$ & $\begin{array}{l}-2.37^{*} \\
(-1.79)\end{array}$ \\
\hline & $\begin{array}{l}\text { Rural * Teacher salary }-30,000 \text { to } 89,000 \\
\text { CFAF }\end{array}$ & $\begin{array}{c}2.07 \\
(1.02) \\
\end{array}$ & $\begin{array}{l}8.50^{* * *} \\
(3.01) \\
\end{array}$ & $\begin{array}{l}6.20^{* *} \\
(2.55) \\
\end{array}$ \\
\hline & $\begin{array}{l}\text { Rural * Teacher salary - } \\
90,000 \text { to } 249,000 \text { CFAF }\end{array}$ & $\begin{array}{c}-0.75 \\
(-0.22) \\
\end{array}$ & $\begin{array}{l}10.33^{* * *} \\
(2.66)\end{array}$ & $\begin{array}{c}5.22 \\
(1.28) \\
\end{array}$ \\
\hline & $\begin{array}{l}\text { Rural * Teacher salary - } \\
250,000 \text { CFAF and above }\end{array}$ & $\begin{array}{l}4.82^{* * *} \\
(3.48)\end{array}$ & $\begin{array}{l}5.16^{*} \\
(1.89)\end{array}$ & $\begin{array}{l}6.85^{* * *} \\
(4.08)\end{array}$ \\
\hline & $\begin{array}{l}\text { Francophone * Teacher salary }-30,000 \text { to } \\
89,000 \text { CFAF }\end{array}$ & & $\begin{array}{l}10.67^{* * *} \\
(3.76)\end{array}$ & \\
\hline & $\begin{array}{l}\text { Francophone }{ }^{*} \text { Teacher salary - } \\
90,000 \text { to } 249,000 \text { CFAF }\end{array}$ & & $\begin{array}{l}10.51^{*} \\
(1.89)\end{array}$ & \\
\hline & $\begin{array}{l}\text { Francophone * Teacher salary - } \\
250,000 \text { CFAF and above }\end{array}$ & & $\begin{array}{c}2.29 \\
(0.81) \\
\end{array}$ & \\
\hline & $\begin{array}{l}\text { Rural * Francophone * Teacher salary }-30,000 \\
\text { to } 89,000 \text { CFAF }\end{array}$ & & $\begin{array}{l}-8.44^{* *} \\
(-2.17)\end{array}$ & \\
\hline & $\begin{array}{l}\text { Rural * Francophone * Teacher salary - } \\
90,000 \text { to } 249,000 \text { CFAF }\end{array}$ & & $\begin{array}{c}-25.46^{* * *} \\
(-4.18)\end{array}$ & \\
\hline & $\begin{array}{l}\text { Rural * Francophone * Teacher salary - } \\
250,000 \text { CFAF and above }\end{array}$ & & $\begin{array}{l}-2.27 \\
(-0.67) \\
\end{array}$ & \\
\hline & Absent Teacher & $\begin{array}{c}-6.19^{* * *} \\
(-4.97)\end{array}$ & $\begin{array}{l}-5.66^{\star \star *} \\
(-5.13)\end{array}$ & $\begin{array}{c}0.19 \\
(0.23)\end{array}$ \\
\hline & Francophone * Absent Teacher & $\begin{array}{c}7.06^{* * *} \\
(4.70) \\
\end{array}$ & $\begin{array}{l}6.67^{* * *} \\
(4.55) \\
\end{array}$ & \\
\hline $\begin{array}{l}\text { Home } \\
\text { and }\end{array}$ & Books & $\begin{array}{c}0.63 \\
(1.01) \\
\end{array}$ & $\begin{array}{l}1.80^{* * *} \\
(2.56)\end{array}$ & $\begin{array}{c}2.11 \\
(1.39)\end{array}$ \\
\hline $\begin{array}{l}\text { Family } \\
\text { Factors }\end{array}$ & Francophone * Books & & & $\begin{array}{l}-3.26^{*} \\
(-1.87)\end{array}$ \\
\hline & Language spoken at home & $\begin{array}{c}-1.36 \\
(-1.45) \\
\end{array}$ & $\begin{array}{l}-0.70 \\
(-0.67) \\
\end{array}$ & $\begin{array}{c}-0.39 \\
(-0.47) \\
\end{array}$ \\
\hline & Rural * Language spoken at home & $\begin{array}{c}2.19 \\
(1.62)\end{array}$ & $\begin{array}{l}2.70^{*} \\
(1.82)\end{array}$ & \\
\hline & Francophone * Language spoken at home & & & $\begin{array}{l}-3.26^{*} \\
(-1.87) \\
\end{array}$ \\
\hline & $\begin{array}{l}\text { Living condition - } \\
\text { one or two items }\end{array}$ & $\begin{array}{l}-7.10^{*} \\
(-1.89)\end{array}$ & $\begin{array}{c}-1.59 \\
(-1.20)\end{array}$ & $\begin{array}{l}-6.75^{*} \\
(-1.65) \\
\end{array}$ \\
\hline & $\begin{array}{l}\text { Living condition - } \\
\text { three items or more }\end{array}$ & $\begin{array}{l}-9.11^{* *} \\
(-2.33) \\
\end{array}$ & $\begin{array}{l}-1.83 \\
(0.99) \\
\end{array}$ & $\begin{array}{c}-5.48 \\
(-1.30) \\
\end{array}$ \\
\hline & $\begin{array}{l}\text { Rural * Living condition - } \\
\text { one or two items }\end{array}$ & $\begin{array}{c}5.08 \\
(1.23) \\
\end{array}$ & & $\begin{array}{c}2.27 \\
(0.50)\end{array}$ \\
\hline & $\begin{array}{l}\text { Rural * Living condition - } \\
\text { three items or more }\end{array}$ & $\begin{array}{l}11.86 \\
(2.37)\end{array}$ & & $\begin{array}{c}4.76 \\
(0.85) \\
\end{array}$ \\
\hline
\end{tabular}




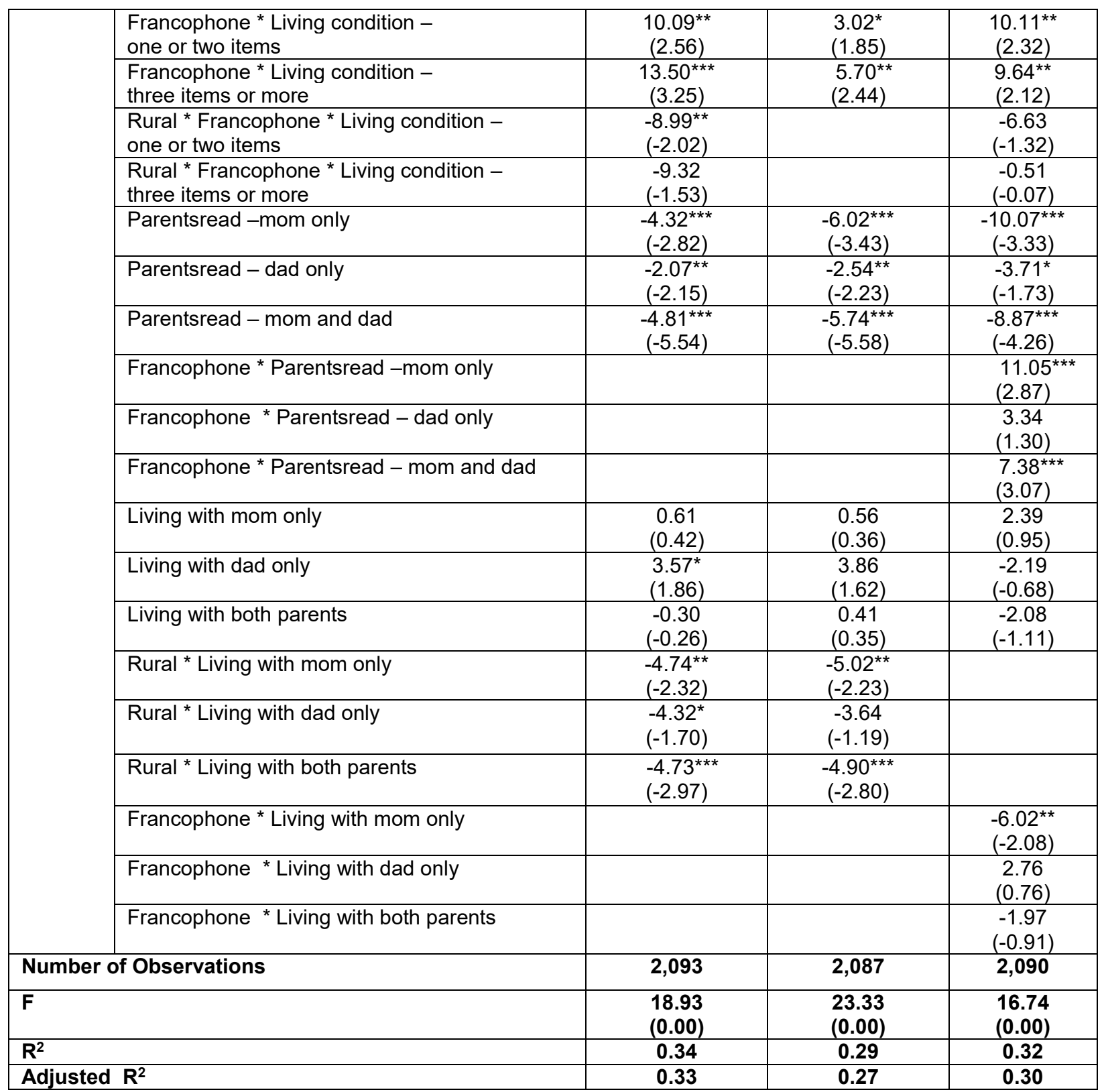

Note: t-statistic reported in parentheses. * significant at 0.1 level; ** significant at the 0.05 level;

*** significant at 0.01 level. Normal standard errors produced for aggregate and language regressions and robust standard error produced for math regression. Adjusted $\mathrm{R}^{2}$ for regression without the standard error correction reported for the math regression. 


\section{APPENDIX C}

Table C1: Variable Description and Data Source

\begin{tabular}{|c|c|c|c|}
\hline Variable & Definition & Measurement & Source \\
\hline $\begin{array}{l}\text { Real GDP per } \\
\text { working } \\
\text { population }\end{array}$ & $\begin{array}{l}\text { GDP per capita is Gross } \\
\text { Domestic Product divided by } \\
\text { midyear population of the } \\
\text { working cohort. }\end{array}$ & $\begin{array}{l}\text { Constant } 2000 \\
\text { US\$ }\end{array}$ & $\begin{array}{l}\text { World Development } \\
\text { Indicators, The World } \\
\text { Bank }\end{array}$ \\
\hline \multirow[t]{4}{*}{$\begin{array}{l}\text { Measures of } \\
\text { human capital }\end{array}$} & $\begin{array}{l}\text { CAS is a combination of the } \\
\text { average numeracy and literacy } \\
\text { scores from MLA, PASEC and } \\
\text { SACMEQ data. }\end{array}$ & Test Scores & $\begin{array}{l}\text { World Development } \\
\text { Indicators, The World } \\
\text { Bank and PASEC }\end{array}$ \\
\hline & $\begin{array}{l}\text { Average number of years of } \\
\text { primary schooling attained by } \\
\text { adult population ( } 15 \text { years or } \\
\text { older). } \\
\text { Education is measured at the } \\
\text { beginning of a period. For } \\
\text { example, primary education for } \\
\text { the } 1965 \text { to } 1970 \text { period is the } \\
1965 \text { value. }\end{array}$ & Years & $\begin{array}{l}\text { Barro, Robert and } \\
\text { Jong-Wha Lee (2010) }\end{array}$ \\
\hline & $\begin{array}{l}\text { Adult literacy rate is the } \\
\text { percentage of people ages } 15 \\
\text { and above who can both read } \\
\text { and write with understanding a } \\
\text { short simple statement about } \\
\text { their everyday life. }\end{array}$ & Per cent & $\begin{array}{l}\text { World Development } \\
\text { Indicators, The World } \\
\text { Bank }\end{array}$ \\
\hline & $\begin{array}{l}\text { Trained teachers in primary } \\
\text { education is the per cent of } \\
\text { total teachers. }\end{array}$ & Per cent & $\begin{array}{l}\text { World Development } \\
\text { Indicators, The World } \\
\text { Bank }\end{array}$ \\
\hline Initial income & $\begin{array}{l}\text { Real GDP per capita at the } \\
\text { beginning of a period or the } \\
\text { earliest period for which data is } \\
\text { available. For example, initial } \\
\text { income for the } 1965 \text { to } 1970 \\
\text { period is real GDP per capita } \\
\text { for } 1965 \text {. }\end{array}$ & $\begin{array}{ll}\text { Constant } & 2000 \\
\text { US\$ } & \end{array}$ & $\begin{array}{l}\text { World Development } \\
\text { Indicators, The World } \\
\text { Bank }\end{array}$ \\
\hline $\begin{array}{l}\text { Capital formation } \\
\text { (\% of GDP) }\end{array}$ & $\begin{array}{l}\text { Gross fixed capital formation } \\
\text { (formerly gross domestic fixed } \\
\text { investment). Calculated as } \\
\text { percentage of GDP. }\end{array}$ & Per cent & $\begin{array}{l}\text { World Development } \\
\text { Indicators, The World } \\
\text { Bank }\end{array}$ \\
\hline $\begin{array}{l}\text { Population } \\
\text { growth }\end{array}$ & $\begin{array}{l}\text { Annual growth rate of the } \\
\text { working population (i.e. } 15 \text { to } \\
64 \text { ) }\end{array}$ & Percent & $\begin{array}{l}\text { World Development } \\
\text { Indicators, The World } \\
\text { Bank }\end{array}$ \\
\hline $\begin{array}{l}\text { Resource } \\
\text { Dependency }\end{array}$ & $\begin{array}{l}\text { Countries where natural } \\
\text { resource exports (agricultural } \\
\text { raw materials, fuel, ore and } \\
\text { metals) exceed } 25 \text { per cent of } \\
\text { average total merchandise } \\
\text { export from } 1960 \text { to } 2010 .\end{array}$ & Digit & $\begin{array}{l}\text { World Development } \\
\text { Indicators, The World } \\
\text { Bank }\end{array}$ \\
\hline
\end{tabular}


Table C2: Regression Country List

\begin{tabular}{|c|c|c|c|c|c|}
\hline Region & Country & $\begin{array}{l}\text { Cross- } \\
\text { Sectional } \\
\text { Regression }\end{array}$ & $\begin{array}{l}\text { Panel and } \\
\text { Pooled OLs } \\
\text { Regressions }\end{array}$ & $\begin{array}{l}\text { Number of } \\
\text { Time Periods } \\
\text { in Panel and } \\
\text { Pooled OLS } \\
\text { Regressions } \\
\end{array}$ & \begin{tabular}{|l|} 
International \\
Regression
\end{tabular} \\
\hline Sub-Saharan Africa & Angola & & & & \\
\hline & Benin & D & D & 3 & D \\
\hline & Botswana & D & D & 2 & $\infty$ \\
\hline & Burkina Faso & & & & \\
\hline & \begin{tabular}{|l} 
Burundi \\
\end{tabular} & $\infty$ & D & 2 & $\infty$ \\
\hline & Cabo Verde & & & & \\
\hline & Cameroon & a & a & 3 & a \\
\hline & Central African Republic & & D & 2 & \\
\hline & Chad & 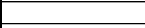 & & & \\
\hline & Comoros & & & & \\
\hline & Congo, Dem. Rep. & & D & 2 & \\
\hline & \begin{tabular}{|l|} 
Congo, Rep. \\
\end{tabular} & D & & & D \\
\hline & Cote d'Ivoire & D & a & 1 & $\infty$ \\
\hline & Equatorial Guinea & & & & \\
\hline & \begin{tabular}{|l|} 
Eritrea \\
\end{tabular} & & & & \\
\hline & \begin{tabular}{|l} 
Ethiopia \\
\end{tabular} & & & & \\
\hline & Gabon & D & D & 1 & D \\
\hline & Gambia, The & & D & 1 & \\
\hline & Ghana & & D & 2 & $\infty$ \\
\hline & Guinea & & & & \\
\hline & Guinea-Bissau & & & & \\
\hline & \begin{tabular}{|l|} 
Kenya \\
\end{tabular} & D & D & 1 & D \\
\hline & \begin{tabular}{|l|} 
Lesotho \\
\end{tabular} & a & D & 1 & $\infty$ \\
\hline & \begin{tabular}{|l|} 
Liberia \\
\end{tabular} & & D & 1 & \\
\hline & Madagascar & & & & \\
\hline & Malawi & a & a & 2 & a \\
\hline & \begin{tabular}{|l|} 
Mali \\
\end{tabular} & D & D & 4 & $\infty$ \\
\hline & \begin{tabular}{|l} 
Mauritania \\
\end{tabular} & D & D & 2 & 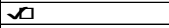 \\
\hline & Mauritius & D & D & 2 & $\infty$ \\
\hline & Mozambique & D & D & 3 & D \\
\hline & Namibia & D & D & 2 & D \\
\hline & \begin{tabular}{|l|} 
Niger \\
\end{tabular} & & D & 2 & \\
\hline & Nigeria & & & & \\
\hline & Rwanda & & D & 3 & \\
\hline & \begin{tabular}{|l} 
Sao Tome and Principe \\
\end{tabular} & & & & \\
\hline & \begin{tabular}{|l|} 
Senegal \\
\end{tabular} & & D & 2 & \\
\hline & Seychelles & & & & \\
\hline & \begin{tabular}{|l} 
Sierra Leone \\
\end{tabular} & & D & 1 & \\
\hline & Somalia & & & & \\
\hline & South Africa & D & D & 2 & 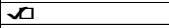 \\
\hline & South Sudan & & & & \\
\hline & Sudan & & D & 2 & \\
\hline & Swaziland & D & D & 3 & $\infty$ \\
\hline & Tanzania & & D & 2 & \\
\hline & Togo & D & D & 1 & D \\
\hline & Uganda & & D & 3 & \\
\hline & Zambia & & D & 1 & \\
\hline & Zimbabwe & & & & \\
\hline Middle East and North Africa & Algeria & & & & 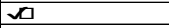 \\
\hline & Egypt, Arab Rep. & & & & 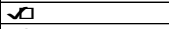 \\
\hline & \begin{tabular}{|l|} 
Iran, Islamic Rep. \\
\end{tabular} & & & & D \\
\hline & Israel & & & & D \\
\hline & Jordan & & & & $\infty$ \\
\hline & Malta & & & & $\infty$ \\
\hline & \begin{tabular}{|l|} 
Morocco \\
\end{tabular} & & & & 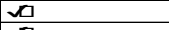 \\
\hline & Saudi Arabia & & & & D \\
\hline & \begin{tabular}{|l|} 
Tunisia \\
\end{tabular} & & & & D \\
\hline Latin America and Caribbean & Chile & & & & D \\
\hline & Colombia & & & & 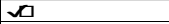 \\
\hline & EI Salvador & & & & $\infty$ \\
\hline Europe and Central Asia & Austria & & & & D \\
\hline & \begin{tabular}{|l|} 
Belgium \\
\end{tabular} & & & & D \\
\hline & \begin{tabular}{|l|} 
Bulgaria \\
\end{tabular} & & & & D \\
\hline & Cyprus & & & & D \\
\hline & \begin{tabular}{|l|l} 
Denmark \\
\end{tabular} & & & & 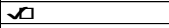 \\
\hline & Finland & & & & $\infty$ \\
\hline & France & & & & $\infty$ \\
\hline & Germany & & & & D \\
\hline & Greece & & & & 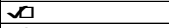 \\
\hline & \begin{tabular}{|l|} 
Iceland \\
\end{tabular} & & & & D \\
\hline & \begin{tabular}{|l|} 
Ireland \\
\end{tabular} & & & & 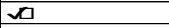 \\
\hline & Italy & & & & $\infty$ \\
\hline & Netherlands & & & & $\infty$ \\
\hline & Norway & & & & D \\
\hline & \begin{tabular}{|l|} 
Portugal \\
\end{tabular} & & & & 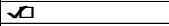 \\
\hline & \begin{tabular}{|l|} 
Spain \\
\end{tabular} & & & & a \\
\hline & \begin{tabular}{|l|} 
Sweden \\
\end{tabular} & & & & 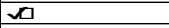 \\
\hline & Switzerland & & & & $\infty$ \\
\hline & \begin{tabular}{|l|} 
Turkey \\
\end{tabular} & & & & $\infty$ \\
\hline & United Kingdom & & & & D \\
\hline East Asia and Pacific & Australia & & & & $\infty$ \\
\hline & Hong Kong SAR, China & & & & D \\
\hline & \begin{tabular}{|l|} 
Indonesia \\
\end{tabular} & & & & D \\
\hline & \begin{tabular}{|l|} 
Japan \\
\end{tabular} & & & & 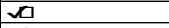 \\
\hline & \begin{tabular}{|l|} 
Korea, Rep. \\
\end{tabular} & & & & D \\
\hline & \begin{tabular}{|l} 
New Zealand \\
\end{tabular} & & & & D \\
\hline & \begin{tabular}{|l|} 
Philippines \\
\end{tabular} & & & & D \\
\hline & \begin{tabular}{|l} 
Singapore \\
\end{tabular} & & & & 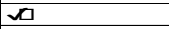 \\
\hline & \begin{tabular}{|l|} 
Thailand \\
\end{tabular} & & & & $\infty$ \\
\hline North America & Canada & & & & $\infty$ \\
\hline & United States & & & & $\infty$ \\
\hline Total & & 18 & 30 & & 62 \\
\hline
\end{tabular}

